\title{
2016 ESC Position Paper on cancer treatments and cardiovascular toxicity developed under the auspices of the ESC Committee for Practice Guidelines
}

\section{The Task Force for cancer treatments and cardiovascular toxicity of the European Society of Cardiology (ESC)}

\author{
Authors/Task Force Members: Jose Luis Zamorano* (Chairperson) (Spain), \\ Patrizio Lancellotti* (Co-Chairperson) (Belgium), Daniel Rodriguez Muñoz (Spain), \\ Victor Aboyans (France), Riccardo Asteggiano (Italy), Maurizio Galderisi (Italy), \\ Gilbert Habib (France), Daniel J. Lenihan ${ }^{1}$ (USA), Gregory Y. H. Lip (UK), \\ Alexander R. Lyon (UK), Teresa Lopez Fernandez (Spain), Dania Mohty (France), \\ Massimo F. Piepoli (Italy), Juan Tamargo (Spain), Adam Torbicki (Poland), and \\ Thomas M. Suter (Switzerland)
}

ESC Committee for Practice Guidelines (CPG): Jose Luis Zamorano (Chairperson) (Spain), Victor Aboyans (France), Stephan Achenbach (Germany), Stefan Agewall (Norway), Lina Badimon (Spain), Gonzalo Barón-Esquivias (Spain), Helmut Baumgartner (Germany), Jeroen J. Bax (The Netherlands), Héctor Bueno (Spain), Scipione Carerj (Italy), Veronica Dean (France), Çetin Erol (Turkey), Donna Fitzsimons (UK), Oliver Gaemperli (Switzerland), Paulus Kirchhof (UK/Germany), Philippe Kolh (Belgium), Patrizio Lancellotti (Belgium), Gregory Y. H. Lip (UK), Petros Nihoyannopoulos (UK), Massimo F. Piepoli (Italy), Piotr Ponikowski (Poland), Marco Roffi (Switzerland), Adam Torbicki (Poland), António Vaz Carneiro (Portugal), and Stephan Windecker (Switzerland)

Document Reviewers: Stephan Achenbach (CPG Review Coordinator) (Germany), Giorgio Minotti (CPG Review Coordinator) (Italy), Stefan Agewall (Norway), Lina Badimon (Spain), Héctor Bueno (Spain), Daniela Cardinale (Italy), Scipione Carerj (Italy), Giuseppe Curigliano (Italy), Evandro de Azambuja (Belgium), Susan Dent (Canada), Cetin Erol (Turkey), Michael S. Ewer (USA), Dimitrios Farmakis (Greece), Rainer Fietkau (Germany), Donna Fitzsimons (UK), Oliver Gaemperli (Switzerland), Paulus Kirchhof (Germany/UK), Philippe Kohl (Belgium), Paul McGale (UK), Piotr Ponikowski (Poland), Juergen Ringwald (Germany), Marco Roffi (Switzerland),

\footnotetext{
* Corresponding authors: Jose Luis Zamorano, Head of Cardiology, University Hospital Ramon Y. Cajal, Carretera De Colmenar Km 9.100, 28034 Madrid, Spain. Tel: + 3491 336 85 15, E-mail: zamorano@secardiologia.es; Patrizio Lancellotti, University of Liège Hospital, GIGA Cardiovascular Sciences, Departments of Cardiology, Heart Valve Clinic, CHU Sart Tilman, Liège, Belgium and Gruppo Villa Maria Care and Research, Anthea Hospital, Bari, Italy. Tel: +32 4366 7194, Fax: +32 4366 7195, E-mail: plancellotti@chu.ulg.ac.be ${ }^{1}$ Representing the International CardiOncology Society (ICOS)

The content of these European Society of Cardiology (ESC) Guidelines has been published for personal and educational use only. No commercial use is authorized. No part of the ESC Guidelines may be translated or reproduced in any form without written permission from the ESC. Permission can be obtained upon submission of a written request to John Wiley \& Sons, the publisher of the European Journal of Heart Failure and the party authorized to handle such permissions on behalf of the ESC (permissions@wiley.com).

Disclaimer. The ESC Guidelines represent the views of the ESC and were produced after careful consideration of the scientific and medical knowledge and the evidence available at the time of their publication. The ESC is not responsible in the event of any contradiction, discrepancy and/or ambiguity between the ESC Guidelines and any other official recommendations or guidelines issued by the relevant public health authorities, in particular in relation to good use of healthcare or therapeutic strategies. Health professionals are encouraged to take the ESC Guidelines fully into account when exercising their clinical judgment, as well as in the determination and the implementation of preventive, diagnostic or therapeutic medical strategies; however, the ESC Guidelines do not override, in any way whatsoever, the individual responsibility of health professionals to make appropriate and accurate decisions in consideration of each patient's health condition and in consultation with that patient and, where appropriate and/or necessary, the patient's caregiver. Nor do the ESC Guidelines exempt health professionals from taking into full and careful consideration the relevant official updated recommendations or guidelines issued by the competent public health authorities, in order to manage each patient's case in light of the scientifically accepted data pursuant to their respective ethical and professional obligations. It is also the health professional's responsibility to verify the applicable rules and regulations relating to drugs and medical devices at the time of prescription.

The article has been co-published with permission in European Heart Journal and European Journal of Heart Failure. All rights reserved in respect of European Heart Journal. (c) European Society of Cardiology 2016. All rights reserved. For permissions please email: permissions@wiley.com.
} 
Jeanette Schulz-Menger (Germany), Justin Stebbing (UK), Rudolf K. Steiner (Switzerland), Sebastian Szmit (Poland), Antonio Vaz Carneiro (Portugal), and Stephan Windecker (Switzerland)

The disclosure forms of all experts involved in the development of these guidelines are available on the ESC website http://www.escardio.org/guidelines.

Keywords European Society of Cardiology • chemotherapy • cardiotoxicity • cardio-oncology • myocardial dysfunction $\bullet$ arrhythmias • ischaemia • early detection • surveillance • cancer therapy

\section{Table of Contents}

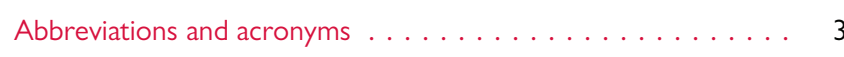
Preamble.......................... 3

1. Introduction ..................... 4

2. Cardiovascular complications of cancer therapy:

pathophysiology and management. . . . . . . . . . . . . 4

2.1 Myocardial dysfunction and heart failure . . . . . . . . 4

2.1.1 Pathophysiology and clinical presentation . . . . . . . 4

2.1.1.1 Anthracyclines . . . . . . . . . . . . . 5

2.1.1.2 Other conventional chemotherapies . . . . . . 6

2.1.1.3 Immunotherapies and targeted therapies . . . . 6

2.1.1.4 Inhibition of the vascular endothelial growth

factor signalling pathway . . . . . . . . . . 7

2.1.1.5 Inhibition of BCR-ABL kinase . . . . . . . 7

2.1.1.6 Proteasome inhibitors . . . . . . . . . . 7

2.1.1.7 Radiotherapy . . . . . . . . . . . . . . . 8

2.1.2 Diagnostic and therapeutic management . . . . . . . 8

2.1.2.1 Screening, risk stratification, and early detection

strategies. . . . . . . . . . . . . . . .

2.1.2.2 Cardiovascular management of patients treated

with anthracyclines $\ldots \ldots \ldots \ldots \ldots \ldots$

2.1.2.3 Cardiovascular management of patients treated

with anti-HER2 . . . . . . . . . . 10

2.1.2.4 Cardiovascular management of patients treated

with VEGF inhibitors . . . . . . . . . . . . . . . . 10

2.1.2.5 Screening and early detection strategies. . . . . 10

2.1.2.6 Diagnostic tools to detect myocardial toxicity. . 10

2.1 .3 Key points . . . . . . . . . . . . . . . . . . . 12

2.2 Coronary artery disease. . . . . . . . . . . . . . . 12

2.2.1 Pathophysiology and clinical presentation . . . . . . 12

2.2.1.1 Fluoropyrimidines . . . . . . . . . . . . . . . . 12

2.2.1.2 Cisplatin . . . . . . . . . . . . . . . . . 12

2.2.1.3 Immune- and targeted therapeutics. . . . . . . . 12

2.2.1.4 Radiotherapy . . . . . . . . . . . . . . . . . . 13

2.2.2 Diagnostic and therapeutic management . . . . . . 13

2.2 .3 Key points . . . . . . . . . . . . . . . . . . . 13

2.3 Valvular disease . . . . . . . . . . . . . . . . 13

2.3.1 Pathophysiology and clinical presentation . . . . . . . 13

2.3.2 Diagnostic and therapeutic management . . . . . . . 14

2.4 Arrhythmias ... . . . . . . . . . . . . . . 14

2.4.1 Pathophysiology and clinical presentation . . . . . . . 14

2.4.1.1 QT prolongation. . . . . . . . . . . . . . . 14
2.4.1.2 Supraventricular arrhythmia . . . . . . . . . . 14

2.4.1.3 Ventricular arrhythmias . . . . . . . . . . . 14

2.4.1.4 Sinus node dysfunction and conduction

defects ......................... 15

2.4.2 Diagnostic and therapeutic management . . . . . . 15

2.4.2.1 QT interval and associated risk factors for $\mathrm{QT}$

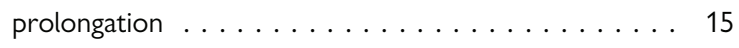

2.4 .3 Key points. . . . . . . . . . . . . . . . . . 16

2.4.3.1 Atrial fibrillation and atrial flutter . . . . . . . 16

2.4.3.2 Bradycardia or atrioventricular block. . . . . . 16

2.5 Arterial hypertension . . . . . . . . . . . . . 16

2.5.1 Pathophysiology and clinical presentation . . . . . . 16

2.5.2 Diagnostic and therapeutic management . . . . . . 17

2.5 .3 Key points . . . . . . . . . . . . . . . . . . 17

2.6 Thromboembolic disease . . . . . . . . . . . . . . 17

2.6.1 Pathophysiology and clinical presentation . . . . . . 17

2.6.1.1 Arterial thrombosis . . . . . . . . . . . . . 17

2.6.1.2 Venous thrombosis and thromboembolism . . . 17

2.6.2 Diagnostic and therapeutic management . . . . . . 18

2.7 Peripheral vascular disease and stroke. . . . . . . . . . 18

2.7.1 Pathophysiology and clinical presentation . . . . . . . 18

2.7.1.1 Peripheral artery disease . . . . . . . . . 18

2.7.1.2 Stroke ... . . . . . . . . . . . . . . 19

2.7.2 Diagnostic and therapeutic management . . . . . . 19

2.8 Pulmonary hypertension . . . . . . . . . . . . . . 19

2.8.1 Pathophysiology and clinical presentation . . . . . . . 19

2.8.2 Diagnostic and therapeutic management . . . . . . . 19

2.9 Other cardiovascular complications of cancer treatment. 20

2.9 .1 Pericardial disease . . . . . . . . . . . . . . . . . 20

2.9.2 Pleural effusion. . . . . . . . . . . . . . . . . 20

2.9 .3 Autonomic dysfunction . . . . . . . . . . . . 20

2.10 Cardiovascular complications of cancer treatment in

special populations . . . . . . . . . . . . . . . . . 20

2.10 .1 Paediatric cancer population . . . . . . . . . . 20

2.10 .2 Elderly patients. . . . . . . . . . . . . . . . 20

2.10 .3 Pregnant women. . . . . . . . . . . . . . . . 20

3. Strategies for prevention and attenuation of cardiovascular complications of cancer therapy . . . . . . . . . . . . . 21

3.1 Treatment options to prevent or recover from cancer

therapy-induced myocardial dysfunction . . . . . . . . . 21

3.1.1 Before cardiotoxic cancer treatment . . . . . . . 21 
3.1.2 Patients with troponin elevation.

3.1.3 Patients with asymptomatic reduction in left

ventricular ejection fraction during or after cancer

treatment . . . . . . . . . . . . . . 21

3.1.4 Patients with asymptomatic reduction in global

longitudinal strain during chemotherapy . . . . . . . . . 22

3.1.5 Patients with heart failure during and following cancer

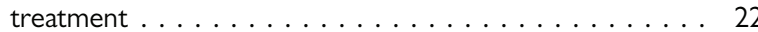

3.1.6 Non-pharmacological interventions with a

cardioprotective effect in patients with cancer . . . . . . 22

3.2 Prevention of thromboembolic events . . . . . . . . . 22

3.3 Strategies for attenuation of complications related to use

of specific agents . . . . . . . . . . . . . . . . . . . 22

3.3.1 Anthracyclines . . . . . . . . . . . . . . . . 22

3.3.2 HERer-2 targeted therapy . . . . . . . . . . 23

3.3.3 Pyrimidine analogues . . . . . . . . . . . . . . 23

3.3.4 Vascular endothelial growth factor signalling pathway

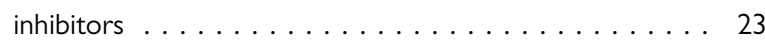

3.3.5 Radiotherapy . . . . . . . . . . . . . . . . . . . . 23

4. Long-term surveillance programmes for cancer survivors . . . 24

4.1 Myocardial dysfunction . . . . . . . . . . . . . . . 24

4.2 Vascular disease . . . . . . . . . . . . . . . . . . 24

4.3 Valvular disease . . . . . . . . . . . . . . . . . 24

5. Future perspectives and research directions ........ 24

6. Appendix ........................ 25

7. References ....................... 25

\section{Abbreviations and acronyms}

$\begin{array}{ll}\text { 2-D } & \text { two-dimensional } \\ 3-D & \text { three-dimensional } \\ 5-F U & \text { 5-fluorouracil } \\ \text { ACE } & \text { angiotensin-converting enzyme } \\ \text { ARB } & \text { angiotensin Il receptor blocker } \\ \text { ASE } & \text { American Society of Echocardiography } \\ \text { BNP } & \text { B-type natriuretic peptide } \\ \text { CABG } & \text { coronary artery bypass graft } \\ \text { CAD } & \text { coronary artery disease } \\ \text { CHA }{ }_{2} \text { DS }{ }_{2} \text {-VASc } & \text { Congestive heart failure or left ventricular } \\ & \text { dysfunction, Hypertension, Age } \geq 75 \text { (doubled), } \\ & \text { Diabetes, Stroke (doubled)-Vascular disease, } \\ \text { CMR } & \text { Age 65-74, Sex category (female) } \\ \text { COT } & \text { cardiac magnetic resonance } \\ \text { CT } & \text { registry Cardiac Oncology Toxicity registry } \\ \text { CTRCD } & \text { computed tomography } \\ \text { CVD } & \text { Cancer Therapeutics-Related } \quad \text { Cardiac } \\ \text { EACVI } & \text { Dysfunction } \\ \text { ECG } & \text { cardiovascular disease } \\ \text { ESC } & \text { European Association of Cardiovascular Imaging } \\ \text { GLS } & \text { electrocardiogram / electrocardiographic } \\ \text { GY } & \text { guropean Society of Cardiology } \\ & \end{array}$

\author{
HAS-BLED Hypertension, Abnormal renal/liver function (1 \\ point each), Stroke, Bleeding history or predis- \\ position, Labile international normalized ratio, \\ Elderly ( $>65$ years), Drugs/alcohol concomitant- \\ ly (1 point each) \\ HDAC histone deacetylase \\ HER2 human epidermal growth factor receptor 2 \\ HF heart failure \\ LMWH low molecular weight heparin \\ LV \\ LVEF \\ NA \\ NOAC \\ NYHA New York Heart Association \\ PAD peripheral artery disease \\ $\mathrm{PAH} \quad$ pulmonary arterial hypertension \\ $\mathrm{PCl} \quad$ percutaneous coronary intervention \\ RCT randomized controlled trial \\ T-DM1 trastuzumab-emtansine \\ TKI tyrosine kinase inhibitor \\ VEGF vascular endothelial growth factor \\ VHD valvular heart disease \\ VKA vitamin $\mathrm{K}$ antagonist \\ VTE venous thromboembolism \\ WHO World Health Organization
}

\section{Preamble}

Guidelines and position papers written under the auspices of the ESC Committee for Practice Guidelines (CPG) summarize and evaluate all available evidence on a particular issue at the time of the writing process, with the aim of assisting health professionals in selecting the best management strategies for an individual patient with a given condition, taking into account the impact on outcome, as well as the risk-benefit ratio of particular diagnostic or therapeutic means. CPG Guidelines and position papers should help health professionals to make decisions in their daily practice. However, the final decisions concerning an individual patient must be made by the responsible health professional(s) in consultation with the patient and caregiver as appropriate.

Members of this Task Force were selected by the ESC to represent professionals involved with the medical care of patients with this pathology. Selected experts in the field undertook a comprehensive review of the published evidence for management (including diagnosis, treatment, prevention and rehabilitation) of a given condition according to CPG policy. A critical evaluation of diagnostic and therapeutic procedures was performed, including assessment of the risk-benefit ratio. Estimates of expected health outcomes for larger populations were included, where data exist.

The experts of the writing and reviewing panels provided declarations of interest forms for all relationships that might be perceived as real or potential sources of conflicts of interest. These forms were compiled into one file and can be found on the ESC website (http://www.escardio.org/guidelines). Any changes in declarations of 
interest that arise during the writing period must be notified to the ESC and updated. The Task Force received its entire financial support from the ESC without any involvement from the healthcare industry.

The ESC CPG supervises and coordinates the preparation of new guidelines and position papers produced by task forces, expert groups or consensus panels. The Committee is also responsible for the endorsement process of these documents. The CPG documents undergo extensive review by the CPG and external experts. After appropriate revisions these documents are approved by all the experts involved in the Task Force. The finalized document is approved by the CPG for publication in the European Heart Journal. The CPG documents were developed after careful consideration of the scientific and medical knowledge and the evidence available at the time of their dating.

The task of developing CPG documents covers not only integration of the most recent research, but also the creation of educational tools and implementation programmes for the recommendations. To implement these documents, condensed pocket guidelines versions, summary slides and an electronic version for digital applications (smartphones, etc.) are produced as well as other educational tools depending on the topic. These versions are abridged and thus, if needed, one should always refer to the full text version, which is freely available on the ESC website. The National Cardiac Societies of the ESC are encouraged to endorse, translate and implement all CPG documents (guidelines and position papers). Implementation programmes are needed because it has been shown that the outcome of disease may be favourably influenced by the thorough application of clinical recommendations.

Surveys and registries are needed to verify that real-life daily practice is in keeping with what is recommended in the guidelines, thus completing the loop between clinical research, writing of guidelines, disseminating them and implementing them into clinical practice.

Health professionals are encouraged to take the CPG Guidelines and Position Papers fully into account when exercising their clinical judgment, as well as in the determination and the implementation of preventive, diagnostic or therapeutic medical strategies. However, these CPG documents do not override in any way whatsoever the individual responsibility of health professionals to make appropriate and accurate decisions in consideration of each patient's health condition and in consultation with that patient and the patient's caregiver where appropriate and/or necessary. It is also the health professional's responsibility to verify the rules and regulations applicable to drugs and devices at the time of prescription.

\section{Introduction}

Advances in treatment have led to improved survival of patients with cancer, but have also increased morbidity and mortality due to treatment side effects. ${ }^{1,2}$ Cardiovascular diseases (CVDs) are one of the most frequent of these side effects, and there is a growing concern that they may lead to premature morbidity and death among cancer survivors. ${ }^{3}$ This may be the result of cardiotoxicity, which involves direct effects of the cancer treatment on heart function and structure, or may be due to accelerated development of CVD, especially in the presence of traditional cardiovascular risk factors. ${ }^{4}$
Although the field of cardio-oncology has received increasing attention in recent years, many aspects of both radiation-induced and cancer drug-induced CVD are still to be fully elucidated. Furthermore, the inability to predict the long-term consequences of cancer treatment-associated cardiovascular side effects leads to under- or overdiagnosis of CVD, sometimes resulting in the failure to prevent adverse events and sometimes to inappropriate interruption of a potentially lifesaving cancer treatment.

The complex issue of CVD as a consequence of previous cancer treatment requires the creation of multidisciplinary teams involving specialists in cardiology, oncology and other related fields. The mutual interest to provide optimal care for patients with cancer and cancer survivors is an important motivation for the development of cardio-oncology teams. However, the extent of care and the interaction between the disciplines involved has not yet been defined. The complexity of the clinical questions to be addressed by cardio-oncologists will require the definition of a curriculum describing the necessary knowledge and skills to deliver optimal care and the hospital setting in which these experts will be active. These cardio-oncology teams should also be involved in the long-term surveillance of cancer survivors with a potential for late-onset cardiovascular complications and in the development of potential new treatments that may have cardiotoxic effects, as well as in the evaluation of cardiac events related to such drugs.

This document reviews the different steps in cardiovascular monitoring and decision-making before, during and after cancer treatment with potential cardiovascular side effects. Although this document is not a formal clinical practice guideline, it aims to assist professionals involved in the treatment of patients with cancer and survivors by providing an expert consensus regarding current standards of care for these individuals.

In general, the cardiovascular complications of cancer therapy can be divided into nine main categories, which are discussed in this document:

- myocardial dysfunction and heart failure (HF);

- coronary artery disease (CAD);

- valvular disease;

- arrhythmias, especially those induced by QT-prolonging drugs;

- arterial hypertension;

- thromboembolic disease;

- peripheral vascular disease and stroke;

- pulmonary hypertension and

- pericardial complications.

\section{Cardiovascular complications of cancer therapy: pathophysiology and management}

\subsection{Myocardial dysfunction and heart failure}

\subsubsection{Pathophysiology and clinical presentation}

Myocardial dysfunction and HF, frequently described as cardiotoxicity, are the most concerning cardiovascular complications of cancer therapies and cause an increase in morbidity and mortality. A collaborative effort among specialists involved in the treatment of patients 
with cancer is critical to prevent and manage cardiotoxicity while not compromising cancer care, to maximize the patient's overall outcome. ${ }^{5}$ The time point when cardiotoxicity becomes clinically manifest varies substantially; some cancer treatments induce side effects that appear early after exposure-and therefore may adversely affect oncological therapy - while others generate cardiac injuries resulting in clinical problems only years later. In addition, some cancer drugs, for example, anthracyclines, can induce progressive cardiac remodelling as a late consequence of earlier myocyte damage, resulting in late cardiomyopathy, while others may cause transient cardiac dysfunction without long-term consequences.

The prediction of long-term cardiovascular prognosis is frequently challenging because patients with cancer typically receive multiple cancer drugs and sometimes radiation, with the potential for cardiotoxic effects from interactions among the different therapeutic modalities. ${ }^{6}$

Left ventricular (LV) dysfunction and HF are relatively common and serious side effects of cancer treatment. Survivors of paediatric cancer, treated with anthracyclines and/or mediastinal radiotherapy, have a 15 -fold increased lifetime risk for HF compared with matched controls. ${ }^{7}$ In older patients with pre-existing cardiovascular risk, the short-term risk for developing $\mathrm{HF}$ is also increased. For example, survivors of aggressive non-Hodgkin lymphoma have a $17 \%$ incidence of clinical HF at 5 years. ${ }^{8}$ There is also growing awareness of the occurrence of LV dysfunction or HF caused by tyrosine kinase inhibitors (TKIs), particularly in cancer patients with pre-existing cardiovascular risk factors.' Table 1 provides an overview of the incidence of LV dysfunction with different chemotherapeutic drugs.

\subsubsection{Anthracyclines}

Anthracyclines have high efficacy for treatment of solid tumours and haematological malignancies, and avoiding their use due to concerns about cardiac side effects may negatively impact prognosis. ${ }^{22,23} \mathrm{On}$ the other hand, anthracyclines may cause irreversible cardiac damage, which in turn affects prognosis. ${ }^{24}$ For example, doxorubicin is associated with a $5 \%$ incidence of congestive HF when a cumulative lifetime dose of $400 \mathrm{mg} / \mathrm{m}^{2}$ is reached, and higher doses lead to an exponential increase in risk, up to $48 \%$ at $700 \mathrm{mg} / \mathrm{m}^{2}$. $^{10}$ However, there is considerable variability among patients in their susceptibility to anthracyclines. While many tolerate standard-dose anthracyclines without long-term complications, treatment-related cardiotoxicity may occur as early as after the first dose in other patients. ${ }^{25}$

The most commonly accepted pathophysiological mechanism of anthracycline-induced cardiotoxicity is the oxidative stress hypothesis, which suggests that the generation of reactive oxygen species and lipid peroxidation of the cell membrane damage cardiomyocytes. Other mechanisms have been suggested to play a role. ${ }^{26-31}$ For a detailed discussion of the cellular and molecular mechanisms, the reader is referred to two reviews. ${ }^{32,33}$

The cardiotoxicity of anthracyclines may be acute, early or late. Acute toxicity, predominantly supraventricular arrhythmia, transient LV dysfunction and electrocardiographic (ECG) changes, develops in $<1 \%$ of patients immediately after infusion and is usually reversible. However, acute cardiac dysfunction may also reflect myocyte injury that eventually can evolve into early or late cardiotoxicity. There are no proven strategies to identify if cardiac dysfunction is reversible or progressive; however, elevation of cardiac
Table I Incidence of left ventricular dysfunction associated with chemotherapy drugs ${ }^{10-21}$

\begin{tabular}{|c|c|}
\hline Chemotherapy agents & Incidence (\%) \\
\hline \multicolumn{2}{|l|}{ Anthracyclines (dose dependent) } \\
\hline $\begin{array}{l}\text { Doxorubicin (Adriamycin) } \\
400 \mathrm{mg} / \mathrm{m}^{2} \\
550 \mathrm{mg} / \mathrm{m}^{2} \\
700 \mathrm{mg} / \mathrm{m}^{2}\end{array}$ & $\begin{array}{l}3-5 \\
7-26 \\
18-48\end{array}$ \\
\hline Idarubicin $\left(>90 \mathrm{mg} / \mathrm{m}^{2}\right)$ & $5-18$ \\
\hline Epirubicin $\left(>900 \mathrm{mg} / \mathrm{m}^{2}\right)$ & $0.9-11.4$ \\
\hline Mitoxanthone $>120 \mathrm{mg} / \mathrm{m}^{2}$ & 2.6 \\
\hline Liposomal anthracyclines $\left(>900 \mathrm{mg} / \mathrm{m}^{2}\right)$ & 2 \\
\hline \multicolumn{2}{|l|}{ Alkylating agents } \\
\hline Cyclophosphamide & $7-28$ \\
\hline $\begin{array}{l}\text { Ifosfamide } \\
<10 \mathrm{~g} / \mathrm{m}^{2} \\
12.5-16 \mathrm{~g} / \mathrm{m}^{2}\end{array}$ & $\begin{array}{l}0.5 \\
17\end{array}$ \\
\hline \multicolumn{2}{|l|}{ Antimetabolites } \\
\hline Clofarabine & 27 \\
\hline \multicolumn{2}{|l|}{ Antimicrotubule agents } \\
\hline Docetaxel & $2.3-13$ \\
\hline Paclitaxel & $<1$ \\
\hline \multicolumn{2}{|l|}{ Monoclonal antibodies } \\
\hline Trastuzumab & $1.7-20.1^{28 a}$ \\
\hline Bevacizumab & $1.6-4^{14 b}$ \\
\hline Pertuzumab & $0.7-1.2$ \\
\hline \multicolumn{2}{|c|}{ Small molecule tyrosine kinase inhibitors } \\
\hline Sunitinib & $2.7-19$ \\
\hline Pazopanib & $7-11$ \\
\hline Sorafenib & $4-8$ \\
\hline Dasatinib & $2-4$ \\
\hline Imatinib mesylate & $0.2-2.7$ \\
\hline Lapatinib & $0.2-1.5$ \\
\hline Nilotinib & 1 \\
\hline \multicolumn{2}{|l|}{ Proteasome inhibitors } \\
\hline Carfilzomib & $\mathrm{II}-25$ \\
\hline Bortezomib & $2-5$ \\
\hline \multicolumn{2}{|l|}{ Miscellanous } \\
\hline Everolimus & $<1$ \\
\hline Temsirolimus & $<1$ \\
\hline
\end{tabular}

${ }^{a}$ When used in combination with anthracyclines and cyclophosphamide. In patients receiving concurrent anthracyclines.

biomarkers may be a way to identify patients at risk for long-term cardiotoxicity.

Early effects occur within the first year of treatment, while late effects manifest themselves after several years (median of 7 years after treatment). ${ }^{34,35}$ In patients treated with commonly used anthracycline doses and $>65$ years of age, the rate of anthracycline-associated HF 
can be as high as $10 \%{ }^{10}$ This classification (early and late) is based on retrospective studies in which the LV ejection fraction (LVEF) decline was determined either after HF development or on random evaluations in paediatric patients with cancer. A recent study by Cardinale et al., ${ }^{36}$ involving 2625 patients (mean follow-up 5.2 years), showed a $9 \%$ overall incidence of cardiotoxicity after anthracycline treatment, and $98 \%$ of cases occurred within the first year and were asymptomatic. Anthracycline-induced cardiotoxicity is most likely a phenomenon characterized by continuous progressive decline in LVEF. Many affected patients may initially be asymptomatic, with clinical manifestations appearing years later, often in the context of other triggering factors, which may indicate that anthracyclines negatively affect compensatory mechanisms. ${ }^{37}$

Furthermore, if anthracycline-associated cardiac dysfunction is detected early and treated with HF medications, patients frequently have a good functional recovery. Conversely, if patients are identified late after the onset of cardiac dysfunction, HF is typically difficult to treat. ${ }^{38}$ Risk factors for anthracycline-related cardiotoxicity include lifetime cumulative dose, infusion regimen and any condition that increases cardiac susceptibility, including pre-existing cardiac disease, hypertension, concomitant use of other chemotherapies or mediastinal radiation therapy and older age (>65 years). ${ }^{13}$ The developing heart is also particularly vulnerable, and paediatric patients treated with anthracyclines are at an exceedingly high risk for anthracycline cardiotoxicity ${ }^{39}$ (Table 2). In patients with one or multiple risk factors for anthracycline cardiotoxicity, the cumulative dose vs. cardiotoxicity curve is shifted to the left and these patients should be monitored carefully or alternative chemotherapeutics considered.

\subsubsection{Other conventional chemotherapies}

Other conventional chemotherapies that can induce myocardial dysfunction and $\mathrm{HF}$ are cyclophosphamide, cisplatin, ifosfamide and taxanes (paclitaxel and docetaxel). Cyclophosphamide cardiotoxicity is relatively rare and is primarily seen in patients receiving high doses $\left(>140 \mathrm{mg} / \mathrm{kg}\right.$ ) before bone marrow transplantation. ${ }^{40}$ HF typically occurs within days of drug administration, and risk

Table 2 Factors associated with risk of cardiotoxicity following treatment with anthracyclines ${ }^{a}$

\begin{tabular}{l}
\hline Risk factors \\
\hline - Cumulative dose \\
- Female sex \\
- Age \\
- >65 years old \\
- Paediatric population (<18 years) \\
- Renal failure \\
- Concomitant or previous radiation therapy involving the heart \\
- Concomitant chemotherapy \\
- alkylating or antimicrotubule agents \\
- immuno- and targeted therapies \\
- Pre-existing conditions \\
- Cardiac diseases associating increased wall stress \\
- Arterial hypertension \\
- Genetic factors
\end{tabular}

${ }^{a}$ Anthracyclines (daunorubicin, doxorubicin, epirubicin, idarubicin) or anthracenedione (mitoxantrone) factors include total bolus dose, older age, combination therapy with other cancer drugs and mediastinal irradiation. ${ }^{41}$ Some alkylating agents similar to cyclophosphamide, such as cisplatin and ifosfamide, infrequently cause HF due to several pathological effects, including myocardial ischaemia. Additionally, platin-containing chemotherapy requires the administration of a high intravenous volume to avoid platin-related toxicity. This volume overload in patients with pre-existing myocardial impairment, rather than the direct toxicity of these drugs, is often the cause of first or recurrent episodes of HF. Docetaxel, a drug frequently used in breast cancer, in combination with or after anthracyclines, cyclophosphamide or trastuzumab, also appears to increase the incidence of HF; however, the contribution of individual agents in multidrug schemes is frequently difficult to assess. ${ }^{42}$ Some reports suggest that taxanes may be safer in patients with pre-existing LV dysfunction, in whom anthracyclines should be avoided, ${ }^{43}$ but the absolute cardiotoxic risks with taxanes are unknown. However, there is considerable debate with regard to patients with breast cancer for whom the true benefits of using anthracyclines vs. taxanes is not as clear as it is for tumours such as lymphomas or sarcomas. The risk-benefit assessment should encompass both the risk factors of the individual patient and the potential efficacy based on the characteristics of the tumour.

\subsubsection{Immunotherapies and targeted therapies}

More recently, immunotherapies and targeted therapies have led to substantial improvement in the efficacy of cancer drugs. Inhibition of human epidermal growth factor receptor 2 (HER2) signalling with either antibodies [trastuzumab, pertuzumab, trastuzumab-emtansine (T-DM1)] or TKIs (lapatinib) have improved outcomes of patients with HER2-positive breast cancer when used in conjunction with chemotherapies. ${ }^{44}$ Initially, cardiotoxicity was high when trastuzumab was given concomitantly with anthracyclines in a trial of metastatic breast cancer. ${ }^{45}$ Applying trastuzumab after anthracyclines, or using an anthracycline-free chemotherapy regimen, substantially reduced the rate of clinical HF. Based on several large-scale trials of adjuvant therapy in breast cancer, all of which prospectively assessed cardiac side effects, the rate of cardiac dysfunction ranged from 7 to $34 \%$, with HF [New York Heart Association (NYHA) class III or IV] rates between 0 and $4 \%$. The relative risks for cardiac dysfunction and HF were 5.1 and 1.8, respectively. ${ }^{44}$ When trastuzumab was used concomitantly with antimetabolites and alkylating agents in patients with gastric cancer, the rates of cardiac dysfunction and $\mathrm{HF}$ were $5 \%$ and $<1 \%$, respectively. ${ }^{46}$ These data indicate that concomitant or previous use of anthracyclines substantially increases the cardiotoxicity of trastuzumab. However, in the aforementioned trials, patients were relatively young (median age in the 50s) and had a normal or nearly normal cardiac function (usually LVEF $\geq 50 \%$ ) without significant prior cardiac disease. The risk of trastuzumab cardiotoxicity in patients with pre-existing cardiac conditions is unknown. This may also explain why some investigators found higher rates of cardiac side effects in registries. In a retrospective observational study based on the International Classification of Diseases codes (without access to LVEF data), the cumulative incidence of the composite of cardiac dysfunction or $\mathrm{HF}$ in patients treated with anthracyclines and trastuzumab was $6.2 \%$ and $20.1 \%$ after 1 and 5 years, respectively. ${ }^{47} \mathrm{~A}$ similar increase 
over time in cardiotoxicity was not seen in the trials of trastuzumab as adjuvant therapy in breast cancer; indeed, a low risk for newonset cardiotoxicity after completion of trastuzumab therapy was found. ${ }^{48-51}$ Long-term follow-up (up to 10 years) data are reassuring in terms of the absence of late-onset HF in patients with low baseline cardiovascular risk treated with trastuzumab. ${ }^{48-51}$ In contrast to anthracyclines, trastuzumab cardiotoxicity typically manifests during treatment. This has led to the implementation of different cardiotoxicity surveillance protocols that vary across countries and centres. Generally, trastuzumab-associated cardiotoxicity is not believed to be cumulative-dose related, although twice the rate of LV dysfunction was reported when patients were treated for 24 rather than the usual 12 months. ${ }^{49}$ Trastuzumab-induced LV dysfunction and HF are usually reversible with trastuzumab interruption and/or treatment with HF therapies. ${ }^{52}$ The mechanism of anti-HER2 drug-induced cardiotoxicity includes structural and functional changes in contractile proteins and mitochondria, but it rarely leads to cell death, explaining the potential for reversibility. ${ }^{53,54}$ Risk factors for anti-HER2 drug-induced cardiotoxicity include previous exposure to anthracyclines, short time ( 3 weeks vs. 3 months) between anthracycline and anti-HER2 treatment, pre-existing arterial hypertension, low LVEF and older age. $^{3,55}$ One of the most relevant clinical implications of trastuzumab-induced cardiotoxicity is treatment interruption, which is associated with an increase in cancer recurrence. ${ }^{56}$ In patients with HER2-positive breast cancer receiving adjuvant trastuzumab, cardiotoxicity was the most common reason for treatment interruption in $13.5 \%$ of patients (30\% for $\mathrm{HF}$ and $70 \%$ for asymptomatic LVEF decline). In most trastuzumab breast cancer registration trials, treatment was stopped when patients developed HF or (in asymptomatic patients) when LVEF dropped below 45\%. ${ }^{52}$ There are no randomized trials to prove that HF drugs will improve cardiac function in patients with trastuzumab-associated cardiac dysfunction. However, analogous to the experience in patients with anthracycline cardiotoxicity, trastuzumab-associated cardiac dysfunction is likely to improve when these patients are treated with angiotensinconverting enzyme (ACE) inhibitors. ${ }^{36,38}$

The cardiotoxicity risk of other anti-HER2-targeted therapies (lapatinib, pertuzumab and T-DM1) appears similar to that of trastuzumab. In a large trial of breast cancer patients comparing the efficacy of adjuvant trastuzumab alone vs. trastuzumab and adjuvant lapatinib in $>8000$ women with a median follow-up of 4.5 years, the incidence of cardiotoxicity ranged from 2 to $5 \%$, and 2 to $3 \%$ of women experienced $\mathrm{HF}^{57}$ In this trial, where cardiac function was assessed prospectively and compared with that at baseline, modern schemes of adjuvant or neoadjuvant chemotherapy were used, including anthracyclines in $>70 \%$ of patients. The cardiotoxicity risk for T-DM1 and pertuzumab also appear similar to trastuzumab, although prospective data from large adjuvant trials are not yet available. $^{58,59}$

\subsubsection{Inhibition of the vascular endothelial growth factor signalling} pathway

Inhibition of the vascular endothelial growth factor (VEGF) signalling pathway benefits patients diagnosed with one of several different solid cancers, but some of the VEGF inhibitors can cause reversible or irreversible cardiac side effects, particularly when used with or after conventional chemotherapies. In a large trial of patients with breast cancer, where cardiac function was prospectively assessed, the anti-VEGF antibody bevacizumab used after chemotherapy induced LV dysfunction in $2 \%$ of patients and HF (NYHA III or IV) in $1 \%$ of patients. ${ }^{60}$ Similarly, cardiotoxicity was found for the TKls sunitinib, pazopanib and axitinib. These drugs induce cardiac dysfunction in $3-15 \%$ of patients and symptomatic HF in $1-10 \%$ of patients. ${ }^{61-64}$ Other anti-VEGF inhibitors such as sorafenib and vandetanib also induce cardiac dysfunction, but prospective data from large clinical trials are missing. A recent meta-analysis evaluated the risk of congestive HF associated with all US Food and Drug Administration-approved VEGF receptor TKIs. A total of 10647 patients from 21 randomized phase II and III trials using approved VEGF receptor TKIs (sunitinib, sorafenib, pazopanib, axitinib, vandetanib, cabozantinib, ponatinib and regorafenib) were included. A significant 2.69-fold increase in the risk of all grades of congestive HF was observed with VEGF receptor TKIs compared with controls not receiving TKIs. However, the risk of severe HF was not significantly increased. The risk of relatively specific TKIs (axitinib) was similar to relatively non-specific TKIs (sunitinib, sorafenib, vandetanib and pazopanib). ${ }^{65}$

VEGF inhibitors also cause substantial arterial hypertension, potentially affecting cardiac function. ${ }^{66}$ Many anti-VEGF cancer drugs inhibit multiple signalling pathways, and identification of the pathophysiological mechanism causing cardiotoxicity can be challenging (see Table 3 and section 2.5). ${ }^{67,68}$ The prognosis of patients experiencing cardiotoxicity with these drugs is difficult to assess accurately, as most of these compounds are used in patients with metastatic disease with limited life expectancy. However, one can speculate that if hypertension is controlled throughout therapy, some potential HF may be reduced. Similarly, if cardiac dysfunction develops, it can be reversible in a large number of patients with appropriate and intensive HF medication. ${ }^{69}$

\subsubsection{Inhibition of BCR-ABL kinase}

The inhibition of BCR-ABL kinase by small molecules such as imatinib has profoundly improved the prognosis of patients with several forms of chronic leukaemia and some forms of gastrointestinal stromal tumours. Although initial reports suggested a risk for imatinib-induced cardiotoxicity, analysis of large cohorts did not confirm these data. ${ }^{73}$ Newer, more potent inhibitors of BCR-ABL, such as nilotinib and ponatinib, have also demonstrated an association with cardiovascular events. ${ }^{74,75}$

\subsubsection{Proteasome inhibitors}

Proteasome inhibitors are a relatively new line of treatment for multiple myeloma. Bortezomib and carfilzomib are the two clinically available drugs potentially causing cardiac dysfunction. Proteasomes, protein complexes responsible for degrading dysfunctional or unneeded proteins, have an important maintenance function in the cardiomyocyte, and cardiac dysfunction and other cardiac issues may be expected if this maintenance function is impaired. ${ }^{76}$ The incidence of HF under bortezomib is relatively low (up to $4 \%$ ) compared with carfilzomib, although it is sometimes aggravated by the concomitant use of steroids. ${ }^{77}$ Carfilzomib is a more potent and irreversible proteosomal inhibitor, and preliminary data suggest a substantially higher risk of HF (up to $25 \%)^{78,79}$ 
Table 3 Factors associated with risk of cardiotoxicity following anti-HER2 compounds and VEGF inhibitors $^{70-72}$

\begin{tabular}{|c|c|}
\hline Agent & Risk factors \\
\hline \multicolumn{2}{|l|}{ Anti-HER2 compounds } \\
\hline $\begin{array}{l}\text { - Antibodies } \\
\text { - Trastuzumab } \\
\text { - Pertuzumab } \\
\text { - T-DMI } \\
\text { - Tyrosine kinase inhibitor } \\
\text { - Lapatinib }\end{array}$ & $\begin{array}{l}\text { - Previous or concomitant } \\
\text { anthracycline treatment (short time } \\
\text { between anthracycline and anti-HER2 } \\
\text { treatment) } \\
\text { - Age }(>65 \text { years) } \\
\text { - High } \mathrm{BMI}>30 \mathrm{~kg} / \mathrm{mg}^{2} \\
\text { - Previous } \mathrm{LV} \text { dysfunction } \\
\text { - Arterial hypertension } \\
\text { - Previous radiation therapy }\end{array}$ \\
\hline \multicolumn{2}{|l|}{ VEGF inhibitors } \\
\hline $\begin{array}{l}\text { - Antibodies } \\
\text { - Bevacizumab } \\
\text { - Ramucirumab }\end{array}$ & $\begin{array}{l}\text { Pre-existing HF, significant CAD } \\
\text { or left side VHD (e.g. mitral } \\
\text { regurgitation), chronic ischaemic } \\
\text { cardiomyopathy } \\
\text { - Previous anthracycline }\end{array}$ \\
\hline $\begin{array}{l}\text { - Tyrosine kinase inhibitors } \\
\text { - Sunitinib } \\
\text { - Pazopanib } \\
\text { - Axitinib } \\
\text { - Neratinib } \\
\text { - Afatinib } \\
\text { - Sorafenib } \\
\text { - Dasatinib }\end{array}$ & $\begin{array}{l}\text { - Arterial hypertension } \\
\text { - Pre-existing cardiac disease }\end{array}$ \\
\hline
\end{tabular}

$\mathrm{BMI}=$ body mass index; $\mathrm{CAD}=$ coronary artery disease; $\mathrm{HER} 2=$ human epidermal growth factor receptor $2 ; \mathrm{HF}=$ heart failure; $\mathrm{MI}=$ myocardial infarction; VEGF = vascular endothelial growth factor; VHD = valvular heart disease.

\subsubsection{Radiotherapy}

The actual incidence of radiation-induced cardiotoxicity is difficult to evaluate for several reasons. These include the long delay between exposure and clinical manifestation of heart disease, the use of concomitant cardiotoxic chemotherapy, continuous improvements in radiation techniques and changes in the treated population and failure to attribute cardiac disease to previous radiotherapy despite increasing awareness of cardiovascular physicians of its long-term side effects. Some studies found a relative risk of fatal cardiovascular events between 2.2 and 12.7 in survivors of Hodgkin lymphoma and between 1 and 2.2 in patients with breast cancer. ${ }^{80,81}$ The absolute excess risk of mortality ranges from 9.3 to 28 per 10000 person-years of follow-up. ${ }^{80}$ Among survivors, the risk of HF was increased 4.9-fold. ${ }^{81}$ In patients with breast cancer treated in the era 1980-2000, the risk of cardiotoxicity was highest in patients treated with both left breast radiotherapy and cardiotoxic chemotherapy, suggesting a synergistic effect on cardiac risk. ${ }^{82}$ Marked interstitial myocardial fibrosis is common in radiotherapy-induced cardiotoxicity, with lesions of variable volumes and distribution. ${ }^{80}$ In 1820 adult survivors of childhood cancer (median age 31 years; median time from diagnosis 23 years) exposed to anthracycline chemotherapy $(n=1050)$, chest-directed radiotherapy $(n=306)$ or both ( $n=464$ ), $22 \%$ of survivors exposed to radiotherapy alone had evidence of diastolic dysfunction and $27.4 \%$ showed reduced
Table 4 Baseline risk factors for cardiotoxicity

\begin{tabular}{|c|c|}
\hline Current myocardial disease & $\begin{array}{l}\text { Demographic and other } \\
\text { CV risk factors }\end{array}$ \\
\hline $\begin{array}{l}\text { - Heart failure (with either preserved } \\
\text { or reduced ejection fraction) } \\
\text { - Asymptomatic LV dysfunction } \\
\text { (LVEF <50\% or high natriuretic } \\
\text { peptidea) } \\
\text { - Evidence of CAD (previous } \\
\text { myocardial infarction, angina, PCl or } \\
\text { CABG, myocardial ischaemia) } \\
\text { - Moderate and severeVHD with } \\
\text { LVH or LV impairment } \\
\text { - Hypertensive heart disease with } \\
\text { LV hypertrophy } \\
\text { - Hypertrophic cardiomyopathy } \\
\text { - Dilated cardiomyopathy } \\
\text { - Restrictive cardiomyopathy } \\
\text { - Cardiac sarcoidosis with myocardial } \\
\text { involvement } \\
\text { - Significant cardiac arrhythmias } \\
\text { (e.g.AF, ventricular tachyarrhythmias) }\end{array}$ & $\begin{array}{l}\text { - Age (paediatric population } \\
<18 \text { years; }>50 \text { years for } \\
\text { trastuzumab; }>65 \text { years for } \\
\text { anthracyclines) } \\
\text { - Family history of premature } \\
\text { CV disease ( }<50 \text { years) } \\
\text { - Arterial hypertension } \\
\text { - Diabetes mellitus } \\
\text { - Hypercholesterolaemia }\end{array}$ \\
\hline $\begin{array}{l}\text { Previous cardiotoxic cancer } \\
\text { treatment }\end{array}$ & Lifestyle risk factors \\
\hline $\begin{array}{l}\text { - Prior anthracycline use } \\
\text { - Prior radiotherapy to chest or } \\
\text { mediastinum }\end{array}$ & $\begin{array}{l}\text { - Smoking } \\
\text { - High alcohol intake } \\
\text { - Obesity } \\
\text { - Sedentary habit }\end{array}$ \\
\hline
\end{tabular}

$\mathrm{AF}=$ atrial fibrillation; $\mathrm{CABG}=$ coronary artery bypass graft; $\mathrm{CAD}=$ coronary artery disease; $C V=$ cardiovascular; $L V=$ left ventricular; $L V E F=$ left ventricular ejection fraction; $\mathrm{LVH}=$ left ventricular hypertrophy; $\mathrm{VHD}=$ valvular heart disease.

${ }^{\text {a }}$-type natriuretic peptide $>100 \mathrm{pg} / \mathrm{ml}$ or $\mathrm{N}$-terminal pro-B-type natriuretic peptide $>400 \mathrm{pg} / \mathrm{ml}$ with no alternative cause.

exercise capacity ( $<490 \mathrm{~m}$ 6-min walk). ${ }^{83}$ Systolic dysfunction is generally observed when radiotherapy is combined with anthracyclines. HF may also be aggravated by concomitant radiation-induced valvular heart disease (VHD) and CAD, and can evolve over years.

\subsubsection{Diagnostic and therapeutic management}

2.1.2.1 Screening, risk stratification and early detection strategies

The first step to identify patients at increased risk for cardiotoxicity consists of a careful baseline assessment of cardiovascular risk factors (Table 4). A limited number of studies have generated risk scores for different oncology patient cohorts. ${ }^{39,84}$ However, none of these risk scores has been validated prospectively, and clinical judgement is required when evaluating the risk at an individual level. Risk assessment should include clinical history and examination and baseline measurement of cardiac function. Cardiac biomarkers (natriuretic peptides or troponins) may be considered in addition, preferably using the same assay that will be used during follow-up measurements, to increase comparability. It is critical to detect subclinical cardiac abnormalities, which may influence clinical decisions regarding the choice of chemotherapy, indication for cardioprotection or increased surveillance frequency (e.g. asymptomatic LV dysfunction). Finally, baseline assessment of cardiovascular risk factors allows appropriate interpretation of subsequent results/changes during regular monitoring. Baseline risk 
assessment is often performed by the oncology team, but referral for cardiology evaluation is highly recommended in high-risk patients. High risk can be determined by both the number of risk factors and their severity. Patients at high risk for developing cardiotoxicity should be examined by a cardiologist with expertise in this field or if necessary, by a cardio-oncology specialist team.

Strategies for screening and detection of cardiotoxicity include cardiac imaging [echocardiography, nuclear imaging, cardiac magnetic resonance $(C M R)]$ and biomarkers (troponin, natriuretic peptides) (see Table 6). The choice of modalities depends upon local expertise and availability, and several important core principles should be considered:

- The same imaging modality and/or biomarker assay should be used for continued screening throughout the treatment pathway. Switching between modalities or assays is strongly discouraged.

Table 5 Anthracycline equivalence dose considering doxorubicin in rapid infusion as a reference ${ }^{94}$

\begin{tabular}{|l|c|c|}
\hline \multicolumn{1}{|c|}{ Drug } & \multicolumn{1}{|c|}{$\begin{array}{c}\text { Relative } \\
\text { cardiotoxicity }\end{array}$} & $\begin{array}{c}\text { Incidence of HF } \\
\text { rises to }>5 \% \text { when } \\
\text { cumulative dose } \\
\text { exceeds }\left(\mathbf{m g} / \mathbf{m}^{2}\right)\end{array}$ \\
\hline $\begin{array}{l}\text { Doxorubicin rapid } \\
\text { infusion }\end{array}$ & 1 & 400 \\
\hline Epirubicin & 0.7 & 900 \\
\hline Daunorubicin & $\sim 0.75$ & 800 \\
\hline Idarubicin & 0.53 & 150 \\
\hline
\end{tabular}

- Modalities and tests with the best reproducibility are preferred. - Imaging modalities that provide additional relevant clinical information are preferred (e.g. right ventricular function, pulmonary pressures, valvular function, pericardial evaluation).

- High quality radiation-free imaging is preferred, if available.

The precise timing and frequency of imaging and/or biomarker sampling will depend upon the specific cancer treatment, total cumulative dose of cardiotoxic chemotherapy, delivery protocol and duration and the patient's baseline cardiovascular risk.

\subsubsection{Cardiovascular management of patients treated with} anthracyclines

For patients treated with adjuvant anthracyclines, baseline cardiac function should be assessed. If systolic dysfunction or significant VHD is found, the patient should be discussed with the oncology team and options for non-anthracycline-containing chemotherapy and/or cardioprotection should be considered. If used, a second assessment of cardiac function should be performed at the end of the treatment, particularly when the patient has an increased risk for cardiotoxicity or consecutive treatment with potentially cardiotoxic targeted therapies will follow. For higher-dose anthracyclinecontaining regimens and in patients with high baseline risk, earlier assessment of cardiac function after a cumulative total doxorubicin (or equivalent) dose of $240 \mathrm{mg} / \mathrm{m}^{2}$ should be considered (see Table 5). ${ }^{10,31,85}$ Measurement of at least one cardiac biomarkerhigh-sensitivity troponin (I or T) or a natriuretic peptide-may be considered at baseline, and determination of high-sensitivity troponin I has been suggested with each cycle of anthracycline-containing chemotherapy. ${ }^{86,87}$ To date, this suggested strategy has not been validated to prevent or improve longer-term toxicity events, but elevation

Table 6 Proposed diagnostic tools for the detection of cardiotoxicity

\begin{tabular}{|c|c|c|c|}
\hline Technique & $\begin{array}{l}\text { Currently available diagnostic } \\
\text { criteria }\end{array}$ & Advantages & Major limitations \\
\hline $\begin{array}{l}\text { Echocardiography: } \\
\text { - 3D-based LVEF } \\
\text { - 2D Simpson's LVEF } \\
\text { - GLS }\end{array}$ & $\begin{array}{l}\text { - LVEF: }>10 \text { percentage points } \\
\text { decrease to a value below the LLN } \\
\text { suggests cardiotoxicity. } \\
\text { - GLS: }>15 \% \text { relative percentage } \\
\text { reduction from baseline may suggest } \\
\text { risk of cardiotoxicity. }\end{array}$ & $\begin{array}{l}\text { - Wide availability. } \\
\text { - Lack of radiation. } \\
\text { - Assessment of haemodynamics and } \\
\text { other cardiac structures. }\end{array}$ & $\begin{array}{l}\text { - Inter-observer variability. } \\
\text { - Image quality. } \\
\text { - GLS: inter-vendor variability, technical } \\
\text { requirements. }\end{array}$ \\
\hline $\begin{array}{l}\text { Nuclear cardiac imaging } \\
\text { (MUGA) }\end{array}$ & $\begin{array}{l}->10 \text { percentage points decrease in } \\
\text { LVEF with a value }<50 \% \text { identifies } \\
\text { patients with cardiotoxicity. }\end{array}$ & - Reproducibility. & $\begin{array}{l}\text { - Cumulative radiation exposure. } \\
\text { - Limited structural and functional } \\
\text { information on other cardiac } \\
\text { structures. }\end{array}$ \\
\hline Cardiac magnetic resonance & $\begin{array}{l}\text { - Typically used if other techniques } \\
\text { are non-diagnostic or to confirm the } \\
\text { presence of LV dysfunction if LVEF is } \\
\text { borderlines. }\end{array}$ & $\begin{array}{l}\text { - Accuracy, reproducibility. } \\
\text { - Detection of diffuse myocardial } \\
\text { fibrosis using TI/T2 mapping and } \\
\text { ECVF evaluation. }\end{array}$ & $\begin{array}{l}\text { - Limited availability. } \\
\text { - Patient's adaptation (claustrophobia, } \\
\text { breath hold, long acquisition times). }\end{array}$ \\
\hline $\begin{array}{l}\text { Cardiac biomarkers: } \\
\text { - Troponin I } \\
\text { - High-sensitivity Troponin I } \\
\text { - BNP } \\
\text { - NT-proBNP }\end{array}$ & $\begin{array}{l}\text {-A rise identifies patients receiving } \\
\text { anthracyclines who may benefit from } \\
\text { ACE-Is. } \\
\text { - Routine role of BNP and NT-proBNP } \\
\text { in surveillance of high-risk patient } \\
\text { needs futher investigation. }\end{array}$ & $\begin{array}{l}\text { - Accuracy, reproducibility. } \\
\text { - Wide availability. } \\
\text { - High-sensitivity. }\end{array}$ & $\begin{array}{l}\text { - Insufficient evidence to establish the } \\
\text { significance of subtle rises. } \\
\text { - Variations with different assays. } \\
\text { - Role for routine surveillance not } \\
\text { clearly established. }\end{array}$ \\
\hline
\end{tabular}

ACE-Is = angiotensin converting enzyme inhibitors; BNP = B-type natriuretic peptide; ECVF = extacellular volume fraction; GLS = global longitudinal strain; $L V=$ left ventricular; LLN = lower limit of normality; LVEF = left ventricular ejection fraction; MUGA = multigated radionuclide angiography; NT-proBNP $=N$-terminal fragment B-type natriuretic peptide. 
of cardiac biomarkers identifies patients at greater risk for cardiotoxicity who may benefit from measures to prevent cardiotoxicity.

2.1.2.3 Cardiovascular management of patients treated with anti-HER2 Patients receiving anti-HER2 therapies frequently, though not always, receive anthracyclines before starting the targeted therapy. In such cases, surveillance should begin before anthracycline administration. Standard screening during treatment depends on local protocols and recommendations, but typically cardiac monitoring is performed every 3 months during and once after completion of anti-HER2 treatment. Some investigators found that the rate of clinically relevant trastuzumab-induced cardiac dysfunction is substantially lower when a confirmatory LV assessment is carried out 3 weeks after an initial (asymptomatic) LVEF decrease. ${ }^{52}$ Several studies have demonstrated an improvement in early detection of LVEF decrease when troponins and speckle tracking echocardiography are used every 3 months during adjuvant trastuzumab treatment. Given the variability in timing of trastuzumab-induced LV dysfunction, measurement of troponin with every cycle may be considered in patients with high baseline risk. ${ }^{88-90}$

\subsubsection{Cardiovascular management of patients treated with} VEGF inhibitors

The optimal timing of surveillance strategies for the various VEGF inhibitors known to cause myocardial dysfunction still needs to be clarified. After baseline assessment, some patients appear to develop LV dysfunction early after treatment onset, whereas in others this is delayed for several months. If baseline risk is high, it may be appropriate to consider early clinical follow-up in the first 2-4 weeks after starting targeted molecular therapy with, for example, sunitinib, sorafenib or pazopanib. Thereafter, the drug labels for all of these drugs suggest a periodic reassessment of cardiac function, but do not state specifically when and how. Currently, it is reasonable to consider periodic echocardiography, for example, every 6 months until stability in LVEF values is achieved. However, limited evidence is available to support any specific surveillance strategy. One observational study suggested surveillance every 2-3 months with troponin or $\mathrm{N}$-terminal pro-B-type natriuretic peptide (NT-proBNP), and echocardiography detected myocardial toxicity in $33 \%$ of patients taking VEGF inhibitors for renal cell carcinoma. ${ }^{9}$

\subsubsection{Screening and early detection strategies}

All patients receiving cardiotoxic chemotherapy should undergo a cardiac assessment, including LV function, during follow-up after treatment completion. A recent study reported a $9 \%$ incidence of LV impairment following anthracycline chemotherapy in a large unselected cohort of 2625 patients, detectable in $98 \%$ of cases within 12 months following the last chemotherapy cycle. ${ }^{38}$ Long-term surveillance should be considered for those who developed evidence of cardiotoxicity during treatment and for those in whom cardioprotective medication has been initiated, to determine whether a trial of weaning is appropriate. Emerging data suggest that adults exposed to high cumulative anthracycline doses and/or chest radiotherapy should be offered lifelong surveillance, and this is now recommended for survivors of childhood cancers. ${ }^{91,92}$ Additionally, recommendations for monitoring survivors of adult-onset cancer are currently under development. 4,93

Baseline echocardiographic assessment of LV function is recommended before initiation of potentially cardiotoxic cancer treatment in all patients, irrespective of clinical history, in order to confirm baseline risk. For low-risk patients (normal baseline echocardiogram, no clinical risk factors), surveillance should be considered with echocardiography every 4 cycles of anti-HER2 treatment or after $200 \mathrm{mg} / \mathrm{m}^{2}$ of doxorubicin (or equivalent) for treatment with anthracyclines. More frequent surveillance may be considered for patients with abnormal baseline echocardiography (e.g. reduced or low normal LVEF, structural heart disease) and those with higher baseline clinical risk (e.g. prior anthracyclines, previous MI, treated HF). Survivors who have completed higher-dose anthracycline-containing chemotherapy $\left(\geq 300 \mathrm{mg} / \mathrm{m}^{2}\right.$ of doxorubicin or equivalent) or who developed cardiotoxicity (e.g. LV impairment) requiring treatment during chemotherapy may be considered for follow-up surveillance echocardiography at 1 and 5 years after completion of cancer treatment.

The optimal modality, extent and frequency of surveillance in adults exposed to cardiotoxic cancer treatment who were asymptomatic at the time of initial treatment remain unclear and are frequently based on expert consensus rather than trial data. ${ }^{95}$ Retrospective observational data in elderly patients with breast cancer treated with adjuvant anthracyclines show that the risk of developing congestive HF continues to increase through $>10$ years of follow-up. ${ }^{96}$ However, there was no such increase in risk of congestive $\mathrm{HF}$ in the long-term follow-up of patients treated with adjuvant anthracyclines followed by trastuzumab. ${ }^{49,50}$ This finding is most likely because the latter patients were substantially younger and therefore their risk of developing cardiotoxicity was lower. Based on these observations, it seems appropriate to conduct regular and long-term surveillance in elderly patients and in patients with risk factors for cardiotoxicity who have been treated with anthracyclines.

\subsubsection{Diagnostic tools to detect myocardial toxicity}

Electrocardiography. ECG is recommended in all patients before and during treatment. It is useful to detect any ECG signs of cardiac toxicity, including resting tachycardia, ST-T wave changes, conduction disturbances, QT interval prolongation or arrhythmias. However, these ECG abnormalities are not specific and can be related to other factors (see Table 10). Of note, these ECG changes can be transitory and are not related to the development of chronic cardiomyopathy.

Echocardiography. Echocardiography is the method of choice for the detection of myocardial dysfunction before, during and after cancer therapy (see Table 6). ${ }^{85,95}$ Unless three-dimensional (3D) echocardiography is used, which is the best echocardiographic method for measuring LVEF when endocardial definition is clear, the two-dimensional (2D) biplane Simpson method is recommended for estimation of LV volumes and ejection fraction in these patients. Cancer therapeutics-related cardiac dysfunction (CTRCD) is defined as a decrease in the LVEF of $>10$ percentage points, to a value below the lower limit of normal. ${ }^{85,97}$ This decrease should be confirmed by repeated cardiac imaging done $2-3$ weeks after the baseline diagnostic study showing the initial decrease in LVEF. The LVEF decrease may be further categorized as symptomatic or asymptomatic, or with regard to reversibility. ${ }^{85}$ Although the exact interval is not established, echocardiographic examination should be repeated during follow-up to confirm recovery, or to detect irreversible LV dysfunction. Echocardiography can also detect other complications 
of cancer therapy, including valvular and pericardial diseases and findings suggestive of pulmonary hypertension. ${ }^{98,99}$

The main limitation of 2D echocardiography is its relatively moderate reproducibility, which can be improved by the use of 3D echocardiography. The latter is associated with the best day-to-day reproducibility, ${ }^{100}$ but remains dependent on image quality, availability and operator experience. For serial evaluation of patients with cancer, LVEF measurements should ideally be performed by the same observer with the same equipment to reduce variability. ${ }^{85}$

Other useful echocardiographic techniques include contrast echocardiography, indicated in patients with suboptimal echocardiograms to improve delineation of the LV endocardial borders. Stress echocardiography may be helpful in the evaluation of patients with intermediate or high pretest probability for CAD, but no data are available with regard to its prognostic value in patients with cancer for HF prediction. Doppler myocardial imaging and deformation imaging is a promising tool and its use should be considered whenever possible. Several recent studies have shown the value of deformation imaging for early detection of LV dysfunction secondary to cancer therapy. ${ }^{92}$ Global systolic longitudinal myocardial strain (GLS) has been reported to accurately predict a subsequent decrease in LVEF. ${ }^{101,102}$ A relative percentage reduction of GLS of $>15 \%$ from baseline is considered abnormal and a marker of early LV subclinical dysfunction. Until standardization of strain imaging through different vendors is fully achieved, the current recommendation is to use the same equipment for the longitudinal follow-up of patients with cancer to facilitate the interpretation of results. These advanced echocardiographic measurements are preferred, when available, to serve as the basis for clinical decisions when performed with adequate expertise at laboratories doing cardiac safety studies. $^{103}$

Diastolic dysfunction is common in patients with cancer, both at baseline and during treatment; however, no evidence has shown that treatment should be stopped based on these findings.

Nuclear cardiac imaging. Evaluation of LV function using multigated radionuclide angiography has been used for years to diagnose chemotherapy-induced cardiotoxicity with good accuracy and reproducibility ${ }^{104}$ and few technical limitations. However, it is constrained by radiation exposure and provides only limited additional information on cardiac structure and haemodynamics (see Table 6). As echocardiography and multigated radionuclide angiography have different reference values, the same technique should be performed for baseline and follow-up studies. ${ }^{105,106}$

Cardiac magnetic resonance. CMR is a helpful tool for the evaluation of cardiac structure and function. It is useful to determine the cause of LV dysfunction and to clarify left and right ventricular function in challenging cases (i.e. borderline or contradictory results from other imaging modalities). ${ }^{93,107}$ It also serves to evaluate the pericardium, especially in patients with chest irradiation. Late gadolinium imaging may be useful to detect scarring or fibrosis, which may have prognostic implications in the context of impaired LV function. ${ }^{108,109}$ Additionally, CMR is an excellent test for the comprehensive evaluation of cardiac masses and infiltrative conditions. Use of unique tissue characterization capabilities of CMR (e.g. inflammation and oedema) will be dependent on acceptance of T2 and T1 mapping and extracellular volume fraction quantification (see Table 6). Diffuse anthracycline fibrosis cannot be evaluated with conventional techniques of late gadolinium enhancement. ${ }^{107}$
Cardiac biomarkers. The use of cardiac biomarkers during cardiotoxic chemotherapy may be considered in order to detect early cardiac injury (see Table 6). The challenge with the available published data is the timing of the laboratory assessment relating to chemotherapy, the definition of the upper limit of normal for a specific test, the use of different laboratory assays, as well as the challenge of the strategy to undertake in case of an abnormal result. ${ }^{86,110}$ There is currently no clear evidence to withhold or interrupt chemotherapy or targeted therapies based on a new abnormal cardiac biomarker result, particularly with the application of increasingly sensitive assays. However, an abnormal biomarker result is indicative of an increased risk of cardiotoxicity.

Single-centre studies show, in patients receiving high-dose combination chemotherapy, that a newly elevated cardiac troponin I from a normal baseline may identify those who develop cardiac dysfunction with a poor prognosis, particularly when troponin elevation persists, and who may benefit from treatment with ACE inhibitors. $^{111-113}$ In patients treated with trastuzumab, particularly when previously exposed to anthracyclines, troponin I elevation can identify patients who will develop cardiac dysfunction and who will not recover despite treatment for HF. ${ }^{88}$

New elevation of serum troponin I detected with high-sensitivity troponin I assays in patients receiving anthracyclines and/or trastuzumab predicts subsequent LV dysfunction. ${ }^{89}$ In patients with breast cancer, a small study demonstrated that the combination of highsensitivity troponin with GLS might provide the greatest sensitivity (93\%) and negative predictive value (91\%) to predict future cardiotoxicity. $^{101}$

The role of cardiac biomarkers to detect cardiotoxicity due to targeted molecular therapies including trastuzumab is still unclear. Evidence supporting surveillance using troponin to predict future LV dysfunction with the use of other immune and targeted cancer therapies is still limited.

The use of natriuretic peptides to detect HF is widely established, and even very low levels can identify high-risk patients and guide therapy. ${ }^{113}$ In the context of chemotherapy, B-type natriuretic peptide (BNP) and NT-proBNP may be useful, but their role in routine surveillance to define the high-risk patient is not established. ${ }^{114}$ Future research needs to determine the optimal timing of biomarker measurement for different chemotherapies and confirm upper limits for each assay to better guide clinicians.

Surveillance and treatment strategies. The timing of cardiotoxicity surveillance using echocardiography and biomarkers needs to be personalized to the patient in the context of their baseline cardiovascular risk and the specific cancer treatment protocol prescribed. The most important element is risk stratification to guide the frequency of assessment and ensure that higher-risk patients have an earlier review to avoid missing early toxicity. ${ }^{115}$ This is based on expert opinion, and evidence is lacking regarding the optimal surveillance strategy to positively impact clinical outcomes. Future research needs to establish the optimal timing of biomarker measurement for the different cancer treatment pathways, confirm upper limits for each assay and better guide clinicians to target cardioprotective therapy to the appropriate patients with cancer.

Patients who develop asymptomatic LV dysfunction or HF during cancer therapy are likely to profit from ACE inhibitors or angiotensin II receptor blockers (ARBs) and beta-blocker treatment similar to the general HF population. ${ }^{116}$ More specifically, patients with 
anthracycline-induced cardiotoxicity have a better cardiac outcome when treated with ACE inhibitors and/or beta-blockers early after detection of cardiac dysfunction, and combination therapy may be more effective than either treatment alone. ${ }^{36,38}$

\subsubsection{Key points}

- Cancer patients treated with potentially cardiotoxic therapy are at high risk of developing $\mathrm{HF}$ and should therefore receive medical care aimed at obtaining strict control of cardiovascular risk factors.

- LVEF should be determined before and periodically during treatment for early detection of cardiac dysfunction in patients receiving potentially cardiotoxic chemotherapy, with a method that provides sufficient image quality and, preferably, using the same method during follow-up.

- This group has decided to consider the lower limit of normal of LVEF in echocardiography as $50 \%$, in line with the definition of cardiotoxicity commonly used in registries and trials in patients with cancer.

- A patient with a significant decrease in LVEF (e.g. a decrease $>10 \%$ ), to a value that does not drop below the lower limit of normal, should undergo repeated assessment of LVEF shortly after and during the duration of cancer treatment.

- If LVEF decreases $>10 \%$ to a value below the lower limit of normal (considered as an LVEF $<50 \%$ ), ACE inhibitors (or ARBs) in combination with beta-blockers are recommended to prevent further LV dysfunction or the development of symptomatic HF, unless contraindicated, as these patients are at high risk of developing HF.

- ACE inhibitors (or ARBs) and beta-blockers are recommended in patients with symptomatic HF or asymptomatic cardiac dysfunction unless contraindicated.

\subsection{Coronary artery disease}

\subsubsection{Pathophysiology and clinical presentation}

Myocardial ischaemia and, to a lesser degree, infarction and ischaemia-induced arrhythmias are side effects of several cancer therapies. The mechanisms by which these drugs cause myocardial ischaemia are diverse and range from a direct vasospastic effect to endothelial injury and acute arterial thrombosis, to long-term changes in lipid metabolism and consequent premature arteriosclerosis (Table 7). Previous mediastinal radiotherapy may accelerate drugrelated coronary damage.

\subsubsection{Fluoropyrimidines}

Fluoropyrimidines such as 5-fluorouracil (5-FU) and its oral form capecitabine are used to treat patients with gastrointestinal and other malignancies. The incidence of myocardial ischaemia varies considerably and may be as high as $10 \%$, depending on dose, scheduling and route of administration. ${ }^{117}$ The mechanisms of 5-FUinduced myocardial ischaemia are multifactorial and include coronary vasospasm and endothelial injury. ${ }^{115}$ Chest pain and ischaemic ECG changes typically occur at rest, and less frequently during exercise, within days of drug administration and sometimes persist even after treatment cessation. However, the problem of fluoropyrimidineinduced myocardial ischaemia may be clinically underestimated; a recent study found silent ischaemia in $\sim 6-7 \%$ of 5-FU-treated patients examined using a stress test. ${ }^{124} 5$-FU can also result in acute myocardial infarction. ${ }^{118}$

\subsubsection{Cisplatin}

Cisplatin may induce arterial thrombosis with subsequent myocardial and cerebrovascular ischaemia in $\sim 2 \%$ of patients. ${ }^{119}$ The pathophysiology is multifactorial, including procoagulant and direct endothelial toxic effects. Cisplatin-treated survivors of testicular cancer have a higher incidence of CAD, with an absolute risk of up to $8 \%$ over 20 years. ${ }^{120,121}$

\subsubsection{Immune and targeted therapeutics}

Among the immune and targeted therapeutics, those inhibiting the VEGF signalling pathway have an increased risk for coronary thrombosis. VEGF signalling is important for endothelial cell survival, and inhibition can induce endothelial injury. The incidence of arterial thrombosis varies depending on the compound and disease studied; for the monoclonal VEGF antibody bevacizumab, it ranges from $<1 \%$ in the setting of adjuvant breast cancer to $3.8 \%$ in metastatic diseases. ${ }^{60,122}$ A recent meta-analysis on the risk of arterial thrombosis induced by anti-VEGF small molecule TKIs found an overall

Table 7 Pathophysiological mechanisms of coronary artery disease in cancer treatment $\mathbf{t}^{7,60,81,99,117-123}$

\begin{tabular}{|c|c|c|}
\hline $\begin{array}{l}\text { Fluoropyrimidines } \\
\text { (5-FU, capecitabine, gemcitabine) }\end{array}$ & $\begin{array}{l}\text { - Endothelial injury } \\
\text { - Vasospasm }\end{array}$ & $\begin{array}{l}\text { - Up to } 18 \% \text { manifest myocardial ischaemia } \\
\text { - Up to } 7-10 \% \text { : silent myocardial ischaemia }\end{array}$ \\
\hline Platinum compounds (cisplatin) & $\begin{array}{l}\text { - Procoagulant status } \\
\text { - Arterial thrombosis }\end{array}$ & $\begin{array}{l}\text { - } 20 \text {-year absolute risk of up to } 8 \% \text { after testicular cancer } \\
\text { - } 2 \% \text { risk of arterial thrombosis }\end{array}$ \\
\hline Radiotherapy & $\begin{array}{l}\text { - Endothelial injury } \\
\text { - Plaque rupture } \\
\text { - Thrombosis }\end{array}$ & $\begin{array}{l}\text { - 2-7-fold increased relative risk of myocardial infarction } \\
\text { - Cumulative } 30 \text {-year coronary events incidence of } 10 \% \text { in } \\
\text { Hogdkin lymphoma survivors } \\
\text { - Risk proportional to irradiation dose }\end{array}$ \\
\hline
\end{tabular}

$5-\mathrm{FU}=5$-fluorouracil; VEGF $=$ vascular endothelial growth factor. 
incidence of $1.7 \%$ for sorafenib and $1.4 \%$ for sunitinib. ${ }^{123}$ Sorafenib has also been reported to induce vasospasm. ${ }^{125}$

\subsubsection{Radiotherapy}

Supradiaphragmal and, in certain patient groups, even infradiaphragmal radiotherapy may be associated with a higher incidence of ischaemic heart disease through the development of severe atherosclerotic and non-atherosclerotic disease, complicated by plaque rupture and thrombosis, and potentially with coronary spasm. ${ }^{126-131}$ Ostial lesions are frequent and a potentially lifethreatening complication. The most exposed coronaries are the left anterior descending during left breast irradiation and the left main stem, circumflex and right coronary arteries during treatment for Hodgkin lymphoma. ${ }^{132,133} \mathrm{~A}$ higher prevalence of stress test abnormalities has been found among women irradiated for left breast cancer compared with right-sided cancer. ${ }^{134}$ The evolution may be rapid, with acute coronary syndrome or sudden death as initial manifestations, but it is more often asymptomatic for a long time. ${ }^{135,136}$ Radiation-related cardiac disease in patients with lymphoma typically manifests 15-20 years after the initial treatment, and younger patients are more susceptible than older patients. ${ }^{137}$ Survivors of Hodgkin lymphoma have a four- to seven-fold increased risk of CAD compared with the general population and a cumulative incidence of CVD up to $50 \% 40$ years after treatment. ${ }^{138}$ Based on these data, it appears appropriate to screen regularly for cardiac diseases patients who received radiation therapy, starting $10-15$ years after the initial cancer treatment and continuing lifelong. The risk of developing $C A D$ or $C A D$-associated events after chest irradiation is modifiable by several factors, including concomitant chemotherapy with anthracyclines, young age, high-fractionated doses, lack of thoracic shielding, cardiovascular risk factors and established CAD. ${ }^{95}$ The risk of myocardial infarction in patients treated for Hodgkin lymphoma is two- to seven-fold higher than in the general population, with a cumulative incidence of $10 \%$ at 30 years. ${ }^{7,81,99}$

\subsubsection{Diagnostic and therapeutic management}

The identification of patients with pre-existing CAD and other CVDs is of paramount importance before initiating cancer treatment. Data suggest that pre-existing CAD substantially increases the risk of developing treatment-related CAD. ${ }^{95}$ In addition, patients who develop an acute coronary syndrome or symptomatic CAD while thrombocytopenic during chemotherapy pose a particular challenge for treatment and need case-by-case multidisciplinary management. Options for medical and interventional therapies are limited, as the use of antiplatelet drugs and anticoagulants is frequently not possible or must be restricted. In patients treated by percutaneous coronary intervention who are subsequently found to have a malignancy, minimal duration of dual antiplatelet therapy should be pursued as far as reasonable, according to the most recent guidelines, ${ }^{139-141}$ to limit bleeding risk. The diagnostic algorithms used to identify CAD in patients with cancer are the same as in patients without cancer, and echocardiography should be included as part of the diagnostic workup in these patients.

The incidence and onset of CAD after radiation therapy is dose dependent; historically, thoracic doses of $>30$ Gy were considered to cause vascular disease. ${ }^{98,122,142}$ However, newer data indicate that substantially lower radiation doses increase the risk of subsequent $C A D$, and traditional risk factors for atherosclerosis magnify the risk even more, expanding the population at risk. ${ }^{143}$ Typically there is a long latency period with asymptomatic CAD after radiation treatment and patients may become symptomatic $\sim 10$ years after the initial cancer therapy. ${ }^{143}$ Presentation of CAD is more often atypical and the prevalence of silent ischaemia may be higher than in conventional patients with CAD, ${ }^{144,145}$ possibly because of concomitant neurotoxicity of radiotherapy, or chemotherapy affecting the patient's perception of angina. Sudden cardiac death in irradiated patients has been reported and linked to diffuse intimal hyperplasia of all coronary arteries or to significant left main stenosis. ${ }^{128,130,136}$ It is difficult to predict the burden of radiationinduced CAD in the future, as the introduction of contemporary heart-sparing radiation techniques should attenuate the problem. These measures include a reduction in dose, tangential fields and shielding of cardiac structures.

Long-term complications of treatment for testicular cancer include a greater than two-fold increased risk of CAD $\sim 10$ years after the initial treatment. ${ }^{120}$ These patients, who are typically in their $20 \mathrm{~s}$ or 30 s when affected by the cancer, are commonly treated with a multidrug cisplatin-based chemotherapy with or without radiation therapy. After almost 20 years of follow-up, compared with patients treated with surgery only, patients treated with chemotherapy and/ or (subdiaphragmal) radiation have more cardiovascular risk factors and an $8 \%$ absolute risk for ischaemic events. ${ }^{137}$

\subsubsection{Key points}

- Assessment of CAD should be based on the history, age and gender of the patient, considering the use of chemotherapy drugs as a risk factor for CAD.

- Clinical evaluation and, when necessary, testing for detection of myocardial ischemia is key to identify patients with latent preexisting CAD. This may have implications in the selection of cancer treatment.

- Patients treated with pyrimidine analogues should be closely monitored for myocardial ischaemia using regular ECGs, and chemotherapy should be withheld if myocardial ischaemia occurs.

- Drug rechallenge after coronary vasospasm should be reserved for when no other alternatives exist, and only under prophylaxis and close monitoring of the patient. Pretreatment with nitrates and/or calcium channel blockers may be considered in this setting.

- Long-term clinical follow-up and, when required, testing for the presence of CAD may be useful to identify patients with cardiac disease who develop long-term complications of chemotherapy and radiotherapy.

\subsection{Valvular disease}

\subsubsection{Pathophysiology and clinical presentation}

Chemotherapeutic agents do not directly affect cardiac valves, but VHD may be observed in patients with cancer for several reasons, including pre-existing valve lesions, radiotherapy, infective endocarditis and secondary to LV dysfunction. ${ }^{85,98,128}$ Radiation-induced VHD has been reported as common, affecting $~ 10 \%$ of treated patients, ${ }^{99,146}$ and includes fibrosis and calcification of the aortic root, 
aortic valve cusps, mitral valve annulus and the base and mid portions of the mitral valve leaflets, sparing the mitral valve tips and commissures, ${ }^{98,99}$ allowing distinction from rheumatic disease. ${ }^{85}$ In patients with Hodgkin lymphoma, radiation dose to the heart valves can increase the risk of clinically significant VHD as the first cardiovascular event after treatment, especially at doses $>30 \mathrm{~Gy} .{ }^{147}$ However, for patients with mediastinal involvement treated today with 20 or $30 \mathrm{~Gy}$, the 30 -year risk would be increased only by $\sim 1.4 \%{ }^{146}$

\subsubsection{Diagnostic and therapeutic management}

Echocardiography is the assessment method of choice, and 3D echocardiography may be useful, particularly for the evaluation of mitral valve commissures. Baseline and repeated echocardiography after radiation therapy involving the heart are recommended in patients with cancer for the diagnosis and follow-up of VHD. ${ }^{80,85,95,148}$

CMR and computed tomography (CT) may be used to assess the severity of $\mathrm{VHD}$, but cardiac $\mathrm{CT}$ is mainly useful for detecting extensive calcifications of the ascending aorta, which may lead to a higher operative risk and sometimes prohibit conventional cardiovascular surgery. Cardiac surgery is also frequently challenging in such patients because of mediastinal fibrosis, impaired wound healing and associated coronary artery, myocardial and pericardial disease. Transcatheter valve implantation (e.g. transcatheter aortic valve implantation) may be a suitable option in this situation. ${ }^{149}$

\subsection{Arrhythmias}

\subsubsection{Pathophysiology and clinical presentation}

Patients with cancer may experience a wide spectrum of cardiac arrhythmias, including sinus tachycardia, bradyarrhythmias or tachyarrhythmias, and conduction defects, some of which may cause severe symptoms or become life-threatening or impose a change in the patient's treatment plan (Table 8). Arrhythmias can be present at baseline in $16-36 \%$ of treated patients with cancer. ${ }^{11,150}$

\subsubsection{QT prolongation}

QT prolongation can be caused by cancer therapies (Table 9), electrolyte disturbances, predisposing factors and concomitant medications (e.g. anti-emetics, cardiac medications, antibiotics, psychotropes). ${ }^{11}$ QT prolongation can lead to life-threatening arrhythmias such as torsade de pointes. The duration of the QT interval and risk factors for QT prolongation should be controlled before, during and after cancer treatment. The risk of QT prolongation varies with different drugs, with arsenic trioxide being the most relevant. This drug, which is used to treat some leukaemias and myelomas, prolongs the QT interval in $26-93 \%$ of patients, and lifethreatening ventricular tachyarrhythmias have been reported not infrequently. ${ }^{151}$ Prolongation of the QTc interval was observed 1-5 weeks after arsenic trioxide infusion and then returned towards baseline by the end of 8 weeks, i.e. before the second course of chemotherapy. ${ }^{152}$ Other cancer therapies that frequently induce QT prolongation are listed in Table 9. Among these, the TKI drug class, and specifically vandetanib, has the second highest incidence of QT prolongation.

\subsubsection{Supraventricular arrhythmia}

Any type of supraventricular arrhythmia may arise acutely during or even after chemotherapy or radiotherapy, of which atrial fibrillation is the most common. The arrhythmia may be related to comorbidities or due to direct tumour effects, LV dysfunction or toxic effects of the cancer treatment. The most common form of cancerrelated atrial fibrillation is postoperative atrial fibrillation, particularly in patients undergoing lung resection. An overview of pathogenetic mechanisms has been published. ${ }^{151,155}$

\subsubsection{Ventricular arrhythmias}

Ventricular arrhythmias can be related to QT prolongation, to acute and chronic toxicity of chemotherapy and radiotherapy

\section{Table 8 Cancer drug agents associated with cardiac arrhythmias}

\begin{tabular}{|l|l|}
\hline Type of arrhythmia & Causative drug \\
\hline Bradycardia & $\begin{array}{l}\text { Arsenic trioxide, bortezomib, capecitabine, cisplatin, cyclophosphamide, doxorubicine, epirubicine, 5-FU, ifosfamide, } \\
\text { IL-2, methotrexate, mitoxantrone, paclitaxel, rituximab, thalidomide. }\end{array}$ \\
\hline Sinus tachycardia & Anthracyclines, carmustine. \\
\hline Atrioventricular block & Anthracyclines, arsenic trioxide, bortezomib, cyclophosphamide, 5-FU, mitoxantrone, rituximab, taxanes, thalidomide. \\
\hline Conduction disturbances & Anthracyclines, cisplatin, 5-FU, imatinib, taxanes. \\
\hline Atrial fibrillation & $\begin{array}{l}\text { Alkylating agents (cisplatin, cyclophosphamide, ifosfamide, melphalan), anthracyclines, antimetabolites (capecitabine, } \\
\text { 5-FU, gemcitabine), IL-2, interferons, rituximab, romidepsin, small molecule TKls (ponatinib, sorafenib, sunitinib, } \\
\text { ibrutinib), topoisomerase II inhibitors (amsacrine, etoposide), taxanes, vinca alkaloids. }\end{array}$ \\
\hline Supraventricular tachycardias & $\begin{array}{l}\text { Alkylating agents (cisplatin, cyclophosphamide, ifosfamide, melphalan), amsacrine, anthracyclines, antimetabolites } \\
\text { (capecitabine, 5-FU, methotrexate), bortezomib, doxorubicin, IL-2, interferons, paclitaxel, ponatinib, romidepsin. }\end{array}$ \\
\hline Ventricular tachycardia/fibrillation & $\begin{array}{l}\text { Alkylating agents (cisplatin, cyclophosphamide, ifosfamide), amsacrine, antimetabolites (capecitabine, 5-FU, } \\
\text { gemcitabine), arsenic trioxide, doxorubicin, interferons, IL-2, methothrexate, paclitaxel, proteasome inhibitors } \\
\text { (bortezomib, carfilzomib), rituximab, romidepsin. }\end{array}$ \\
\hline Sudden cardiac death & $\begin{array}{l}\text { Anthracyclines (reported as very rare), arsenic trioxide (secondary to torsade de pointes), 5-FU (probably related } \\
\text { to ischaemia and coronary spasm), interferons, nilotinib, romidepsin. }\end{array}$ \\
\hline
\end{tabular}

5-FU = 5-fluorouracil; IL-2 = interleukin 2; TKI = tyrosine kinase inhibitor. 
Table 9 Cancer drug agents associated with QT prolongation and Torsade de Pointes ${ }^{151,153,154}$

\begin{tabular}{|c|c|c|c|c|}
\hline Cancer drug agents & $\begin{array}{l}\text { Average QT } \\
\text { prolongation (ms) }\end{array}$ & $\begin{array}{l}\text { Increase in } \\
\text { QTc }>60 \mathrm{~ms}(\%)\end{array}$ & QTc >500 ms (\%) & $\begin{array}{l}\text { Torsade de pointes } \\
\text { (\%) }\end{array}$ \\
\hline \multicolumn{5}{|l|}{ Anthracyclines } \\
\hline Doxorubicin & 14 & $11-14$ & NA & NA \\
\hline \multicolumn{5}{|c|}{ Histone deacetylase inhibitors } \\
\hline Depsipeptide & 14 & $20-23.8$ & NA & NA \\
\hline Vorinostat & $<10$ & $2.7-6$ & $<1$ & NA \\
\hline \multicolumn{5}{|c|}{ Tyrosine kinase inhibitors } \\
\hline Axitinib & $<10$ & NA & NA & NA \\
\hline Bosutinib & NA & 0.34 & 0.2 & NA \\
\hline Cabozantinib & $10-15$ & NA & NA & NA \\
\hline Crizotinib & $9-13$ & 3.5 & 1.3 & NA \\
\hline Dasatinib & $3-13$ & $0.6-3$ & $<1.4$ & NA \\
\hline Lapatinib & $6-13$ & II & 6.1 & NA \\
\hline Nilotinib & $5-15$ & $1.9-4.7$ & $<1.2$ & NA \\
\hline Pazopanib & NA & NA & 2 & $<0.3$ \\
\hline Ponatinib & $<10$ & NA & NA & NA \\
\hline Sorafenib & $8-13$ & NA & NA & NA \\
\hline Sunitinib & $9.6-15.4$ & $1-4$ & 0.5 & $<0.1$ \\
\hline Vandetanib & 36 & $12-15$ & $4.3-8$ & Described, \% NA \\
\hline Vemurafenib & $13-15$ & 1.6 & 1.6 & Described, \% NA \\
\hline \multicolumn{5}{|l|}{ Others } \\
\hline Arsenic trioxide & 35.4 & 35 & $25-60$ & 2.5 \\
\hline
\end{tabular}

$\mathrm{NA}=$ not available

Table I0 Risk factors for QT prolongation in cancer patients

\begin{tabular}{|c|c|}
\hline \multicolumn{2}{|l|}{ Risk factors for QT prolongation } \\
\hline Correctable & Non-correctable \\
\hline $\begin{array}{l}\text { Electrolyte imbalance } \\
\text { - Nausea and emesis } \\
\text { - Diarrhoea } \\
\text { - Treatment with loop diuretics } \\
\text { - Hypokalaemia ( } \leq 3.5 \mathrm{mEg} / \mathrm{L}) \\
\text { - Hypomagnesaemia }(\leq 1.6 \mathrm{mg} / \mathrm{dL}) \\
\text { - Hypocalcaemia }(\leq 8.5 \mathrm{mg} / \mathrm{dL}) \\
\text { Hypothyroidism } \\
\text { Concurrent use of } \\
\text { QT-prolonging drugs } \\
\text { - Antiarrhythmic } \\
\text { - Anti-infective } \\
\text { - Antibiotic } \\
\text { - Antifungal } \\
\text { - Psychotropic } \\
\text { - Antidepressant } \\
\text { - Antipsychotic } \\
\text { - Antiemetic } \\
\text { - Antihistamine }\end{array}$ & $\begin{array}{l}\text { - Family history of sudden } \\
\text { death (occult congenital } \\
\text { LQTS or genetic } \\
\text { polymorphisms) } \\
\text { - Personal history of syncope } \\
\text { - Baseline QTc interval } \\
\text { prolongation } \\
\text { - Female gender } \\
\text { - Advanced age } \\
\text { - Heart disease } \\
\text { - Myocardial infarction } \\
\text { - Impaired renal function } \\
\text { - Impaired hepatic drug } \\
\text { metabolism }\end{array}$ \\
\hline
\end{tabular}

LQTS = long QT syndrome. (mainly LV dysfunction and ischaemia) and to predisposing factors (Table 10).

\subsubsection{Sinus node dysfunction and conduction defects}

Sinus node dysfunction and conduction defects may arise following radiotherapy and are often permanent. Paclitaxel and thalidomide can result in sinus node dysfunction and bradyarrhythmias and heart block. $^{151}$

\subsubsection{Diagnostic and therapeutic management}

Arrhythmias in patients with cancer can occur before, during and shortly after treatment. Management should be individualized and decisions on the use of anti-arrhythmic drugs or device therapy (implantable or external wearable cardioverter defibrillators) ${ }^{156}$ should consider the competing risks of cardiac- and cancer-related life expectancy, quality of life and complication risks.

2.4.2.1 QT interval and associated risk factors for QT prolongation The QT interval and associated risk factors for QT prolongation (Table 10) should be assessed before and during treatment. QTc intervals $>450 \mathrm{~ms}$ in men and $>460 \mathrm{~ms}$ in women are suggested as a guideline for the upper limit of normal on baseline ECG evaluation. ${ }^{156,157}$ QTc prolongation $>500 \mathrm{~ms}$ and a $\Delta \mathrm{QT}$ (i.e. change from baseline) of $>60 \mathrm{~ms}$ are considered to be of particular concern because torsades de pointes rarely occurs when QTc is $<500$ ms. $^{156}$ ECG and electrolyte monitoring during treatment 
should be considered at baseline, 7-15 days after initiation or changes in dose, monthly during the first 3 months and then periodically during treatment depending on the chemotherapy drug and patient status. Patients experiencing diarrhoea should be monitored more frequently, and those receiving treatment with arsenic trioxide should be monitored weekly with ECG.

Management is generally dependent on correcting the predisposing factors (e.g. concomitant electrolyte abnormalities, QT-prolonging drugs). A full list of QT-prolonging drugs and which concomitant drugs should be avoided whenever possible can be found at http://www.crediblemeds.org. A general recommendation from the US Food and Drug Administration and European Medicines Agency is that if during treatment QTc is $>500 \mathrm{~ms}$ (or QTc prolongation is $>60 \mathrm{~ms}$ above baseline), treatment should be temporarily interrupted, electrolyte abnormalities corrected and cardiac risk factors for QT prolongation controlled. ${ }^{151,154,156}$ Treatment can then be resumed at a reduced dose once the QTc normalizes. As malignancy is usually associated with substantial morbidity and mortality, benefits from the efficacy of targeted therapies have the potential to outweigh the risk of torsade de pointes. ${ }^{154,155,158}$ If no alternative therapy exists, the frequency of ECG monitoring of the QT interval should be increased. The frequency of monitoring should be individualized depending on the patient's characteristics and the causative drug.

The development of bursts of torsade de pointes is unusual, but requires intravenous administration of magnesium sulphate $(10 \mathrm{~mL})$ and, in some acute situations, overdrive transvenous pacing or isoprenaline titrated to a heart rate $>90$ beats per minute to prevent new episodes in the acute setting. If sustained ventricular arrhythmias and haemodynamic instability occur, non-synchronized defibrillation must be performed.

\subsubsection{Key points}

- A 12-lead ECG should be recorded and the QT interval, corrected for heart rate with Bazett's or Fridericia's formula, should be obtained in all patients at baseline.

- Patients with a history of QT prolongation, relevant cardiac disease, treated with QT-prolonging drugs, bradycardia, thyroid dysfunction or electrolyte abnormalities should be monitored by repeated 12-lead ECG.

- Consider treatment discontinuation or alternative regimens if the QTc is $>500 \mathrm{~ms}$, QTc prolongation is $>60$ ms or dysrhythmias are encountered.

- Conditions known to provoke torsades de pointes, especially hypokalaemia and extreme bradycardia, should be avoided in patients with drug-induced QT prolongation.

- Exposure to other QT-prolonging drugs should be minimized in patients treated with potentially QT-prolonging chemotherapy.

\subsubsection{Atrial fibrillation and atrial flutter}

The initial approach to the management of atrial fibrillation and atrial flutter requires the usual decisions regarding rhythm management, thromboembolic prophylaxis and effective stroke prevention with oral anticoagulation. However, the balance between thromboembolic and bleeding risks of atrial fibrillation \{as assessed by the $\mathrm{CHA}_{2} \mathrm{DS}_{2}$-VASc [Congestive heart failure or left ventricular dysfunction, Hypertension, Age $\geq 75$ years (doubled), Diabetes, Stroke (doubled), Vascular disease, Age 65-74 years, Sex category (female)] and HAS-BLED [Hypertension, Abnormal rena//liver function (1 point each), Stroke, Bleeding history or predisposition, Labile international normalized ratio, Elderly ( $>65$ years), Drugs/alcohol concomitantly (1 point each)] scores, respectively\} is particularly challenging in patients with cancer. While cancer may cause a prothrombotic state, it may also predispose to bleeding. On the other hand, the $\mathrm{CHA}_{2} \mathrm{DS}_{2}$-VASc and HAS-BLED risk scores have not been validated in patients with cancer. Thus the decision on antithrombotic therapy for stroke prevention may be quite challenging and should not be based only on the risk assessment scores used for the general population.

In patients with a $\mathrm{CHA}_{2} \mathrm{DS}_{2}$-VASc score $\geq 2$, anticoagulation can generally be considered if the platelet count is $>50000 / \mathrm{mm}^{3}$, usually with a vitamin $\mathrm{K}$ antagonist and with good anticoagulation control (with time in the therapeutic range $>70 \%$ ). Close liaison with haematologists/oncologists is advised. The occurrence of atrial fibrillation at any point (e.g. during chemotherapy, surgery or radiotherapy) suggests an intrinsic predisposition to arrhythmia. In terms of thromboprophylaxis, this again depends on the presence of stroke risk factors, where anticoagulation would be recommended with a $\mathrm{CHA}_{2} \mathrm{DS}_{2}-\mathrm{VASc}$ score $\geq 2$. Even with lower-risk patients with atrial fibrillation, prophylaxis may be considered, given the risk of venous thromboembolism (VTE) in patients with cancer.

Full assessment of the patient, including echocardiography, is advised, and decisions on anticoagulation should consider other co-morbidities, bleeding risks and patient values and preferences. Anticoagulation options include therapeutic low molecular weight heparin (LMWH) (as a short- to intermediate-term measure), a vitamin $\mathrm{K}$ antagonist (VKA; e.g. warfarin) if the international normalized ratio control is stable and effective or a non-VKA oral anticoagulant (NOAC). Warfarin is often avoided in cancer patients with metastatic disease and high bleeding risk, with LMWH the traditionally preferred option, given the risk for variations in the international normalized ratio. The role and safety of NOACs in this patient group remains to be clarified. Although trials generally excluded patients with a platelet count of $<100000 / \mathrm{mm}^{3}$ or limited survival, a meta-analysis of the patients with cancer in NOAC trials suggested these new drugs are safe. ${ }^{159}$

Generally, an individualized approach to the management of atrial fibrillation is needed, and decisions on rate or rhythm control should be patient-centred and symptom directed. A beta-blocker or nondihydropyridine calcium channel blocker may help with rate control in atrial fibrillation and with suppression of supraventricular tachycardia. Digitalis may be considered as an alternative in patients with intolerance to the former, with systolic dysfunction or HF.

\subsubsection{Bradycardia or atrioventricular block}

The development of bradycardia or atrioventricular block requires an individualized approach to management, with correction of the causative factor(s), when feasible, before decisions are made on drugs and/or pacing (whether temporary or permanent).

\subsection{Arterial hypertension}

\subsubsection{Pathophysiology and clinical presentation}

Hypertension is a frequent co-morbidity in patients with cancer. It can also be a causative factor, such as in renal cancer. ${ }^{160}$ VEGF 
inhibitors have a high risk (11-45\%) of inducing new hypertension or destabilizing previously controlled hypertension, including severe hypertension in 2-20\% of cases. ${ }^{161,162}$ The incidence and severity depend upon patient age, history of hypertension, CVD history type of cancer (i.e. renal vs. non-renal cell cancer), drug type and dose, schedule used and associated cancer therapies. In a meta-analysis of clinical trials, the incidence of hypertension was increased by a factor of 7.5, 6.1 and 3.9, respectively, under bevacizumab, sorafenib and sunitinib. ${ }^{163,164}$

A summary of the incidence of hypertension reported in patients with cancer taking these drugs can be found in the appendix at the end of this document. Nitric oxide pathway inhibition, vascular rarefaction (i.e. reduced number of vessels), oxidative stress and glomerular injury developing from loss of VEGF effect represent some of the main proposed mechanisms. ${ }^{162,163}$ VEGF inhibition may also cause renal thrombotic microangiopathy. ${ }^{164}$ Drug-related hypertension can occur from initiation until 1 year after treatment onset. In the case of sunitinib, cancer efficacy may be correlated with the occurrence and degree of hypertension, but there is no evidence that antihypertensive therapy impairs oncology responses. ${ }^{9}$

\subsubsection{Diagnostic and therapeutic management}

Management of hypertension aims at reducing the short-term risk of its related morbidities while maintaining effective anti-angiogenic therapy for optimal cancer treatment. ${ }^{165}$ The goal is to identify hypertension $(>140 / 90 \mathrm{mmHg})$ and maintain blood pressure $(<140 / 90 \mathrm{mmHg}$, or lower in case of overt proteinuria). Baseline assessment of CVD risk factors (including a history of hypertension and current blood pressure levels) and management of arterial hypertension should be performed before initiation of a VEGF inhibitor. Pain control and stress management are necessary for adequate estimation of blood pressure. Other medications used in these patients (e.g. steroids, non-steroidal anti-inflammatory drugs, erythropoietin) may also predispose to or cause hypertension. When white-coat hypertension is suspected, ambulatory blood pressure measurement should be considered and lifestyle modification encouraged. ${ }^{166}$

After the initiation of VEGF inhibitors, early detection and reactive management of blood pressure elevations are necessary to avoid severe complications, and aggressive pharmacological management is recommended. ${ }^{167-171}$ ACE inhibitors, ARBs and non-dihydropyridine calcium channel blockers (amlodipine, felodipine) are proposed as first-line therapies. ${ }^{172}$ ACE inhibitors and beta-blockers are the preferred antihypertensive drugs in patients with HF or at risk of HF or LV dysfunction. ${ }^{173}$ Because decreased nitric oxide signalling plays a key role in the pathogenesis of hypertension, ${ }^{169}$ drugs that increase nitric oxide signalling, such as the beta1-blocker nebivolol, may represent a valuable option in this population. ${ }^{116}$ Other beta-blockers with vasodilatory effects, such as carvedilol, can be considered. Diltiazem and verapamil inhibit cytochrome P450 3A4, and because many VEGF inhibitors are a substrate of this isoenzyme, this combination results in increased drug plasma levels and should therefore be avoided. Inhibitors of phosphodiesterase-5, such as sildenafil and tadalafil, may also offer an antihypertensive therapy option, although available data are limited in patients with arterial hypertension. ${ }^{174,175}$ Diuretics have the risk of electrolyte depletion and consequent QT prolongation and although they may be used, caution is advised and they should not be considered as first-line therapy because VEGF inhibitors can produce severe diarrhoea and potential dehydration. ${ }^{9,172}$ However, there is minimal trial-based evidence suggesting a superiority of any specific class of antihypertensive drug in patients treated with these VEGF inhibitors. ${ }^{175,176}$

Close monitoring and evaluation of treatment adherence are necessary when severe hypertension is present. To ensure efficacy and tolerance of antihypertensive drugs, follow-up is mandatory. Patients with resistant hypertension should be referred to cardiooncology or hypertension specialist assessment to minimize interruption of VEGF inhibitors.

\subsubsection{Key points}

- Hypertension should be adequately treated according to the current standing clinical practice guidelines, and blood pressure should be monitored before initiating cancer treatment and periodically during treatment, depending on the patient's characteristics and adequate blood pressure control.

- Hypertension in patients with cancer is manageable with conventional antihypertensive treatment, but early and aggressive treatment is encouraged to prevent the development of cardiovascular complications (i.e. HF).

- ACE inhibitors or ARBs, beta-blockers and dihydropyridine calcium channel blockers are the preferred antihypertensive drugs. Non-dihydropyridine calcium channel blockers should preferably be avoided due to drug interactions.

- Dose reduction and reinforcement of antihypertensive treatment or discontinuation of VEGF inhibitors can be considered if blood pressure is not controlled. Once blood pressure control is achieved, VEGF inhibitors can be restarted to achieve maximum cancer efficacy.

\subsection{Thromboembolic disease}

\subsubsection{Pathophysiology and clinical presentation}

Tumour cells can trigger coagulation through different pathways, including procoagulant, antifibrinolytic and pro-aggregating activities; release of pro-inflammatory and pro-angiogenic cytokines and interaction with vascular and blood cells through adhesion molecules. ${ }^{177}$

\subsubsection{Arterial thrombosis}

Intra-arterial thrombotic events are rare in patients with cancer, with an incidence of $\sim 1 \%$. They occur mostly in metastatic pancreatic, breast, colorectal and lung cancers, under anthracyclines and taxane- and platinum-based chemotherapies, and affected patients have a poor prognosis. ${ }^{178}$ The prothrombotic state may facilitate embolic events secondary to atrial fibrillation (see section 2.4.3.1). Some cancer therapies, especially VEGF inhibitors, may favour thromboembolic complications ${ }^{9}$ (see section 2.2). In patients with breast cancer under hormonal therapy, higher rates of arterial thrombotic events are reported under aromatase inhibitors compared with tamoxifen, which are at least partly explained by the more favourable effects of tamoxifen on the lipid profile. ${ }^{179}$

\subsubsection{Venous thrombosis and thromboembolism}

Venous thrombosis and VTE occur frequently in patients with cancer, may affect up to $20 \%$ of hospitalized patients and are frequently 
underrecognized. ${ }^{180}$ They can be related to chemotherapy, including its administration route (use of indwelling venous catheters), and also to the cancer itself and the patient's previous risk of venous thrombosis. VTE is the most common cause of death after surgery for cancer. Antithrombotic prophylaxis should be given for a minimum of 4 weeks after surgery. VTE is common in ambulatory patients with cancer (bladder, colon, ovary, lung, stomach and pancreas) during chemotherapy treatment; however, the role of prophylaxis is unclear. Improved patient selection and/or antithrombotic agents are required. ${ }^{181}$ Table 11 summarizes clinical risk factors associated with VTE. ${ }^{182}$ Some biological factors are also considered as predictive of VTE in cancer (platelet count, leucocyte count, d-dimers, etc.). The combination of chemotherapy and VEGF inhibitors increases the risk of VTE and recurrent VTE six-fold and two-fold, respectively. ${ }^{183}$ In patients with breast cancer, higher rates of VTE are reported under tamoxifen compared with aromatase inhibitors. ${ }^{181}$

\subsubsection{Diagnostic and therapeutic management}

The detection of thrombotic events in patients undergoing chemotherapy is based mainly on clinical symptoms. No systematic screening strategy has shown any benefit. Incidental pulmonary embolism or venous thrombosis can be detected during imaging for cancer (e.g. chest positron emission tomography-computed tomography). The management of these silent thrombotic events is still unclear. As the risk for (symptomatic) recurrence and mortality is increased, these cases are usually treated in a similar manner to symptomatic VTE. ${ }^{184}$

The decision to administer anticoagulation for VTE prevention in patients with cancer should always take into consideration the patient's bleeding risk and life expectancy; these may change over time, requiring periodic reassessment. Treatment of a confirmed episode of acute VTE in haemodynamically stable patients consists of

Table I I Clinical factors associated with increased risk of cancer-associated venous thromboembolism (modified from Khorana et al. ${ }^{182}$ )

\begin{tabular}{|l|}
\hline Cancer-related factors \\
- Primary site of cancer (mostly pancreas, brain, stomach, kidney, lung, \\
- lymphoma, myeloma) \\
- Histology (speciallly adenocarcinoma) \\
- Advanced stage (metastatic) \\
- Initial period after cancer diagnosis \\
\hline Patient-related factors \\
- Demographics: older age, female sex, African ethnicity \\
- Comorbidities (infection, chronic kidney disease, pulmonary disease, \\
- atherothrombotic disease, obesity) \\
- History of venous thromboembolism, inherited thrombophilia \\
\hline - Low performance status \\
\hline Treatment-related factors \\
- Major surgery \\
- Hospitalization \\
- Chemotherapy and anti-angiogenic agents \\
- Hormonal therapy \\
- Transfusions \\
- Central venous catheters \\
\hline
\end{tabular}

LMWH given over a period of 3-6 months. This strategy is superior to VKA therapy in patients with cancer in terms of reduced VTE events, with no difference regarding mortality or bleeding in clinical trials. ${ }^{185}$ Bleeding risk can be six times higher under anticoagulation for deep vein thrombosis in patients with vs. without cancer. ${ }^{186}$ Cancer is a strong risk factor for VTE recurrence. Consequently, chronic anticoagulation after the acute phase of treatment, and until the cancer is considered cured, should be considered. The choice of anticoagulation discontinuation or maintenance under LMWH or switching to VKAs should be discussed on an individual basis after considering the cancer therapy success, the risk of VTE recurrence and bleeding, as well as the patient's preference. ${ }^{187}$ Current data on NOACs are limited to a subgroup analysis of patients with cancer within large trials comparing these drugs with VKAs in VTE. ${ }^{188,189}$ Overall, no differences were reported between NOACs and VKAs for either VTE recurrence or bleeding. Results from specific trials involving NOACs in patients with cancer are awaited. No comparison between NOACs and LMWH is currently available. Different NOACs may differ because of potential drug interactions and sensitivity to renal or hepatic dysfunction. ${ }^{190}$

Recurrent VTE may still occur despite VKA or LMWH therapy in patients with cancer, and may be managed by switching from VKA to LMWH or increasing the LMWH dose. ${ }^{191}$ A vena cava filter, either definitive or retractable, may be implanted when anticoagulation is contraindicated or failing. However, the risk of filter thrombosis and occlusion leading to distal propagation of thrombosis with postthrombotic syndrome should be considered. No clinical advantage was found in the systematic placement of a vena cava filter in addition to anticoagulation with fondaparinux in patients with cancer. ${ }^{192}$

There is no conclusive evidence on the benefits of thrombolysis in case of haemodynamically unstable pulmonary embolism in patients with cancer. Increased bleeding risk should be expected, but because of high pulmonary embolism-related early mortality risk, thrombolysis may still be considered, on a case-by-case basis, taking into account the patient's quality-adjusted life expectancy related to the individual cancer. It is important to keep in mind contraindications to fibrinolytic therapy in patients with brain tumours or metastasis. Surgical embolectomy may be considered, but surgery imparts significant morbidity, and cardiopulmonary bypass requires aggressive anticoagulation. ${ }^{189}$

The management of arterial thrombotic events in patients with cancer has been poorly addressed, and the use of antithrombotic therapies, thrombolysis and/or endovascular intervention should be discussed on a case-by-case basis with multidisciplinary consultation involving the cardio-oncology team, when available. In case of recurrences, control of cardiovascular risk factors and the search for anti-phospholipid antibodies has been proposed. ${ }^{193}$

\subsection{Peripheral vascular disease and stroke}

2.7.1 Pathophysiology and clinical presentation

2.7.1.1 Peripheral artery disease

Severe atherosclerotic and non-atherosclerotic peripheral artery disease (PAD) in the lower extremities can occur (in up to 30\%) in patients treated with nilotinib, ponatinib or BCR-ABL TKIs used for chronic myeloid leukaemia, even in the absence of CVD risk 
factors, although the latter increases the likelihood of PAD. ${ }^{74}$ PAD can occur as early as in the first months of therapy or as a late effect several years after treatment. Other cancer therapy-related peripheral arterial toxicity includes Raynaud's phenomenon and ischaemic stroke (i.e. with L-asparaginase, cisplatin, methotrexate, 5-FU and paclitaxel). ${ }^{194}$

\subsubsection{Stroke}

The risk of stroke is increased — at least doubled — after mediastinal, cervical or cranial radiotherapy. ${ }^{195}$ Endothelial damage and thrombus formation may occur after irradiation of cerebral small vessels. ${ }^{196}$ In medium or large vessels, three mechanisms are described: vasa vasorum occlusions with medial necrosis and fibrosis; adventitial fibrosis and accelerated atherosclerosis, leading to increased carotid stiffness and intima-media thickness and advanced atherosclerosis (occurring $>10$ years after radiotherapy). ${ }^{197,198}$ Similar consequences are reported for the aorta and other peripheral arteries, including the subclavian and iliofemoral, with ischaemic limb symptoms. ${ }^{199}$

\subsubsection{Diagnostic and therapeutic management}

The assessment of PAD risk at baseline (risk factor assessment, clinical examination, ankle-brachial index measurement) is recommended. Fontaine stages 1-2 (asymptomatic or with intermittent claudication only) require risk factor control and periodic clinical, metabolic and haemodynamic follow-up. ${ }^{200}$ Antiplatelet drugs should be considered mostly in symptomatic PAD. In case of severe PAD at baseline or during cancer therapy, revascularization should be individualized and discussed in a multidisciplinary meeting with experts in haematology, vascular surgery and cardio-oncology. ${ }^{201}$

Patients irradiated for head and neck cancer or lymphoma should undergo cerebrovascular ultrasound screening, especially beyond 5 years after irradiation. Duplex imaging may be considered at least every 5 years, or earlier and/or more frequently if the results of the first examination are abnormal. Other locations of post-radiation arterial lesions are usually discovered by clinical examination or when symptomatic. Stringent risk factor management is required to halt plaque progression. Antiplatelet therapy may be considered. Significant stenosis (e.g. carotid arteries) may require stenting or surgery. ${ }^{201,202}$

\subsection{Pulmonary hypertension \\ 2.8.1 Pathophysiology and clinical presentation}

Pulmonary hypertension is a rare but serious complication of some cancer agents and stem cell bone marrow transplantation. ${ }^{203}$ The TKI imatinib improved haemodynamics in patients with advanced pulmonary arterial hypertension (PAH). ${ }^{204,205}$ However, a drug of the same TKI family_-dasatinib, used as second-line treatment for chronic myelogenous leukaemia - can induce severe precapillary pulmonary hypertension. ${ }^{206}$ This condition appears 8-40 months after exposure to dasatinib, with clinical and haemodynamic presentation suggestive of $\mathrm{PAH}$. Unlike other forms of $\mathrm{PAH}$, this is often reversible after drug discontinuation or replacement with another TKI, such as nilotinib. Recently, cyclophosphamide and other alkylating agents were suggested as contributing to the development of pulmonary veno-occlusive disease ${ }^{207}$ involving predominantly small venules and representing the most severe form of pulmonary hypertension lacking effective pharmacological treatment.

\subsubsection{Diagnostic and therapeutic management}

Baseline echocardiographic assessment, including the search for signs of right ventricular overload, should be considered in individuals requiring treatment with cancer drugs that can cause pulmonary hypertension (e.g. dasatinib) (Table 12). This approach may help in interpretation of follow-up echocardiographic examinations in patients reporting exercise limitation or exertional dyspnoea during cancer therapy. Patients with echocardiographic signs suggesting increased baseline pulmonary arterial pressure require cardiology assessment to determine its aetiology, as it may affect the strategy of cancer treatment, particularly when due to LV dysfunction or chronic thromboembolic pulmonary hypertension. ${ }^{208}$

Non-invasive cardiovascular surveillance should be considered in all patients during treatment with cancer drugs known to cause PAH, particularly in case of the appearance of new exertional dyspnoea, fatigue or angina (Table 12). Echocardiography may be considered every 3-6 months in asymptomatic patients. It is unclear whether patients with baseline signs of right ventricular overload due to co-morbidities commonly associated with elevated pulmonary arterial pressure (e.g. chronic obstructive pulmonary disease, left heart dysfunction) are at higher risk of chemotherapy-induced $\mathrm{PAH}$ and require more frequent surveillance with echocardiography.

Table I 2 Strategies for surveillance and management of drug-induced pulmonary hypertension

\begin{tabular}{|c|c|}
\hline $\begin{array}{l}\text { Baseline } \\
\text { assessment }\end{array}$ & $\begin{array}{l}\text { - Consider risk factors and associated conditions for } \\
\text { PAH }^{\text {a }} \\
\text { - Assess NYHAMHO functional class } \\
\text { - Consider 6-minute walk test } \\
\text { - Consider NT-proBNP } \\
\text { - Assess echocardiographic level of probability of PH }\end{array}$ \\
\hline strategy & $\begin{array}{l}\text { Asymptomatic } \\
\text { - Assess NYHA/WHO functional class every } 3 \text { months } \\
\text { - Assess echocardiographic level of PAP every } \\
3 \text { months } \\
\text { - Consider presence of other indications for right heart } \\
\text { catheterization } \\
\text { - Consider further evaluation for suspected } \mathrm{PH}^{\mathrm{a}} \\
\text { Symptomatic } \\
\text { - Assess NYHA/WHO functional class } \\
\text { - Perform 6-minute walk test } \\
\text { - Sample blood for NT-proBNP } \\
\text { - Assess echocardiographic level of probability of PH } \\
\text { - Consider indications for right heart catheterization } \\
\text { in PH referral centre } \\
\text { - Consider interruption of cancer therapy }\end{array}$ \\
\hline
\end{tabular}

NT-proBNP $=$ N-terminal fragment B-type natriuretic peptide; $\mathrm{NYHA}=\mathrm{New}$ York Heart Association; $\mathrm{PAH}=$ pulmonary arterial hypertension; $\mathrm{PAP}=$ pulmonary arterial pressure; $\mathrm{PH}=$ pulmonary hypertension; $\mathrm{WHO}=$ World Health Organization

a See diagnostic algorithms for suspected PH in European Society of Cardiology (ESC)/ European Respiratory Society (ERS) Guidelines on Pulmonary Hypertension $(2015)^{208}$

${ }^{\mathrm{b}}$ Dasatinib-induced $\mathrm{PH}$ usually reversible with drug cessation. 
When drug-induced $\mathrm{PAH}$ is suspected, referral to a specialized pulmonary hypertension team is recommended to assess indications for right heart catheterization. ${ }^{208}$ Multidisciplinary team discussions should be held with oncology or haematology regarding the risk-benefit ratio of continuing cancer treatment with $\mathrm{PAH}$ drug therapy vs. stopping or replacing the culprit drug. ${ }^{208}$ Dasatinib-induced pulmonary hypertension is often reversible with drug cessation, although usually without restoration of normal right heart haemodynamics. ${ }^{206}$ Targeted therapy for PAH is used temporarily or permanently.

\subsection{Other cardiovascular complications of cancer treatment \\ 2.9.1 Pericardial disease}

Acute pericarditis may occur with the use of several chemotherapeutic drugs (predominantly anthracyclines, but also cyclophosphamide, cytarabine and bleomycin), while it has become uncommon during radiotherapy and is usually associated with pericardiac mediastinal tumours. Acute pericarditis with typical chest pain, fever, ST-T changes and large effusions, even leading to tamponade, may develop 2-145 months after thoracic radiotherapy, with an absolute cumulative incidence of $2-5 \%$. Transthoracic echocardiography is the method of choice for the evaluation of patients with suspected pericardial disease due to chemotherapy, but CT can be of help, particularly to identify calcification. Treatment of pericardial effusion consists primarily of non-steroidal anti-inflammatory drugs and colchicine. Pericardiocentesis may be required for large effusions and those causing haemodynamic compromise, eventually followed by surgical pericardial windowing.

Delayed pericardial disease may develop 6 months to 15 years after radiation treatment ${ }^{95,209,210}$ and includes pericarditis and chronic pericardial effusion (usually asymptomatic). Although most cases resolve spontaneously, there are reports of occurrence of chronic and/or constrictive pericarditis after high-dose radiotherapy administration in up to $20 \%$ of patients. ${ }^{211,212}$

\subsubsection{Pleural effusion}

Pleural effusion related to the cancer itself, $\mathrm{HF}$, infections or other causes is common in patients with cancer. Some cancer drugs (e.g. dasatinib and imatinib) may induce fluid retention or a reversible pleural effusion through additional unknown mechanisms. ${ }^{213}$

\subsubsection{Autonomic dysfunction}

Radiotherapy damage to the cardiac nervous system may lead to sympathetic-vagal imbalance characterized by inappropriate sinus tachycardia, altered heart rate variability and decreased sensitivity. This may lead to a higher pain threshold or silent ischaemia in cancer survivors with manifest CAD. ${ }^{214}$ Its management does not differ from that in non-cancer patients.

\subsection{Cardiovascular complications of cancer treatment in special populations}

Cardiotoxicity of cancer therapy has special characteristics in some clinical subgroups.

\subsubsection{Paediatric cancer population}

A steadily growing number of childhood cancer survivors have to face lifelong side effects of cancer therapies, some of them affecting the cardiovascular system. ${ }^{91-93}$ Indeed, the risk for severe cardiovascular conditions is increased eight-fold, putting cardiac disease among the leading causes of death in long-term survivors of childhood cancer. ${ }^{215}$ Anthracyclines and radiotherapy are the most commonly implicated cardiotoxic agents in childhood cancer. ${ }^{216} \mathrm{~A}$ recent large follow-up trial found cardiovascular complications in $8.1 \%$ of $>32000$ childhood cancer survivors. Therapies for hepatic cancer, Hodgkin lymphoma and leukaemia were related to the highest overall risks for CVD, with $\mathrm{HF}$ \{relative risk 5.2 [95\% confidence interval (Cl) $4.5-5.9]$ \} the most common, followed by valvular dysfunction [relative risk $4.6(95 \% \mathrm{Cl} 3.8-5.5)$ ] and cerebrovascular diseases [relative risk $3.7(95 \% \mathrm{Cl} 3.4-4.1)$ ]. Compared with a control group, the risk for any CVD varied considerably, with an almost 20 -fold increase in young patients compared with merely 1.3 for survivors $>60$ years of age due to a sharp increase in the incidence of common CVD. ${ }^{217}$ A recently published harmonization of international guidelines recommends lifelong follow-up for survivors of childhood cancer treated with either high-dose anthracyclines, highdose radiotherapy to the chest or both. ${ }^{91,92}$

\subsubsection{Elderly patients}

Elderly patients treated with cancer therapy are the second subpopulation most commonly affected by cardiotoxicity, due largely to the common prevalence of classic cardiovascular risk factors and co-morbidities. A history of HF, cardiac dysfunction, arterial hypertension, diabetes or CAD all make the cardiovascular system more vulnerable to the additional burden of chemotherapy or radiation. $^{218-220}$

\subsubsection{Pregnant women}

There is very little evidence regarding maternal risk of cardiotoxicity. It can be expected that cardiotoxicity can be influenced by pharmacokinetic and pharmacodynamic changes occurring during pregnancy. In a recent review, the authors mentioned decreased anthracycline plasma levels in pregnant vs. non-pregnant women. ${ }^{221}$ On the other hand, cardiovascular overload due to the high-output state in pregnancy may counterbalance this toxicity-limiting effect and the net result is difficult to predict. Data from a small registry and a case-control trial involving 10 pregnant women suggest that the cardiotoxicity risk in pregnancy is similar to that of an agematched female population. ${ }^{222,223}$ However, in view of uncertainties and the limited number of pregnant women requiring chemotherapy, a strategy of monitoring, including clinical cardiac assessment and echocardiographic functional evaluation, before starting chemotherapy and re-evaluation before every dose should be considered.

The scarce existing data, which are mostly in vitro and experimental, suggest low placental transfer of cancer drugs, including anthracyclines, with limited exposure of the foetus. ${ }^{224}$ However, it is not clear whether even small concentrations of anthracyclines affect the normal development of cardiomyocytes. The long-term case observation does not show significant long-term cardiotoxic effects in children born of mothers treated with cancer therapy during pregnancy. ${ }^{225}$ 


\section{Strategies for prevention and attenuation of cardiovascular complications of cancer therapy}

\subsection{Treatment options to prevent or recover from cancer therapy-induced myocardial dysfunction}

\subsubsection{Before cardiotoxic cancer treatment}

The timing and selection of cardioprotection depends upon various clinical variables. If baseline cardiotoxicity risk is high due to preexisting CVD, previous anthracycline-containing chemotherapy or poorly controlled cardiovascular risk factors, then a very stringent optimization of risk factor control has to be obtained and a prophylactic cardioprotective medication regimen should be considered (Table 13). Cancer patients with low baseline risk scheduled for high total cumulative anthracycline doses (>250-300 mg/m² doxorubicin or equivalent) may also be considered for prophylactic cardioprotective medication. One small study randomized adults with haematological malignancies scheduled for high-dose anthracycline chemotherapy to enalapril and carvedilol at HF therapy doses vs. normal care, starting cardiac drugs before the first cycle of chemotherapy. The decrease in LVEF observed in the control arm at the 6-month follow-up was prevented in patients receiving both cardioprotective drugs. ${ }^{226}$ Whether patients with a low baseline risk who are treated with anthracyclines also profit from preventive treatment with ACE inhibitors, ARBs or beta-blocker therapy remains controversial, and no recommendation can be made at this time. In a recent prospective, placebo-controlled trial in patients with early breast cancer treated with anthracyclines, the ARB candesartan, compared with placebo or beta-blocker therapy, attenuated the decrease in LVEF but had no effect on GLS or cardiac biomarkers. ${ }^{227}$ In this trial, metoprolol did not prevent a chemotherapy-associated decrease in LVEF. Similarly, neither the ACE inhibitor perindopri nor the beta-blocker bisoprolol had any effect on cardiac remodelling in trastuzumab-treated patients with early breast cancer, although most of these patients were not pretreated with anthracyclines and therefore were at a lower risk of cancer treatmentassociated cardiac side effects. ${ }^{228}$

Cancer patients with pre-existing clinical HF or significant LV dysfunction at baseline require specialist cardiology review, preferably in a specialist cardio-oncology clinic, where available, and the risk vs. benefit regarding selection of chemotherapy options should be discussed with the oncology team. ${ }^{229-232}$ Options include selection of an alternative non-cardiotoxic chemotherapy, anthracycline preparations with lower cardiotoxicity (e.g. liposomal doxorubicin), reduced-dose schedules and/or additional cardioprotective drugs (e.g. ACE inhibitors, beta-blockers, aldosterone antagonists or dexrazoxane) (Table 13).

Dexrazoxane, an intracellular iron-chelating agent, prevents the reduction in LV function caused by doxorubicin and can therefore be considered an alternative to doxorubicin in selected cases. ${ }^{233-239}$ In a Cochrane meta-analysis in adult patients with cancer treated with anthracyclines, dexrazoxane significantly reduced the risk of HF with no evidence for a difference in efficacy rate, survival or occurrence of secondary malignancies between dexrazoxane and control groups. ${ }^{240}$ Other meta-analyses showed no differences in secondary malignancies in children treated with dexrazoxane. ${ }^{241,242}$ Currently the
Table I 3 Strategies to reduce chemotherapy-induced cardiotoxicity $^{226-228,245-248}$

\begin{tabular}{|c|c|}
\hline $\begin{array}{l}\text { Chemotherapy } \\
\text { drug }\end{array}$ & $\begin{array}{l}\text { Potential cardioprotective } \\
\text { measure }\end{array}$ \\
\hline \multirow{4}{*}{$\begin{array}{l}\text { All chemotherapy } \\
\text { drugs }\end{array}$} & Identify and treat cardiovascular risk factors \\
\hline & Treat comorbidities (CAD, HF, PAD, HTN) \\
\hline & $\begin{array}{l}\text { QTc prolongation and torsade de pointes: } \\
\text { - Avoid QT prolonging drugs } \\
\text { - Manage electrolyte abnormalities }\end{array}$ \\
\hline & Minimize cardiac irradiation \\
\hline \multirow[t]{7}{*}{$\begin{array}{l}\text { Anthracyclines and } \\
\text { analogues }\end{array}$} & $\begin{array}{l}\text { Limit cumulative dose }\left(\mathrm{mg} / \mathrm{m}^{2}\right) \text { : } \\
\text { - Daunorubicin }<800 \\
\text { - Doxorubicin }<360 \\
\text { - Epirubicin }<720 \\
\text { - Mitoxantrone }<160 \\
\text { - Idarubicin }<150\end{array}$ \\
\hline & $\begin{array}{l}\text { Altered delivery systems (liposomal } \\
\text { doxorubicin) or continuous infusions }\end{array}$ \\
\hline & Dexrazoxane as an alternative \\
\hline & ACE-Is or ARBs \\
\hline & $\beta$-blockers \\
\hline & Statins \\
\hline & Aerobic exercise \\
\hline \multirow[t]{2}{*}{ Trastuzumab } & ACE-Is \\
\hline & $\beta$-blockers \\
\hline
\end{tabular}

$\mathrm{ACE}=$ angiotensin converting enzyme; $\mathrm{ACE}-\mathrm{I}=$ angiotensin converting enzyme inhibitor; $\mathrm{CAD}=$ coronary artery disease; $\mathrm{HF}=$ heart failure; $\mathrm{HTN}=$ hypertension; PAD = peripheral artery disease; $\mathrm{RCT}=$ randomized controlled trial.

European license for dexrazoxane use is only for adults with advanced or metastatic breast cancer who have received a cumulative dose of $>300 \mathrm{mg} / \mathrm{m}^{2}$ doxorubicin or $>540 \mathrm{mg} / \mathrm{m}^{2}$ epirubicin and would benefit from continued anthracycline-based therapy. ${ }^{243,244}$

\subsubsection{Patients with troponin elevation}

Initiation of cardioprotection may be considered in patients with cancer who have a troponin increase during treatment with highdose anthracycline-containing chemotherapy regimens. A clinical trial that randomized 114 patients who received high-dose chemotherapy and experienced an early (within $72 \mathrm{~h}$ after each cycle) increase in troponin levels to enalapril vs. placebo showed a significantly lower incidence of cardiac events, including HF and asymptomatic LV dysfunction, after a follow-up of 12 months in the group treated with enalapril. ${ }^{113}$

\subsubsection{Patients with asymptomatic reduction in left} ventricular ejection fraction during or after cancer treatment

LVEF reduction meeting the definition of cardiotoxicity may be considered as stage B HF (i.e. patients with structural heart disease but no current or previous symptoms of HF), particularly if there is a concomitant increase in natriuretic peptide. Depending upon the magnitude of the decrease and the LVEF value, initiating one or more guideline-based HF therapies should be considered. ${ }^{176,249}$ 
One observational study evaluated the efficacy of enalapril and carvedilol in patients with LVEF $\leq 45 \%$ detected following high-dose anthracycline-based chemotherapy. Although there was no control group, full LVEF recovery occurred in $42 \%$ of patients treated with enalapril and carvedilol. Importantly, cardiac-specific treatment within 6 months after the end of chemotherapy increased the likelihood of LV function recovery. ${ }^{38}$ In a longer-term study, optimal HF therapy appeared to be associated with an improvement in LV dysfunction noted after chemotherapy. ${ }^{36}$

\subsubsection{Patients with asymptomatic reduction in global} longitudinal strain during chemotherapy

Currently there is no evidence to guide specific cardioprotection if early signs of subclinical myocardial dysfunction are detected during echocardiography-based GLS surveillance. ${ }^{85,90,250}$ GLS may be a more sensitive tool to detect early cardiotoxicity, but based on currently available evidence, cancer treatment should not be stopped, interrupted or reduced in dose based on a new GLS reduction alone.

\subsubsection{Patients with heart failure during and following cancer treatment}

Cancer patients presenting with clinical HF during or following cancer treatment should be treated according to current ESC guidelines for HF. ${ }^{176,251}$ When presenting during chemotherapy, referral to a cardio-oncology specialist service is preferable, and close liaison with the oncology team is required to determine the necessity and duration of any interruption of cancer treatment, with interruption of cancer treatment recommended until the patient is clinically stable. Risk vs. benefit of further treatment with the previous regimen will depend upon several clinical factors, including the severity of LV dysfunction, clinical HF status, cancer prognosis and efficacy of the cancer therapy.

If rechallenge with a drug having previously generated cardiotoxicity is planned, continuation with cardioprotective drug therapy such as ACE inhibitors and beta-blockers is strongly recommended. ${ }^{36,230}$ Other potential options include the selection of preparations with a potentially less cardiotoxic profile (e.g. liposomal doxorubicin ${ }^{251-253}$ ) or possibly other less cardiotoxic drugs (e.g. dexrazoxane) when indicated (see section 3.1.1). ${ }^{240,254}$

\subsubsection{Non-pharmacological interventions with a cardioprotective effect in patients with cancer}

Positive health-promoting behaviour, including lifestyle factors (healthy diet, smoking cessation, regular exercise, weight control) should be strongly advised. In particular, aerobic exercise is considered a promising non-pharmacological strategy to prevent and/or treat chemotherapy-induced cardiotoxicity. Walking and cycling activities, even at significant levels of physical exercise, have been tested, and the benefit was greater when the exercise was more intensive, but not until exhaustion, which should be strongly discouraged. ${ }^{255,256}$

Patients receiving cancer treatment often have multiple physical and psychological adverse effects. A multidisciplinary approach is essential for long-term management of patients with cancer. ${ }^{257}$ A review of 56 trials involving 4826 participants showed an improvement in quality of life and physical ability during and after an exercise training programme (Table 14). ${ }^{258}$
Table I4 Summarizes the potential benefits of exercise during and/or after cancer treatment

\begin{tabular}{l}
\hline Improvement of: \\
- Cardiorespiratory and cardiovascular function \\
- Body composition (preservation or increase in muscle mass, loss of \\
fat mass) \\
- Immune function \\
- Chemotherapy completion rates \\
- Muscle strength and flexibility \\
- Body image, self-esteem and mood \\
\hline Reduction in: \\
- Number and severity of side effects including nausea, fatigue and pain \\
- Reduction of hospitalization duration \\
- Reduction of stress, depression and anxiety \\
\hline
\end{tabular}

\subsection{Prevention of thromboembolic events}

Chemotherapy increases the risk of VTE, a common cause of death in ambulatory patients. Currently, primary prevention, mainly using LMWH, should be proposed in high-risk ambulatory patients receiving chemotherapy (with multiple myeloma receiving anti-angiogenic agents or locally advanced or metastatic pancreatic or lung cancers) who do not have excessive bleeding risk. ${ }^{259-261}$

In patients hospitalized for cancer, several guidelines advocate the use of thromboprophylaxis, although a recent meta-analysis of subgroups of trials including patients with cancer hospitalized for medical conditions failed to find evidence of any global benefit or risk of primary thromboprophylaxis. ${ }^{262}$ Studies are under way to validate thromboprophylaxis based on risk factors and biomarkers. Meanwhile, it is reasonable to consider thromboprophylaxis with LMWH based on individual benefit-risk assessments.

For patients with central venous catheters, there is a reduction in symptomatic deep vein thrombosis with the use of heparin and of asymptomatic deep vein thrombosis with VKA compared with no anticoagulation. However, heparins are associated with a higher risk of thrombocytopaenia and asymptomatic deep vein thrombosis compared with VKA, and therefore treatment decisions should be individualized. ${ }^{263}$

\subsection{Strategies for attenuation of complications related to use of specific agents}

\subsubsection{Anthracyclines}

Several strategies can be used to prevent the LV dysfunction and HF induced by anthracyclines while maintaining antineoplastic efficacy, including reduction in the cumulative dose; use of continuous infusions (up to 48-96 h) to decrease peak plasma levels in adult patients ${ }^{264-266}$; use of analogues (epirubicin, pixantrone) ${ }^{267}$ or liposomal formulations, which are thought to have a lower risk of cardiotoxicity and provide comparable antitumour efficacy or use of dexrazoxane as a cardioprotectant. ${ }^{255,268-272}$ When there is evidence of equal efficacy or superiority of non-anthracycline regimens, they should be considered, particularly in patients with established cardiovascular risk factors or previous exposure to anthracyclines. $^{87,273}$ 
Taxanes reduce doxorubicin elimination, resulting in higher plasma levels, ${ }^{274}$ and promote its myocardial metabolism into more toxic metabolites. ${ }^{275}$ Paclitaxel used in combination with anthracyclines enhances their cardiotoxicity. ${ }^{276}$ In this setting, paclitaxel is more cardiotoxic than docetaxel. Thus it is recommended to administer anthracyclines before paclitaxel, separate the infusions and/or limit the cumulative doxorubicin dose to $360 \mathrm{mg} / \mathrm{m}^{2}$. ${ }^{277}$ As indicated above, the role of cardiac medications (ACE inhibitors, $A R B s$ and beta-blockers) for the prevention of anthracyclineassociated cardiac side effects in patients with normal cardiac function and low risk before starting cancer treatment remains controversial, and more data are needed.

\subsubsection{HER2 targeted therapy}

Co-administration of anthracyclines and trastuzumab markedly increases the incidence of HF, but cardiotoxicity can be reduced significantly by introducing a drug-free interval between the two agents. ${ }^{277-281}$ In patients with metastatic disease who developed $\mathrm{HF}$, an association was observed between treatment with ACE inhibitors and beta-blockers and LVEF recovery at 12 months, and a further rechallenge with trastuzumab did not necessarily lead to redevelopment of $\mathrm{HF}^{282}$ Additionally, in patients with breast cancer and normal LVEF before receiving trastuzumab and anthracycline therapy, continuous use of beta-blockers reduces the incidence of $\mathrm{HF}^{37,38}$ Whether this finding is also true for patients who were treated predominately with non-anthracyclines before trastuzumab remains controversial and no recommendation can be made. ${ }^{228}$ The National Cancer Research Institute ${ }^{283}$ recommends that if LVEF decreases to $<45 \%$ or $>10$ percentage points from baseline to a value between $45 \%$ and $49 \%$, trastuzumab should be interrupted and ACE inhibitors should be started; trastuzumab may be reinitiated if the LVEF is restored to $>49 \%$. If LVEF decreases below $50 \%$ but $>44 \%$, trastuzumab may be continued but an ACE inhibitor should be initiated. If the decrease occurs despite ACE inhibitor therapy, the patient should be referred to a cardiologist, and preferably a cardio-oncology service where available. In selected cases it may be preferable to choose a beta-blocker rather than an ACE inhibitor, depending on co-morbidities. The reversibility of LV dysfunction and the opportunity to resume administration of trastuzumab after improvement in HF needs to be evaluated in a prompt manner, and management should be individualized considering the each patient's characteristics. ${ }^{37,85}$ Ongoing trials are evaluating the prophylactic role of candesartan (NCT00459771), lisinopril-carvedilol (NCT01009918) and perindopril-bisoprolol (NCT01016886) combinations in reducing trastuzumab-induced cardiotoxicity.

The European Society for Medical Oncology guideline ${ }^{87}$ for prevention of trastuzumab-induced cardiotoxicity recommends a delay between completion of an anthracycline-based regimen and initiation of trastuzumab, careful assessment of cardiac function before starting and during follow-up and prophylaxis with ACE inhibitors for the control of hypertension or new-onset LV dysfunction.

Regular aerobic exercise seems a promising strategy to attenuate doxorubicin-induced LV dysfunction, ${ }^{284}$ but not trastuzumabinduced cardiotoxicity. ${ }^{285}$

\subsubsection{Pyrimidine analogues}

In cancer patients with pre-existing CAD receiving drugs that may produce myocardial ischaemia, aggressive control of CAD risk factors (smoking, hypertension, diabetes, hyperlipidaemia) followed by pharmacological treatment according to ESC guidelines ${ }^{286}$ should precede the administration of these drugs. Patients treated with pyrimidine analogues frequently present angina pectoris, ischaemia-related ECG abnormalities, arrhythmias and myocardial infarction, even in patients with normal coronary arteries. ${ }^{120,287}$ Risk markedly increases in patients with a history of CAD, and since prophylactic administration of nitrates and/or calcium channel blockers may not be effective, pyrimidine analogues should be discouraged in these patients. ${ }^{288-290}$ However, if an alternative therapy is not available, close monitoring of the patient is advised. ${ }^{289}$

\subsubsection{Vascular endothelial growth factor signalling pathway inhibitors}

Careful assessment of cardiovascular risk factors at baseline, close blood pressure monitoring and discontinuation of drugs known to raise blood pressure are essential to ensure prompt and aggressive management of hypertension in patients treated with VEGF signalling pathway inhibitors. Pharmacological strategies have been reviewed (see section 2.5).

\subsubsection{Radiotherapy}

Heart-sparing radiotherapy techniques should be oriented towards lowering the dose of radiation and the cardiac volume exposed [from regional radiotherapy to involved field or involved node radiotherapy (e.g. in Hodgkin lymphoma)]. ${ }^{291}$ These results may be reached using modern techniques based on 3D treatment planning with a dose-volume histogram and virtual simulation programmes. ${ }^{292,293}$ Using CT or magnetic resonance imaging, powerful software systems are able to precisely delineate the contours of the cancer and to guide delivery of radiation. To reduce the cardiac radiation dose during radiotherapy, the following techniques and strategies have been described:

- The deep inspiration breath-hold technique, or respiratory gating, allowing shielding of the heart from tangential fields and reduction of radiation to organs at risk without compromising clinical target volume. ${ }^{294}$

- Multiple or rotational sources of radiation beams (photons/ electrons).

- Linear accelerator photons allowing treatment of patients with equal weighting of anterior and posterior portals, with subcarinal block and the shrinking field technique.

- Intensity-modulated radiation beams using multileaf collimators are superior to partial shielding.

- Reporting and minimization of radiation doses received by normal tissue. $^{295}$

- Tracking systems, consisting of a small linear particle accelerator mounted on a general purpose industrial robot with a robotic arm, allowing the energy to be directed at any part of the body from any location. The robotic mounting through a complex imaging system and software allows very fast repositioning of the source and adaptation of radiation delivery, according to patient movement and cancer modification, with an accuracy of $0.5 \mathrm{~mm}$. This method of radiotherapy treatment resembles a surgical treatment and is also called 'radiosurgery. 295

- Planning of radiotherapy to minimize the maximal distance between the anterior cardiac contour and posterior tangential field edges. 
- Supine voluntary deep inspiration breath-hold techniques reduced whole heart and left anterior descending coronary artery radiation doses for some patients with left-sided breast cancer. ${ }^{296}$

Despite adoption of these measures, irradiation of the heart is unavoidable when the target volume is close, such as in left breast cancer and some cases of Hodgkin lymphoma.

\section{Long-term surveillance programmes for cancer survivors}

The population of patients surviving for long periods after the diagnosis and treatment of cancer has substantially increased over the past decade. ${ }^{297,298}$ It is imperative to raise awareness of possible cardiac disease among cancer survivors as well as to provide appropriate follow-up of such patients in clinical practice. Patients should be informed of their increased risk of CVD at the outset of their chemotherapy and should be advised and supported to make appropriate lifestyle modifications. They should also be instructed to promptly report early signs and symptoms of CVD.

Depending on the cancer and the treatment, a range of cardiovascular complications can arise. For the purposes of clarity, only the most common will be discussed here, but a strategy to screen for important cardiovascular conditions will be outlined. In general, the cardiovascular concerns can be summarized in categories related to myocardial dysfunction, vascular disease and VHD.

\subsection{Myocardial dysfunction}

Both paediatric and adult survivors of anthracycline-based chemotherapy have a lifelong risk for the development of LV dysfunction and HF. ${ }^{10,34,299}$ The time lapse between treatment and the development of HF can be very long (>10 years). ${ }^{300}$ Thus, even in asymptomatic patients treated with cardiotoxic therapy, particularly anthracyclines, LV dysfunction and HF can potentially occur. Periodic screening with cardiac imaging and biomarkers, such as BNP, should be considered in survivors, particularly those treated with high cumulative doses or who demonstrated reversible LV dysfunction during cancer treatment. ${ }^{113,301}$ Any symptom suggestive of HF should be similarly investigated, as many intercurrent illnesses may unmask reduced cardiac reserve in patients with previous anthracycline exposure. Early discontinuation of cardioprotective HF therapy is not recommended. Although clinical trial data are still lacking, the recommendation of this Task Force is to continue HF therapy indefinitely unless normal systolic LV function remains stable after cessation of HF therapy and no further cancer therapy is planned. Since trastuzumab-induced cardiac dysfunction is frequently reversible, cessation of $\mathrm{HF}$ treatment after normalization of LVEF may be considered for these patients. ${ }^{3}$

\subsection{Vascular disease}

Evaluation for CAD, ischaemia and vascular disease is recommended in patients with a history of mediastinal radiation, even if asymptomatic, starting 5 years post-treatment and then at least every 5 years thereafter. ${ }^{302,303}$ At least one major study suggested that important cardiac disease is silent in a high percentage of patients with cancer who received mediastinal radiation, and screening for ischaemic heart disease is a recommended practice. ${ }^{304}$ Vascular damage may be present in areas distant to the radiation field when patients are also given chemotherapy in addition to radiotherapy. ${ }^{305}$ Owing to the increased risk of stroke in patients with previous neck irradiation, ultrasound scanning of carotid arteries to rule out the presence of subclinical atherosclerosis could be included for a comprehensive cerebrovascular risk assessment.

\subsection{Valvular disease}

Radiation-induced VHD is an increasingly recognized entity occurring late after mediastinal radiotherapy, with a median time to diagnosis of 22 years. ${ }^{306} \mathrm{~A}$ minority of patients have completely normal functioning aortic valves at the 20-year follow-up. Childhood cancer survivors have a higher than expected incidence of tricuspid regurgitation, and the explanation remains to be determined. ${ }^{307}$ Affected survivors are often no longer under the care of a treating cancer specialist at the time of VHD diagnosis and, strikingly, the diagnosis of cancer or history of radiation therapy is often not mentioned in the patients' current medical records. ${ }^{308}$ The European Association of Cardiovascular Imaging and the American Society of Echocardiography (EACVI/ASE) recommend a focused yearly history and physical examination with echocardiography in symptomatic patients. ${ }^{95}$ For asymptomatic patients, the EACVI/ASE consensus document ${ }^{95}$ recommends a screening transthoracic echocardiogram at 10 years post-radiation and serial exams every 5 years thereafter. Transoesophageal echocardiography adds important information, especially when significant calcification or fibrosis is present and limits transthoracic image quality. In addition, 3D echocardiography may be helpful in the evaluation of mitral valve morphology. CMR may also be useful in those with suboptimal echocardiography or discrepant results. ${ }^{309}$

\section{Future perspectives and research directions}

Cardio-oncology is a field with many unmet needs and gaps in knowledge to guide best practice. ${ }^{310}$ The barriers separating oncology and cardiology are dissolving rapidly from both disciplines, because for patients with cancer, cure is not enough. The number of long-term survivors is increasing, with the focus on cardiac health becoming a priority. A close collaboration between oncologists and cardiologists is already perceptible in several centres where a cardio-oncology team is clearly identifiable. Some centres, called cardiac-oncology centres, have developed a well-structured service that includes several healthcare professionals (nurses, doctors, cardiologists, imaging specialists, oncologists, etc.) with expertise in this field.

Cardiologists have particular challenges and responsibilities in this emerging interdisciplinary alliance. These include a careful initial evaluation before starting potentially cardiotoxic chemotherapy and optimal control of pre-existing cardiovascular risk factors, followed by ongoing cardiac safety monitoring for early signs of cardiovascular toxicity and timely implementation of preventive or therapeutic measures. ${ }^{231,233}$ All of this coordinated activity is crucial to reduce both the burden of potential cardiovascular complications as well as the number of patients disqualified from specific cancer treatment because of emergent CVD. ${ }^{311,312}$ Oncologists and haematologists are faced with uncertainty over whether to 
disqualify a patient from treatment due to baseline CVD, although cancer therapy might be lifesaving, or administer treatment and wait until signs of cardiac injury. ${ }^{313}$ The latter strategy requires reliable and sensitive methods for the early detection of cardiac toxicity, which still remain to be defined, and effective strategies to mitigate potential cardiac injury. ${ }^{85}$ Indeed, there is an urgent need for more validated data to optimally manage and support patients at risk of cardiovascular complications and exacerbation of cardiac disease during the course of cancer treatment.

One of the most important unresolved issues is the choice between a primary vs. secondary prevention strategy. ${ }^{6}$ It is still unclear whether primary prevention is only relevant in patients at highest cardiovascular risk or when using therapy with a high cardiotoxic potential. Data on the prevalence and severity of clinically relevant cardiotoxicity are generally disease and treatment specific and are lacking for many clinical situations. For instance, a young patient with breast cancer without cardiovascular risk factors is unlikely to benefit from primary prevention during most breast cancer treatment, whereas an elderly patient with lymphoma would likely benefit from cardioprotection during anthracycline therapy. Therefore, it is also unclear whether a primary protection strategy is justified and cost effective in lowrisk populations. The existing evidence supporting cardiovascular preventive strategies in cardio-oncology is only suggestive and requires further validation. ${ }^{37,230,248,314}$ With the encouraging trend of the steadily improving survival rate for childhood cancer survivors, there is an increasing responsibility to identify patients with adverse health outcomes related to past cancer treatments.

While primary prevention of cardiotoxicity is still in the research domain, secondary prevention has already entered clinical practice guidelines despite persistent unresolved questions. ${ }^{287}$ There is some evidence that good control of common cardiovascular risk factors at initiation of chemotherapy mitigates the cardiovascular consequences of cancer treatment in patients with a history of hypertension, diabetes and HF. ${ }^{83,117}$ Prospectively validated criteria of early cardiotoxicity, which would be representative of late morbidity and mortality, are needed. The sensitivity of the current approach based on serial assessment of LVEF is insufficient. ${ }^{304}$ The combined biomarker and imaging approach also suffers from a set of limitations. ${ }^{101}$ Several circulating biomarkers (troponin I and BNP or NT-proBNP) have been identified as useful for the early detection of myocardial dysfunction and overt HF related to cancer therapies. ${ }^{88,89,113,315}$ However, conclusive data are needed to establish whether biomarkers reliably predict clinically relevant late consequences of cancer treatment. The effect of interrupting cancer therapy remains to be determined, but should not be taken lightly, as there are examples in general of interruptions or incomplete treatment courses having an adverse effect on optimal cancer treatment outcomes.

All of these challenges call for further concerted research. At this stage, large, properly designed comprehensive trials could provide answers to several of the above questions. As an example, primary prevention could be compared with careful observation in which secondary prevention measures would be triggered by a reduction in LVEF or a significant increase in a cardiac biomarker. ${ }^{302}$ Concomitant biobanking of blood samples, not only for testing cardiac biomarker levels, but also for genetic and epigenetic characterization of patients, could provide future means to differentiate patients who are particularly susceptible or resistant to cardiotoxicity from a specific cancer treatment.

A strategy that could better stratify risk would identify patients in which primary prevention or secondary prevention would be the most beneficial. To succeed, there is a need for

- Refining the predisposing factors for the development of CVD related to cancer treatment,

- Evaluating the rate of subclinical LV dysfunction and its transition to overt HF,

- Defining the most reliable cardiac monitoring approach and

- Determining the clinical effect and outcome (in terms of morbidity and mortality) after cancer therapy.

All of these actions are in concert with the aims of the recently launched EACVI/Heart Failure Association Cardiac Oncology Toxicity (COT) registry. ${ }^{316}$

Comparing clinically relevant outcomes with genetic, epigenetic, biomarker and imaging characteristics assessed at baseline and during active cancer treatment could provide data that would allow the construction of true evidence-based strategies and open a new era in cardio-oncology. The medical, social, ethical and economic relevance of such a trial would be convincing for public and European granting agencies. One of the important goals of this position paper is to catalyse such initiatives. The alliance between oncologists and cardiologists should also act as a lobby for introducing the analysis of early and late cardiovascular side effects of new cancer drugs into clinical trials, especially for patients with childhood cancer who are at increased risk of chronic medical problems concerning the vascular system. Innovative pharmaceutical companies should recognize that the time when cardiovascular safety will determine the choice of personalized cancer treatment, with all the economic and marketing implications of such an approach, is just around the corner. $^{75}$

\section{Appendix}

Supplementary Table Most recent reviews and meta-analyses on the incidence of hypertension with major VEGF inhibitor treatment

\begin{tabular}{|l|c|c|c|c|}
\hline Drug & $\begin{array}{c}\text { Number } \\
\text { of } \\
\text { studies } \\
\text { included }\end{array}$ & $\begin{array}{c}\text { Number } \\
\text { of } \\
\text { patients }\end{array}$ & $\begin{array}{c}\text { Incidence } \\
\text { of all } \\
\text { grades of } \\
\text { HTN, \% }\end{array}$ & $\begin{array}{c}\text { Incidence } \\
\text { of stage } \\
3-4 \text { HTN, } \\
\%\end{array}$ \\
\hline Bevacizumab $^{165}$ & 20 & 6754 & 23.6 & 7.9 \\
\hline Sunitinib $^{167}$ & 13 & 4999 & 21.6 & 6.8 \\
\hline Sorafenib $^{168}$ & 13 & 2492 & 15.3 & 4.4 \\
\hline Axitinib $^{169}$ & 10 & 1908 & 40.1 & 13.1 \\
\hline Vandetanib $^{170}$ & 11 & 3154 & 24.2 & 6.8 \\
\hline Regorafenib $^{171}$ & 5 & 750 & 44.4 & 12.5 \\
\hline
\end{tabular}

HTN = hypertension; VEGF = vascular endothelial growth factor 


\section{References}

1. Ferlay J, Steliarova-Foucher E, Lortet-Tieulent J, Rosso S, Coebergh JW, Comber H, Forman D, Bray F. Cancer incidence and mortality patterns in Europe: estimates for 40 countries in 2012. Eur J Cancer 2013;49:1374-1403.

2. Siegel R, DeSantis C, Virgo K, Stein K, Mariotto A, Smith T, Cooper D, Gansler T, Lerro C, Fedewa S, Lin C, Leach C, Cannady RS, Cho H, Scoppa S, Hachey M, Kirch R, Jemal A, Ward E. Cancer treatment and survivorship statistics, 2012. CA Cancer J Clin 2012;62:220-241.

3. Ewer MS, Ewer SM. Cardiotoxicity of anticancer treatments. Nat Rev Cardiol 2015; 12:620.

4. Armstrong GT, Oeffinger KC, Chen Y, Kawashima T, Yasui Y, Leisenring W, Stovall M, Chow EJ, Sklar CA, Mulrooney DA, Mertens AC, Border W, Durand JB, Robison LL, Meacham LR. Modifiable risk factors and major cardiac events among adult survivors of childhood cancer. I Clin Oncol 2013:31: $3673-3680$.

5. Suter TM, Ewer MS. Cancer drugs and the heart: importance and management. Eur Heart / 2013;34:1102-1111.

6. Khouri MG, Douglas PS, Mackey JR, Martin M, Scott JM, Scherrer-Crosbie M, Jones LW. Cancer therapy-induced cardiac toxicity in early breast cancer: addressing the unresolved issues. Circulation 2012;126:2749-2763.

7. Oeffinger KC, Mertens AC, Sklar CA, Kawashima T, Hudson MM, Meadows AT, Friedman DL, Marina N, Hobbie W, Kadan-Lottick NS, Schwartz CL, Leisenring W, Robison LL, Childhood Cancer Survivor Study. Chronic health conditions in adult survivors of childhood cancer. N Engl J Med 2006;355:1572-1582.

8. Limat S, Daguindau E, Cahn JY, Nerich V, Brion A, Perrin S, Woronoff-Lemsi MC, Deconinck E. Incidence and risk-factors of CHOP/R-CHOP-related cardiotoxicity in patients with aggressive non-Hodgkin's lymphoma. J Clin Pharm Ther 2014;39:168-174

9. Hall PS, Harshman LC, Srinivas S, Witteles RM. The frequency and severity of cardiovascular toxicity from targeted therapy in advanced renal cell carcinoma patients. JACC Heart Fail 2013;1:72-78.

10. Swain SM, Whaley FS, Ewer MS. Congestive heart failure in patients treated with doxorubicin: a retrospective analysis of three trials. Cancer 2003;97:2869-2879.

11. Yeh ET, Bickford CL. Cardiovascular complications of cancer therapy: incidence, pathogenesis, diagnosis, and management. J Am Coll Cardiol 2009;53:2231-2247.

12. Todaro MC, Oreto L, Qamar R, Paterick TE, Carerj S, Khandheria BK. Cardioncology: state of the heart. Int J Cardiol 2013;168:680-687.

13. Herrmann J, Lerman A, Sandhu NP, Villarraga HR, Mulvagh SL, Kohli M. Evaluation and management of patients with heart disease and cancer: cardio-oncology. Mayo Clin Proc 2014;89:1287-1306

14. Truong J, Yan AT, Cramarossa G, Chan KK. Chemotherapy-induced cardiotoxicity: detection, prevention, and management. Can / Cardiol 2014;30:869-878.

15. Svoboda M, Poprach A, Dobes S, Kiss I, Vyzula R. Cardiac toxicity of targeted therapies used in the treatment for solid tumours: a review. Cardiovasc Toxicol 2012;12: 191-207.

16. Bhave M, Akhter N, Rosen ST. Cardiovascular toxicity of biologic agents for cancer therapy. Oncology (Williston Park) 2014:28:482-490.

17. Curigliano G, Mayer EL, Burstein HJ, Winer EP, Goldhirsch A. Cardiac toxicity from systemic cancer therapy: a comprehensive review. Prog Cardiovasc Dis 2010;53:94-104

18. Monsuez JJ, Charniot JC, Vignat N, Artigou JY. Cardiac side-effects of cancer chemotherapy. Int J Cardiol 2010;144:3-15.

19. Senkus E, Jassem J. Cardiovascular effects of systemic cancer treatment. Cancer Treat Rev 2011:37:300-311.

20. Perez EA, Koehler M, Byrne J, Preston AJ, Rappold E, Ewer MS. Cardiac safety of lapatinib: pooled analysis of 3689 patients enrolled in clinical trials. Mayo Clin Proc 2008;83:679-686

21. Ryberg M, Nielsen D, Cortese G, Nielsen G, Skovsgaard T, Andersen PK. New insight into epirubicin cardiac toxicity: competing risks analysis of 1097 breast cancer patients. J Natl Cancer Inst 2008;100:1058-1067.

22. Early Breast Cancer Trialists' Collaborative Group. Effects of chemotherapy and hormonal therapy for early breast cancer on recurrence and 15-year survival: an overview of the randomised trials. Lancet 2005;365:1687-1717.

23. Hershman DL, McBride RB, Eisenberger A, Tsai WY, Grann VR, Jacobson JS. Doxorubicin, cardiac risk factors, and cardiac toxicity in elderly patients with diffuse B-cell non-Hodgkin's lymphoma. J Clin Oncol 2008;26:3159-3165.

24. Felker GM, Thompson RE, Hare JM, Hruban RH, Clemetson DE, Howard DL, Baughman KL, Kasper EK. Underlying causes and long-term survival in patients with initially unexplained cardiomyopathy. N Engl J Med 2000;342:1077-1084.

25. Bristow MR, Thompson PD, Martin RP, Mason JW, Billingham ME, Harrison DC. Early anthracycline cardiotoxicity. Am J Med 1978;65:823-832

26. Doroshow JH. Anthracycline antibiotic-stimulated superoxide, hydrogen peroxide, and hydroxyl radical production by NADH dehydrogenase. Cancer Res 1983; 43:4543-4551.
27. Lim CC, Zuppinger C, Guo X, Kuster GM, Helmes M, Eppenberger HM, Suter TM, Liao R, Sawyer DB. Anthracyclines induce calpain-dependent titin proteolysis and necrosis in cardiomyocytes. J Biol Chem 2004;279:8290-8299.

28. Zhang S, Liu X, Bawa-Khalfe T, Lu LS, Lyu YL, Liu LF, Yeh ET. Identification of the molecular basis of doxorubicin-induced cardiotoxicity. Nat Med 2012;18: $1639-1642$.

29. Shan K, Lincoff AM, Young JB. Anthracycline-induced cardiotoxicity. Ann Intern Med 1996;125:47-58.

30. Franco VI, Lipshultz SE. Cardiac complications in childhood cancer survivors treated with anthracyclines. Cardiol Young 2015;25(Suppl 2):107-116.

31. Drafts BC, Twomley KM, D'Agostino R Jr, Lawrence J, Avis N, Ellis LR, Thohan V, Jordan J, Melin SA, Torti FM, Little WC, Hamilton CA, Hundley WG. Low to moderate dose anthracycline-based chemotherapy is associated with early noninvasive imaging evidence of subclinical cardiovascular disease. JACC Cardiovasc Imaging 2013;6:877-885.

32. Sawyer DB, Peng X, Chen B, Pentassuglia L, Lim CC. Mechanisms of anthracycline cardiac injury: can we identify strategies for cardioprotection? Prog Cardiovasc Dis 2010;53:105-113.

33. Vejpongsa P, Yeh ET. Prevention of anthracycline-induced cardiotoxicity: challenges and opportunities. J Am Coll Cardiol 2014;64:938-945.

34. Steinherz LJ, Steinherz PG, Tan CT, Heller G, Murphy ML. Cardiac toxicity 4 to 20 years after completing anthracycline therapy. JAMA 1991;266:1672-1677.

35. Von Hoff DD, Layard MW, Basa P, Davis HL Jr, Von Hoff AL, Rozencweig M, Muggia FM. Risk factors for doxorubicin-induced congestive heart failure. Ann Intern Med 1979;91:710-717.

36. Cardinale D, Colombo A, Bacchiani G, Tedeschi I, Meroni CA, Veglia F, Civelli M, Lamantia G, Colombo N, Curigliano G, Fiorentini C, Cipolla CM. Early detection of anthracycline cardiotoxicity and improvement with heart failure therapy. Circulation 2015;131:1981-1988.

37. Eschenhagen T, Force T, Ewer MS, de Keulenaer GW, Suter TM, Anker SD, Avkiran M, de Azambuja E, Balligand JL, Brutsaert DL, Condorelli G, Hansen A, Heymans S, Hill JA, Hirsch E, Hilfiker-Kleiner D, Janssens S, de Jong S, Neubauer G, Pieske B, Ponikowski P, Pirmohamed M, Rauchhaus M, Sawyer D, Sugden PH, Wojta J, Zannad F, Shah AM. Cardiovascular side effects of cancer therapies: a position statement from the Heart Failure Association of the European Society of Cardiology. Eur J Heart Fail 2011;13:1-10.

38. Cardinale D, Colombo A, Lamantia G, Colombo N Civelli M, De Giacomi G, Rubino M, Veglia F, Fiorentini C, Cipolla CM. Anthracycline-induced cardiomyopathy: clinical relevance and response to pharmacologic therapy. J Am Coll Cardiol 2010;55:213-220.

39. Chow EJ, Chen Y, Kremer LC, Breslow NE, Hudson MM, Armstrong GT, Border WL, Feijen EA, Green DM, Meacham LR, Meeske KA, Mulrooney DA, Ness KK, Oeffinger KC, Sklar CA, Stovall M, van der Pal HJ, Weathers RE, Robison LL, Yasui Y. Individual prediction of heart failure among childhood cancer survivors. I Clin Oncol 2015:33:394-402

40. Braverman AC, Antin JH, Plappert MT, Cook EF, Lee RT. Cyclophosphamide cardiotoxicity in bone marrow transplantation: a prospective evaluation of new dosing regimens. / Clin Oncol 1991;9:1215-1223.

41. Gottdiener IS, Appelbaum FR, Ferrans V], Deisseroth A, Ziegler I. Cardiotoxicity associated with high-dose cyclophosphamide therapy. Arch Intern Med 1981;141: 758-763.

42. Mackey JR, Martin M, Pienkowski T, Rolski J, Guastalla JP, Sami A, Glaspy J, Juhos E, Wardley A, Fornander T, Hainsworth I, Coleman R, Modiano MR, Vinholes I Pinter T, Rodriguez-Lescure A, Colwell B, Whitlock P, Provencher L, Laing K, Walde D, Price C, Hugh JC, Childs BH, Bassi K, Lindsay MA, Wilson V, Rupin M, Houe V, Vogel C, TRIO/BCIRG 001 Investigators. Adjuvant docetaxel, doxorubicin, and cyclophosphamide in node-positive breast cancer: 10-year follow-up of the phase 3 randomised BCIRG 001 trial. Lancet Oncol 2013;14: $72-80$.

43. Gollerkeri A, Harrold L, Rose M, Jain D, Burtness BA. Use of paclitaxel in patients with pre-existing cardiomyopathy: a review of our experience. Int J Cancer 2001; 93:139-141.

44. Moja L, Tagliabue L, Balduzzi S, Parmelli E, Pistotti V, Guarneri V, D’Amico R. Trastuzumab containing regimens for early breast cancer. Cochrane Database Syst Rev 2012; 4:CD006243.

45. Slamon DJ, Leyland-Jones B, Shak S, Fuchs H, Paton V, Bajamonde A, Fleming T, Eiermann W, Wolter J, Pegram M, Baselga J, Norton L. Use of chemotherapy plus a monoclonal antibody against HER2 for metastatic breast cancer that overexpresses HER2. N Engl J Med 2001;344:783-792.

46. Shah MA. Update on metastatic gastric and esophageal cancers. J Clin Oncol 2015; 33:1760-1769.

47. Bowles EJ, Wellman R, Feigelson HS, Onitilo AA, Freedman AN, Delate T, Allen LA, Nekhlyudov L, Goddard KA, Davis RL, Habel LA, Yood MU, McCarty C, Magid DJ, Wagner EH, Pharmacovigilance Study Team. Risk of heart 
failure in breast cancer patients after anthracycline and trastuzumab treatment: a retrospective cohort study. J Natl Cancer Inst 2012;104:1293-1305.

48. Goldhirsch A, Gelber RD, Piccart-Gebhart MJ, de Azambuja E, Procter M, Suter TM, Jackisch C, Cameron D, Weber HA, Heinzmann D, Dal Lago L McFadden E, Dowsett M, Untch M, Gianni L, Bell R, Kohne CH, Vindevoghel A, Andersson M, Brunt AM, Otero-Reyes D, Song S, Smith I, Leyland-Jones B, Baselga J, Herceptin Adjuvant Trial Study Team. 2 years versus 1 year of adjuvant trastuzumab for HER2-positive breast cancer (HERA): an open-label, randomised controlled trial. Lancet 2013;382:1021-1028.

49. de Azambuja E, Procter MJ, van Veldhuisen DJ, Agbor-Tarh D, Metzger-Filho O, Steinseifer J, Untch M, Smith IE, Gianni L, Baselga J, Jackisch C, Cameron DA, Bell R, Leyland-Jones B, Dowsett M, Gelber RD, Piccart-Gebhart MJ, Suter TM. Trastuzumab-associated cardiac events at 8 years of median follow-up in the Herceptin Adjuvant trial (BIG 1-01). J Clin Oncol 2014;32:2159-2165.

50. Romond EH, Jeong JH, Rastogi P, Swain SM, Geyer CE Jr, Ewer MS, Rathi $\bigvee$, Fehrenbacher L, Brufsky A, Azar CA, Flynn PJ, Zapas JL, Polikoff J, Gross HM, Biggs DD, Atkins JN, Tan-Chiu E, Zheng P, Yothers G, Mamounas EP, Wolmark N. Seven-year follow-up assessment of cardiac function in NSABP $\mathrm{B}-31$, a randomized trial comparing doxorubicin and cyclophosphamide followed by paclitaxel (ACP) with ACP plus trastuzumab as adjuvant therapy for patients with node-positive, human epidermal growth factor receptor 2-positive breast cancer. I Clin Oncol 2012;30:3792-3799.

51. Advani PP, Ballman KV, Dockter TJ, Colon-Otero G, Perez EA. Long-Term Cardiac Safety Analysis of NCCTG N9831 (Alliance) Adjuvant Trastuzumab Trial. J Clin Oncol 2016;34:581-587.

52. Suter TM, Procter M, van Veldhuisen DJ, Muscholl M, Bergh J, Carlomagno C Perren T, Passalacqua R, Bighin C, Klijn JG, Ageev FT, Hitre E, Groetz J. Iwata H, Knap M, Gnant M, Muehlbauer S, Spence A, Gelber RD, Piccart-Gebhart MJ. Trastuzumab-associated cardiac adverse effects in the herceptin adjuvant trial. J Clin Oncol 2007;25:3859-3865.

53. Cote GM, Sawyer DB, Chabner BA. ERBB2 inhibition and heart failure. N Engl Med 2012;367:2150-2153.

54. Ewer MS, Lippman SM. Type II chemotherapy-related cardiac dysfunction: time to recognize a new entity. I Clin Oncol 2005;23:2900-2902.

55. de Azambuja E, Bedard PL, Suter T, Piccart-Gebhart M. Cardiac toxicity with anti-HER-2 therapies: what have we learned so far? Target Oncol 2009;4:77-88.

56. Yu AF, Yadav NU, Lung BY, Eaton AA, Thaler HT, Hudis CA, Dang CT, Steingart RM. Trastuzumab interruption and treatment-induced cardiotoxicity in early HER2-positive breast cancer. Breast Cancer Res Treat 2015;149:489-495.

57. Piccart-Gebhart M, Holmes E, Baselga J, de Azambuja E, Dueck AC, Viale G, Zujewski JA, Goldhirsch A, Armour A, Pritchard KI, McCullough AE, Dolci S, McFadden E, Holmes AP, Tonghua L, Eidtmann H, Dinh P, Di Cosimo S, Harbeck N, Tjulandin S, Im YH, Huang CS, Dieras V, Hillman DW, Wolff AC, Jackisch C, Lang I, Untch M, Smith I, Boyle F, Xu B, Gomez H, Suter T, Gelber RD, Perez EA. Adjuvant lapatinib and trastuzumab for early human epidermal growth factor receptor 2-positive breast cancer: results from the randomized phase III Adjuvant Lapatinib and/or Trastuzumab Treatment Optimization trial. J Clin Oncol 2016;34:1034-1042.

58. Krop IE, Suter TM, Dang CT, Dirix L, Romieu G, Zamagni C, Citron ML, Campone M, Xu N, Smitt M, Gianni L. Feasibility and cardiac safety of trastuzumab emtansine after anthracycline-based chemotherapy as (neo)adjuvant therapy for human epidermal growth factor receptor 2-positive early-stage breast cancer. I Clin Oncol 2015;33:1136-1142.

59. Lenihan D, Suter T, Brammer M, Neate C, Ross G, Baselga J. Pooled analysis of cardiac safety in patients with cancer treated with pertuzumab. Ann Oncol 2012 23:791-800

60. Cameron D, Brown J, Dent R, Jackisch C, Mackey J, Pivot X, Steger GG, Suter TM, Toi M, Parmar M, Laeufle R, Im YH, Romieu G, Harvey V, Lipatov O, Pienkowski T. Cottu P, Chan A, Im SA, Hall PS, Bubuteishvili-Pacaud L, Henschel V, Deurloo RJ Pallaud C, Bell R. Adjuvant bevacizumab-containing therapy in triple-negative breast cancer (BEATRICE): primary results of a randomised, phase 3 trial. Lancet Oncol 2013;14:933-942.

61. Motzer RJ, Hutson TE, Cella D, Reeves J, Hawkins R, Guo J, Nathan P, Staehler M, de Souza P, Merchan IR, Boleti E, Fife K, Jin J, Jones R, Uemura H, De Giorgi U, Harmenberg U, Wang J, Sternberg CN, Deen K, McCann L, Hackshaw MD, Crescenzo R, Pandite LN, Choueiri TK. Pazopanib versus sunitinib in metastatic renal-cell carcinoma. N EnglJ Med 2013;369:722-731.

62. Motzer RJ, Escudier B, Tomczak P, Hutson TE, Michaelson MD, Negrier S, Oudard S, Gore ME, Tarazi J, Hariharan S, Chen C, Rosbrook B, Kim S, Rini BI. Axitinib versus sorafenib as second-line treatment for advanced renal cell carcinoma: overall survival analysis and updated results from a randomised phase 3 trial. Lancet Oncol 2013:14:552-562.

63. Steingart RM, Bakris GL, Chen HX, Chen MH, Force T, Ivy SP, Leier CV, Liu G, Lenihan D, Lindenfeld J, Maitland ML, Remick SC, Tang WH. Management of cardiac toxicity in patients receiving vascular endothelial growth factor signaling pathway inhibitors. Am Heart J 2012;163:156-163.

64. Qi WX, Shen Z, Tang LN, Yao Y. Congestive heart failure risk in cancer patients treated with vascular endothelial growth factor tyrosine kinase inhibitors: a systematic review and meta-analysis of 36 clinical trials. Br J Clin Pharmacol 2014 78:748-762.

65. Ghatalia P, Morgan C], Je Y, Nguyen PL, Trinh QD, Choueiri TK, Sonpavde G. Congestive heart failure with vascular endothelial growth factor receptor tyrosine kinase inhibitors. Crit Rev Oncol Hematol 2015;94:228-237.

66. Ewer MS, Suter TM, Lenihan DJ, Niculescu L, Breazna A, Demetri GD, Motzer RJ. Cardiovascular events among 1090 cancer patients treated with sunitinib, interferon, or placebo: a comprehensive adjudicated database analysis demonstrating clinically meaningful reversibility of cardiac events. Eur J Cancer 2014;50 2162-2170.

67. Force T, Krause DS, Van Etten RA. Molecular mechanisms of cardiotoxicity of tyrosine kinase inhibition. Nat Rev Cancer 2007;7:332-344.

68. Moslehi JJ, Deininger M. Tyrosine kinase inhibitor-associated cardiovascular toxicity in chronic myeloid leukemia. J Clin Oncol 2015;33:4210-4218.

69. Shelburne N, Adhikari B, Brell J, Davis M, Desvigne-Nickens P, Freedman A Minasian L, Force T, Remick SC. Cancer treatment-related cardiotoxicity: current state of knowledge and future research priorities. J Natl Cancer Inst 2014;106.

70. Fuchs CS, Tomasek J, Yong C], Dumitru F, Passalacqua R, Goswami C, Safran H, dos Santos LV, Aprile G, Ferry DR, Melichar B, Tehfe M, Topuzov E, Zalcberg JR Chau I, Campbell W, Sivanandan C, Pikiel J, Koshiji M, Hsu Y, Liepa AM, Gao L, Schwartz JD, Tabernero J, REGARD Trial Investigators. Ramucirumab monotherapy for previously treated advanced gastric or gastro-oesophageal junction adenocarcinoma (REGARD): an international, randomised, multicentre, placebocontrolled, phase 3 trial. Lancet 2014:383:31-39.

71. Wilke H, Muro K, Van Cutsem E, Oh SC, Bodoky G, Shimada Y, Hironaka S Sugimoto N, Lipatov O, Kim TY, Cunningham D, Rougier P, Komatsu Y, Ajani J, Emig M, Carlesi R, Ferry D, Chandrawansa K, Schwartz JD, Ohtsu A, RAINBOW Study Group. Ramucirumab plus paclitaxel versus placebo plus paclitaxel in patients with previously treated advanced gastric or gastro-oesophageal junction adenocarcinoma (RAINBOW): a double-blind, randomised phase 3 trial. Lance Oncol 2014;15:1224-1235.

72. Garon EB, Ciuleanu TE, Arrieta O, Prabhash K, Syrigos KN, Goksel T, Park K, Gorbunova V, Kowalyszyn RD, Pikiel J, Czyzewicz G, Orlov SV, Lewanski CR, Thomas M, Bidoli P, Dakhil S, Gans S, Kim JH, Grigorescu A, Karaseva N, Reck M, Cappuzzo F, Alexandris E, Sashegyi A, Yurasov S, Perol M. Ramucirumab plus docetaxel versus placebo plus docetaxel for second-line treatment of stage IV non-small-cell lung cancer after disease progression on platinum-based therapy (REVEL): a multicentre, double-blind, randomised phase 3 trial. Lancet 2014;384 665-673.

73. Verweij J, Casali PG, Kotasek D, Le Cesne A, Reichard P, Judson IR, Issels R, van Oosterom AT, Van Glabbeke M, Blay JY. Imatinib does not induce cardiac left ventricular failure in gastrointestinal stromal tumours patients: analysis of EORTC-ISG-AGITG study 62005. Eur J Cancer 2007;43:974-978.

74. Valent P. Hadzijusufovic E, Schernthaner GH, Wolf D, Rea D, le Coutre P. Vascular safety issues in $C M L$ patients treated with BCR/ABL1 kinase inhibitors. Blood 2015;125:901-906.

75. Groarke JD, Cheng S, Moslehi J. Cancer-drug discovery and cardiovascular surveillance. N Engl J Med 2013:369:1779-1781.

76. Stewart AK, Rajkumar SV, Dimopoulos MA, Masszi T, Spicka I, Oriol A, Hajek R, Rosinol L, Siegel DS, Mihaylov GG, Goranova-Marinova V, Rajnics P, Suvorov A Niesvizky R, Jakubowiak AJ, San-Miguel JF, Ludwig H, Wang M, Maisnar V Minarik J, Bensinger WI, Mateos MV, Ben-Yehuda D, Kukreti V, Zojwalla N, Tonda ME, Yang X, Xing B, Moreau P, Palumbo A, ASPIRE Investigators. Carfilzomib, lenalidomide, and dexamethasone for relapsed multiple myeloma. $N$ Engl Med 2015;372:142-152.

77. Willis MS, Patterson C. Proteotoxicity and cardiac dysfunction-Alzheimer's disease of the heart? N Engl J Med 2013;368:455-464.

78. Russell SD, Lyon A, Lenihan DJ, Moreau P, Joshua D, Chng W-J, Palumbo A, Goldschmidt H, Hájek R, Facon T, Ludwig H, Pour L, Niesvizky R, Oriol A Rosiñol L, Suvorov A, Gaidano G, Goranova-Marinova V, Gillenwater HH, Mohamed N, Feng S, Dimopoulos MA. Serial echocardiographic assessment of patients (pts) with relapsed multiple myeloma (RMM) receiving carfilzomib and dexamethasone $(\mathrm{Kd})$ vs bortezomib and dexamethasone (Vd): a substudy of the phase 3 Endeavor Trial (NCT01568866). Blood 2015;126:abstract 4250.

79. Lendvai N, Devlin S, Patel M, Knapp KM, Ekman D, Grundberg I, Chung DJ, Hassoun H, Koehne G, Lesokhin AM, Landau H, Giralt SA, Korde NS, Landgren $\mathrm{O}$. Biomarkers of cardiotoxicity among multiple myeloma patients subsequently treated with proteasome inhibitor therapy. Blood 2015;126:abstract 4257.

80. Jaworski C, Mariani JA, Wheeler G, Kaye DM. Cardiac complications of thoracic irradiation. J Am Coll Cardiol 2013;61:2319-2328. 
81. Aleman BM, van den Belt-Dusebout AW, De Bruin ML, van 't Veer MB, Baaijens MH, de Boer JP, Hart AA, Klokman WJ, Kuenen MA, Ouwens GM, Bartelink $\mathrm{H}$, van Leeuwen FE. Late cardiotoxicity after treatment for Hodgkin lymphoma. Blood 2007;109:1878-1886.

82. Hooning MJ, Botma A, Aleman BM, Baaijens MH, Bartelink H, Klijn JG, Taylor CW, van Leeuwen FE. Long-term risk of cardiovascular disease in 10-year survivors of breast cancer. J Natl Cancer Inst 2007;99:365-375.

83. Armstrong GT, Joshi VM, Ness KK, Marwick TH, Zhang N, Srivastava D, Griffin BP, Grimm RA, Thomas J, Phelan D, Collier P, Krull KR, Mulrooney DA, Green DM, Hudson MM, Robison LL, Plana JC. Comprehensive echocardiographic detection of treatment-related cardiac dysfunction in adult survivors of childhood cancer: results from the St. Jude Lifetime Cohort Study. J Am Coll Cardiol 2015;65:2511-2522

84. Ezaz G, Long JB, Gross CP, Chen J. Risk prediction model for heart failure and cardiomyopathy after adjuvant trastuzumab therapy for breast cancer. J Am Heart Assoc 2014;3:e000472.

85. Plana JC, Galderisi M, Barac A, Ewer MS, Ky B, Scherrer-Crosbie M, Ganame J, Sebag IA, Agler DA, Badano LP, Banchs J, Cardinale D, Carver J, Cerqueira M, DeCara JM, Edvardsen T, Flamm SD, Force T, Griffin BP, Jerusalem G, Liu JE, Magalhaes A, Marwick T, Sanchez LY, Sicari R, Villarraga HR, Lancellotti P. Expert consensus for multimodality imaging evaluation of adult patients during and after cancer therapy: a report from the American Society of Echocardiography and the European Association of Cardiovascular Imaging. Eur Heart J Cardiovasc Imaging 2014:15:1063-1093.

86. Cardinale D, Sandri MT. Role of biomarkers in chemotherapy-induced cardiotoxicity. Prog Cardiovasc Dis 2010;53:121-129.

87. Curigliano G, Cardinale D, Suter T, Plataniotis G, de Azambuja E, Sandri MT, Criscitiello C, Goldhirsch A, Cipolla C, Roila F, ESMO Guidelines Working Group. Cardiovascular toxicity induced by chemotherapy, targeted agents and radiotherapy: ESMO Clinical Practice Guidelines. Ann Oncol 2012;23(Suppl 7):vii155-vii166

88. Cardinale D, Colombo A, Torrisi R, Sandri MT, Civelli M, Salvatici M, Lamantia G, Colombo N, Cortinovis S, Dessanai MA, Nole F, Veglia F, Cipolla CM. Trastuzumab-induced cardiotoxicity: clinical and prognostic implications of troponin I evaluation. J Clin Oncol 2010;28:3910-3916.

89. Ky B, Putt M, Sawaya H, French B, Januzzi JL Jr. Sebag IA, Plana JC, Cohen V, Banchs J, Carver JR, Wiegers SE, Martin RP, Picard MH, Gerszten RE, Halpern EF, Passeri J, Kuter I, Scherrer-Crosbie M. Early increases in multiple biomarkers predict subsequent cardiotoxicity in patients with breast cancer treated with doxorubicin, taxanes, and trastuzumab. J Am Coll Cardiol 2014;63:809-816.

90. Thavendiranathan P, Poulin F, Lim KD, Plana JC, Woo A, Marwick TH. Use of myocardial strain imaging by echocardiography for the early detection of cardiotoxicity in patients during and after cancer chemotherapy: a systematic review. J Am Coll Cardiol 2014;63:2751-2768.

91. Lipshultz SE, Adams MJ, Colan SD, Constine LS, Herman EH, Hsu DT, Hudson MM, Kremer LC, Landy DC, Miller TL, Oeffinger KC, Rosenthal DN, Sable CA, Sallan SE, Singh GK, Steinberger J, Cochran TR, Wilkinson JD, American Heart Association Congenital Heart Defects Committee of the Council on Cardiovascular Disease in the Young, Council on Basic Cardiovascular Sciences, Council on Cardiovascular and Stroke Nursing, Council on Cardiovascular Radiology and Intervention, Council on Clinical Cardiology, Council on Epidemiology and Prevention, Council on Nutrition Physical Activity and Metabolism. Long-term cardiovascular toxicity in children, adolescents, and young adults who receive cancer therapy: pathophysiology, course, monitoring, management, prevention, and research directions: a scientific statement from the American Heart Association. Circulation 2013;128:1927-1995.

92. Armenian SH, Hudson MM, Mulder RL, Chen MH, Constine LS, Dwyer M, Nathan PC, Tissing WJ, Shankar S, Sieswerda E, Skinner R, Steinberger J, van Dalen EC, van der Pal H, Wallace WH, Levitt G, Kremer LC, International Late Effects of Childhood Cancer Guideline Harmonization Group. Recommendations for cardiomyopathy surveillance for survivors of childhood cancer: a report from the International Late Effects of Childhood Cancer Guideline Harmonization Group. Lancet Oncol 2015;16:e123-136.

93. Armstrong GT, Plana JC, Zhang N, Srivastava D, Green DM, Ness KK, Daniel Donovan F, Metzger ML, Arevalo A, Durand JB, Joshi V, Hudson MM, Robison LL, Flamm SD. Screening adult survivors of childhood cancer for cardiomyopathy: comparison of echocardiography and cardiac magnetic resonance imaging. J Clin Oncol 2012;30:2876-2884.

94. Ewer MS. Anthracycline cardiotoxicity: clinical aspects, recognition, monitoring, treatment, and prevention. In: Ewer MS, Yeh ET, eds. Cancer and the Heart. Shelton, CT, USA: People's Medical Publishing House; 2013, 11-41.

95. Lancellotti P, Nkomo VT, Badano LP, Bergler-Klein J, Bogaert J, Davin L, Cosyns B, Coucke P, Dulgheru R, Edvardsen T, Gaemperli O, Galderisi M, Griffin B, Heidenreich PA, Nieman K, Plana JC, Port SC, Scherrer-Crosbie M, Schwartz RG, Sebag IA, Voigt JU, Wann S, Yang PC, European Society of
Cardiology Working Groups on Nuclear Cardiology and Cardiac Computed Tomography and Cardiovascular Magnetic Resonance, American Society of Nuclear Cardiology, Society for Cardiovascular Magnetic Resonance, Society of Cardiovascular Computed Tomography. Expert consensus for multi-modality imaging evaluation of cardiovascular complications of radiotherapy in adults: a report from the European Association of Cardiovascular Imaging and the American Society of Echocardiography. Eur Heart / Cardiovasc Imaging 2013;14:721-740.

96. Pinder MC, Duan Z, Goodwin JS, Hortobagyi GN, Giordano SH. Congestive heart failure in older women treated with adjuvant anthracycline chemotherapy for breast cancer. J Clin Oncol 2007;25:3808-3815.

97. Lang RM, Badano LP, Mor-Avi V, Afilalo J, Armstrong A, Ernande L, Flachskampf FA, Foster E, Goldstein SA, Kuznetsova T, Lancellotti P, Muraru D, Picard MH, Rietzschel ER, Rudski L, Spencer KT, Tsang W, Voigt JU. Recommendations for cardiac chamber quantification by echocardiography in adults: an update from the American Society of Echocardiography and the European Association of Cardiovascular Imaging. J Am Soc Echocardiogr 2015;28:1-39.e14.

98. Hering D, Faber L, Horstkotte D. Echocardiographic features of radiation-associated valvular disease. Am J Cardiol 2003;92:226-230.

99. Hull MC, Morris CG, Pepine Cl. Mendenhall NP. Valvular dysfunction and carotid, subclavian, and coronary artery disease in survivors of Hodgkin lymphoma treated with radiation therapy. JAMA 2003;290:2831-2837.

100. Thavendiranathan P, Grant AD, Negishi T, Plana JC, Popovic ZB, Marwick TH. Reproducibility of echocardiographic techniques for sequential assessment of left ventricular ejection fraction and volumes: application to patients undergoing cancer chemotherapy. J Am Coll Cardiol 2013;61:77-84.

101. Sawaya H, Sebag IA, Plana JC, Januzzi JL, Ky B, Tan TC, Cohen V, Banchs J, Carver JR, Wiegers SE, Martin RP, Picard MH, Gerszten RE, Halpern EF, Passeri J, Kuter I, Scherrer-Crosbie M. Assessment of echocardiography and biomarkers for the extended prediction of cardiotoxicity in patients treated with anthracyclines, taxanes, and trastuzumab. Circ Cardiovasc Imaging 2012;5:596-603.

102. Negishi K, Negishi T, Hare JL, Haluska BA, Plana JC, Marwick TH. Independent and incremental value of deformation indices for prediction of trastuzumab-induced cardiotoxicity. J Am Soc Echocardiogr 2013;26:493-498.

103. Voigt JU, Pedrizzetti G, Lysyansky P, Marwick TH, Houle H, Baumann R, Pedri S, Ito Y, Abe Y, Metz S, Song JH, Hamilton J, Sengupta PP, Kolias TJ, d'Hooge J, Aurigemma GP, Thomas JD, Badano LP. Definitions for a common standard for 2D speckle tracking echocardiography: consensus document of the EACVI/ ASE/Industry Task Force to standardize deformation imaging. Eur Heart J Cardiovasc Imaging 2015;16:1-11.

104. Gottdiener JS, Mathisen DJ, Borer JS, Bonow RO, Myers CE, Barr LH, Schwartz DE, Bacharach SL, Green MV, Rosenberg SA. Doxorubicin cardiotoxicity: assessment of late left ventricular dysfunction by radionuclide cineangiography. Ann Intern Med 1981;94:430-435.

105. Bellenger NG, Burgess MI, Ray SG, Lahiri A, Coats AJ, Cleland JG, Pennell DJ. Comparison of left ventricular ejection fraction and volumes in heart failure by echocardiography, radionuclide ventriculography and cardiovascular magnetic resonance; are they interchangeable? Eur Heart J 2000;21:1387-1396.

106. Schwartz RG, Jain D, Storozynsky E. Traditional and novel methods to assess and prevent chemotherapy-related cardiac dysfunction noninvasively. I Nucl Cardiol 2013;20:443-464

107. Thavendiranathan P, Wintersperger BJ, Flamm SD, Marwick TH. Cardiac MRI in the assessment of cardiac injury and toxicity from cancer chemotherapy: a systematic review. Circ Cardiovasc Imaging 2013;6:1080-1091.

108. Penugonda N. Cardiac MRI in infiltrative disorders: a concise review. Curr Cardiol Rev 2010;6:134-136.

109. Gulati A, Jabbour A, Ismail TF, Guha K, Khwaja J, Raza S, Morarji K, Brown TD, Ismail NA, Dweck MR, Di Pietro E, Roughton M, Wage R, Daryani $Y$, O'Hanlon R, Sheppard MN, Alpendurada F, Lyon AR, Cook SA, Cowie MR, Assomull RG, Pennell DJ, Prasad SK. Association of fibrosis with mortality and sudden cardiac death in patients with nonischemic dilated cardiomyopathy. JAMA 2013;309:896-908.

110. Ky B, Carver JR. Biomarker approach to the detection and cardioprotective strategies during anthracycline chemotherapy. Heart Fail Clin 2011;7:323-331.

111. Cardinale D, Sandri MT, Martinoni A, Tricca A, Civelli M, Lamantia G, Cinieri S, Martinelli G, Cipolla CM, Fiorentini C. Left ventricular dysfunction predicted by early troponin I release after high-dose chemotherapy. J Am Coll Cardiol 2000; 36:517-522.

112. Cardinale D, Sandri MT, Colombo A, Colombo N, Boeri M, Lamantia G, Civelli M, Peccatori F, Martinelli G, Fiorentini C, Cipolla CM. Prognostic value of troponin I in cardiac risk stratification of cancer patients undergoing high-dose chemotherapy. Circulation 2004:109:2749-2754.

113. Ledwidge M, Gallagher J, Conlon C, Tallon E, O'Connell E, Dawkins I, Watson C, O'Hanlon R, Bermingham M, Patle A, Badabhagni MR, Murtagh G, Voon V, Tilson L, Barry M, McDonald L, Maurer B, McDonald K. Natriuretic peptide-based 
screening and collaborative care for heart failure: the STOP-HF randomized trial. JAMA 2013;310:66-74.

114. Thakur A, Witteles RM. Cancer therapy-induced left ventricular dysfunction: interventions and prognosis. J Card Fail 2014:20:155-158.

115. Polk A, Vistisen K, Vaage-Nilsen M, Nielsen DL. A systematic review of the pathophysiology of 5-fluorouracil-induced cardiotoxicity. BMC Pharmacol Toxicol 2014; 15:47.

116. Copur MS, Obermiller A. An algorithm for the management of hypertension in the setting of vascular endothelial growth factor signaling inhibition. Clin Colorecta Cancer 2011;10:151-156.

117. Frickhofen N, Beck FJ, Jung B, Fuhr HG, Andrasch H, Sigmund M. Capecitabine can induce acute coronary syndrome similar to 5-fluorouracil. Ann Oncol 2002;13 797-801.

118. Kosmas C, Kallistratos MS, Kopterides P, Syrios J, Skopelitis H, Mylonakis N, Karabelis A, Tsavaris N. Cardiotoxicity of fluoropyrimidines in different schedules of administration: a prospective study. J Cancer Res Clin Oncol 2008;134:75-82.

119. Moore RA, Adel N, Riedel E, Bhutani M, Feldman DR, Tabbara NE, Soff G Parameswaran R, Hassoun $\mathrm{H}$. High incidence of thromboembolic events in patients treated with cisplatin-based chemotherapy: a large retrospective analysis. J Clin Oncol 2011;29:3466-3473.

120. Haugnes HS, Wethal T, Aass N, Dahl O, Klepp O, Langberg CW, Wilsgaard T, Bremnes RM, Fossa SD. Cardiovascular risk factors and morbidity in long-term survivors of testicular cancer: a 20-year follow-up study. J Clin Oncol 2010;28 4649-4657.

121. Huddart RA, Norman A, Shahidi M, Horwich A, Coward D, Nicholls J, Dearnaley DP. Cardiovascular disease as a long-term complication of treatment for testicular cancer. J Clin Oncol 2003;21:1513-1523.

122. Scappaticci FA, Skillings JR, Holden SN, Gerber HP, Miller K, Kabbinavar F Bergsland E, Ngai J, Holmgren E, Wang J, Hurwitz H. Arterial thromboembolic events in patients with metastatic carcinoma treated with chemotherapy and bevacizumab. J Natl Cancer Inst 2007;99:1232-1239.

123. Choueiri TK, Schutz FA, Je Y, Rosenberg JE, Bellmunt J. Risk of arterial thrombo embolic events with sunitinib and sorafenib: a systematic review and meta-analysis of clinical trials. / Clin Oncol 2010;28:2280-2285.

124. Lestuzzi C, Vaccher E, Talamini R, Lleshi A, Meneguzzo N, Viel E, Scalone S, Tartuferi L, Buonadonna A, Ejiofor L, Schmoll HJ. Effort myocardial ischemia during chemotherapy with 5-fluorouracil: an underestimated risk. Ann Oncol 2014;25 1059-1064.

125. Arima Y, Oshima S, Noda K, Fukushima H, Taniguchi I, Nakamura S, Shono M, Ogawa $\mathrm{H}$. Sorafenib-induced acute myocardial infarction due to coronary artery spasm. / Cardiol 2009;54:512-515.

126. McGale P, Darby SC, Hall P, Adolfsson J, Bengtsson NO, Bennet AM, Fornander T, Gigante B, Jensen MB, Peto R, Rahimi K, Taylor CW, Ewertz M. Incidence of heart disease in 35,000 women treated with radiotherapy for breast cancer in Denmark and Sweden. Radiother Oncol 2011;100:167-175.

127. Virmani R, Farb A, Carter AJ, Jones RM. Comparative pathology radiation-induced coronary artery disease in man and animals. Semin Interv Cardio 1998;3:163-172.

128. Brosius FC 3rd, Waller BF, Roberts WC. Radiation heart disease. Analysis of 16 young (aged 15 to 33 years) necropsy patients who received over 3,500 rads to the heart. Am J Med 1981;70:519-530.

129. Veinot JP, Edwards WD. Pathology of radiation-induced heart disease: a surgical and autopsy study of 27 cases. Hum Pathol 1996;27:766-773.

130. McEniery PT, Dorosti K, Schiavone WA, Pedrick TJ, Sheldon WC. Clinica and angiographic features of coronary artery disease after chest irradiation. Am J Cardiol 1987;60:1020-1024

131. King V, Constine LS, Clark D, Schwartz RG, Muhs AG, Henzler M, Hutson A Rubin P. Symptomatic coronary artery disease after mantle irradiation for Hodgkin's disease. Int J Radiat Oncol Biol Phys 1996;36:881-889.

132. Darby SC, Ewertz M, McGale P, Bennet AM, Blom-Goldman U, Bronnum D, Correa C, Cutter D, Gagliardi G, Gigante B, Jensen MB, Nisbet A, Peto R, Rahimi K, Taylor C, Hall P. Risk of ischemic heart disease in women after radiotherapy for breast cancer. N Engl J Med 2013;368:987-998.

133. Storey MR, Munden R, Strom EA, McNeese MD, Buchholz TA. Coronary artery dosimetry in intact left breast irradiation. Cancer J 2001;7:492-497.

134. Correa CR, Litt HI, Hwang WT, Ferrari VA, Solin LJ, Harris EE. Coronary artery findings after left-sided compared with right-sided radiation treatment for earlystage breast cancer. I Clin Oncol 2007:25:3031-3037.

135. Vijayakumar S, Rosenberg I, Spelbring D, Brandt T. Estimation of doses to heart, coronary arteries, and spinal cord in mediastinal irradiation for Hodgkin's disease. Med Dosim 1991; 16:237-241.

136. Orzan F, Brusca A, Conte MR, Presbitero P, Figliomeni MC. Severe coronary artery disease after radiation therapy of the chest and mediastinum: clinical presentation and treatment. Br Heart J 1993;69:496-500.
137. van Nimwegen FA, Schaapveld M, Cutter DJ, Janus CP, Krol AD, Hauptmann $M$, Kooijman K, Roesink J, van der Maazen R, Darby SC, Aleman BM, van Leeuwen FE. Radiation dose-response relationship for risk of coronary heart disease in survivors of Hodgkin lymphoma. J Clin Oncol 2016;34:235-243.

138. van Nimwegen FA, Schaapveld M, Janus CP, Krol AD, Petersen EJ, Raemaekers JM, Kok WE, Aleman BM, van Leeuwen FE. Cardiovascular disease after Hodgkin lymphoma treatment: 40-year disease risk. JAMA Intern Med 2015;175 1007-1017.

139. Windecker S, Kolh P, Alfonso F, Collet JP, Cremer J, Falk V, Filippatos G, Hamm C Head SJ, Juni P, Kappetein AP, Kastrati A, Knuuti J, Landmesser U, Laufer G, Neumann FJ, Richter DJ, Schauerte P, Sousa Uva M, Stefanini GG, Taggart DP, Torracca L, Valgimigli M, Wijns W, Witkowski A. 2014 ESC/EACTS Guidelines on myocardial revascularization: the Task Force on Myocardial Revascularization of the European Society of Cardiology (ESC) and the European Association for Cardio-Thoracic Surgery (EACTS). Developed with the special contribution of the European Association of Percutaneous Cardiovascular Interventions (EAPCI). Eur Heart J 2014;35:2541-2619.

140. Roffi M, Patrono C, Collet JP, Mueller C, Valgimigli M, Andreotti F, Bax J Borger MA, Brotons C, Chew DP, Gencer B, Hasenfuss G, Kjeldsen K Lancellotti P, Landmesser U, Mehilli J, Mukherjee D, Storey RF, Windecker S, Baumgartner H, Gaemperli O, Achenbach S, Agewall S, Badimon L, Baigent C, Bueno H, Bugiardini R, Carerj S, Casselman F, Cuisset T, Erol C, Fitzsimons D, Halle M, Hamm C, Hildick-Smith D, Huber K, lliodromitis E, James S, Lewis BS, Lip GY, Piepoli MF, Richter D, Rosemann T, Sechtem U, Steg PG, Vrints C, Luis Zamorano J. 2015 ESC Guidelines for the management of acute coronary syndromes in patients presenting without persistent ST-segment elevation: Task Force for the Management of Acute Coronary Syndromes in Patients Presenting without Persistent ST-Segment Elevation of the European Society of Cardiology (ESC). Eur Heart J 2016;37:267-315.

141. Task Force on the management of ST-segment elevation acute myocardial infarction of the European Society of Cardiology (ESC), Steg PG, James SK, Atar D, Badano LP, Blomstrom-Lundqvist C, Borger MA, Di Mario C, Dickstein K, Ducrocq G, Fernandez-Aviles F, Gershlick AH, Giannuzzi P, Halvorsen S, Huber K, Juni P, Kastrati A, Knuuti J, Lenzen MJ, Mahaffey KW, Valgimigli M, van 't Hof A, Widimsky P, Zahger D. ESC Guidelines for the management of acute myocardial infarction in patients presenting with ST-segment elevation. Eur Heart / 2012;33:2569-2619

142. Brouwer CA, Postma A, Hooimeijer HL, Smit AJ, Vonk JM, van Roon AM, van den Berg MP, Dolsma WV, Lefrandt JD, Bink-Boelkens MT, Zwart N, de Vries EG Tissing WJ, Gietema JA. Endothelial damage in long-term survivors of childhood cancer. J Clin Oncol 2013;31:3906-3913.

143. de Haas EC, Oosting SF, Lefrandt JD, Wolffenbuttel BH, Sleijfer DT, Gietema JA. The metabolic syndrome in cancer survivors. Lancet Oncol 2010;11:193-203.

144. Prosnitz RG, Hubbs JL, Evans ES, Zhou SM, Yu X, Blazing MA, Hollis DR, Tisch A, Wong TZ, Borges-Neto S, Hardenbergh PH, Marks LB. Prospective assessment of radiotherapy-associated cardiac toxicity in breast cancer patients: analysis of data 3 to 6 years after treatment. Cancer 2007;110:1840-1850.

145. Gyenes G, Fornander T, Carlens P, Glas U, Rutqvist LE. Detection of radiation-induced myocardial damage by technetium- $99 \mathrm{~m}$ sestamibi scintigraphy. Eur J Nucl Med 1997;24:286-292.

146. Malanca M, Cimadevilla C, Brochet E, lung B, Vahanian A, Messika-Zeitoun D. Radiotherapy-induced mitral stenosis: a three-dimensional perspective. J Am Soc Echocardiogr 2010;23:108 e101-102.

147. Cutter DJ, Schaapveld M, Darby SC, Hauptmann M, van Nimwegen FA, Krol AD Janus CP, van Leeuwen FE, Aleman BM. Risk of valvular heart disease after treatment for Hodgkin lymphoma. I Natl Cancer Inst 2015;107:djv008.

148. Groarke JD, Nguyen PL, Nohria A, Ferrari R, Cheng S, Moslehi J. Cardiovascular complications of radiation therapy for thoracic malignancies: the role for noninvasive imaging for detection of cardiovascular disease. Eur Heart J 2014;35 612-623.

149. Joint Task Force on the Management of Valvular Heart Disease of the European Society of Cardiology (ESC), European Association for Cardio-Thoracic Surgery (EACTS), Vahanian A, Alfieri O, Andreotti F, Antunes MJ, Baron-Esquivias G, Baumgartner H, Borger MA, Carrel TP, De Bonis M, Evangelista A, Falk V, lung B, Lancellotti P, Pierard L, Price S, Schafers HJ, Schuler G, Stepinska J, Swedberg K, Takkenberg J, Von Oppell UO, Windecker S, Zamorano JL, Zembala M. Guidelines on the management of valvular heart disease (version 2012). Eur Heart J 2012;33:2451-2496.

150. Tamargo J, Caballero R, Delpon E. Cancer chemotherapy and cardiac arrhythmias: a review. Drug Saf 2015;38:129-152.

151. Lenihan DJ, Kowey PR. Overview and management of cardiac adverse events associated with tyrosine kinase inhibitors. Oncologist 2013;18:900-908.

152. Soignet SL, Frankel SR, Douer D, Tallman MS, Kantarjian H, Calleja E, Stone RM, Kalaycio M, Scheinberg DA, Steinherz P, Sievers EL, Coutre S, Dahlberg S, 
Ellison R, Warrell RP Jr. United States multicenter study of arsenic trioxide in relapsed acute promyelocytic leukemia. J Clin Oncol 2001;19:3852-3860.

153. Shah RR, Morganroth J, Shah DR. Cardiovascular safety of tyrosine kinase inhibitors: with a special focus on cardiac repolarisation (QT interval). Drug Saf 2013; 36:295-316.

154. Strevel EL, Ing DJ, Siu LL. Molecularly targeted oncology therapeutics and prolongation of the QT interval. J Clin Oncol 2007; 25:3362-3371.

155. Farmakis D, Parissis J, Filippatos G. Insights into onco-cardiology: atrial fibrillation in cancer. J Am Coll Cardiol 2014;63:945-953.

156. Priori SG, Blomstrom-Lundqvist C, Mazzanti A, Blom N, Borggrefe M, Camm J, Elliott PM, Fitzsimons D, Hatala R, Hindricks G, Kirchhof P, Kjeldsen K, Kuck KH, Hernandez-Madrid A, Nikolaou N, Norekval TM, Spaulding C, Van Veldhuisen DJ. 2015 ESC Guidelines for the management of patients with ventricular arrhythmias and the prevention of sudden cardiac death: the Task Force for the Management of Patients with Ventricular Arrhythmias and the Prevention of Sudden Cardiac Death of the European Society of Cardiology (ESC). Endorsed by: Association for European Paediatric and Congenital Cardiology (AEPC). Eur Heart J 2015;36:2793-2867.

157. Al-Khatib SM, LaPointe NM, Kramer JM, Califf RM. What clinicians should know about the QT interval. JAMA 2003;289:2120-2127.

158. Bates SE, Rosing DR, Fojo T, Piekarz RL. Challenges of evaluating the cardiac effects of anticancer agents. Clin Cancer Res 2006:12:3871-3874.

159. Larsen TB, Nielsen PB, Skjoth F, Rasmussen LH, Lip GY. Non-vitamin K antagonist oral anticoagulants and the treatment of venous thromboembolism in cancer patients: a semi systematic review and meta-analysis of safety and efficacy outcomes. PLoS One 2014:9:e114445.

160. Colt JS, Schwartz K, Graubard BI, Davis F, Ruterbusch J, DiGaetano R, Purdue M, Rothman N, Wacholder S, Chow WH. Hypertension and risk of renal cell carcinoma among white and black Americans. Epidemiology 2011;22:797-804.

161. Milan A, Puglisi E, Ferrari L, Bruno G, Losano I, Veglio F. Arterial hypertension and cancer. Int J Cancer 2014;134:2269-2277.

162. Izzedine H, Ederhy S, Goldwasser F, Soria JC, Milano G, Cohen A, Khayat D, Spano JP. Management of hypertension in angiogenesis inhibitor-treated patients. Ann Oncol 2009;20:807-815.

163. Wu S, Chen JJ, Kudelka A, Lu J, Zhu X. Incidence and risk of hypertension with sorafenib in patients with cancer: a systematic review and meta-analysis. Lancet Oncol 2008;9:117-123.

164. Eremina V, Jefferson JA, Kowalewska J, Hochster H, Haas M, Weisstuch J, Richardson C, Kopp JB, Kabir MG, Backx PH, Gerber HP, Ferrara N, Barisoni L, Alpers CE, Quaggin SE. VEGF inhibition and renal thrombotic microangiopathy. N Engl J Med 2008;358:1129-1136.

165. Ranpura V, Pulipati B, Chu D, Zhu X, Wu S. Increased risk of high-grade hypertension with bevacizumab in cancer patients: a meta-analysis. Am J Hypertens 2010;23: 460-468.

166. Mancia G, Fagard R, Narkiewicz K, Redon J, Zanchetti A, Bohm M, Christiaens T, Cifkova R, De Backer G, Dominiczak A, Galderisi M, Grobbee DE, Jaarsma T, Kirchhof P, Kjeldsen SE, Laurent S, Manolis AJ, Nilsson PM, Ruilope LM, Schmieder RE, Sirnes PA, Sleight P, Viigimaa M, Waeber B, Zannad F, Redon J, Dominiczak A, Narkiewicz K, Nilsson PM, Burnier M, Viigimaa M, Ambrosioni E, Caufield M, Coca A, Olsen MH, Schmieder RE, Tsioufis C, van de Borne P, Zamorano JL, Achenbach S, Baumgartner H, Bax JJ, Bueno H, Dean V, Deaton C, Erol C, Fagard R, Ferrari R, Hasdai D, Hoes AW, Kirchhof P, Knuuti J, Kolh P, Lancellotti P, Linhart A, Nihoyannopoulos P, Piepoli MF, Ponikowski P, Sirnes PA, Tamargo JL, Tendera M, Torbicki A, Wijns W, Windecker S, Clement DL, Coca A, Gillebert TC, Tendera M, Rosei EA, Ambrosioni E, Anker SD, Bauersachs J, Hitij JB, Caulfield M, De Buyzere M, De Geest S, Derumeaux GA, Erdine S, Farsang C, Funck-Brentano C, Gerc V, Germano G, Gielen S, Haller H, Hoes AW, Jordan J, Kahan T, Komajda M, Lovic D, Mahrholdt H, Olsen MH, Ostergren J, Parati G, Perk J, Polonia J, Popescu BA, Reiner Z, Ryden L, Sirenko Y, Stanton A, Struijker-Boudier H, Tsioufis C, van de Borne P, Vlachopoulos C, Volpe M, Wood DA. 2013 ESH/ESC guidelines for the management of arterial hypertension: the Task Force for the Management of Arterial Hypertension of the European Society of Hypertension (ESH) and of the European Society of Cardiology (ESC). Eur Heart J 2013;34:2159-2219.

167. Zhu X, Stergiopoulos K, Wu S. Risk of hypertension and renal dysfunction with an angiogenesis inhibitor sunitinib: systematic review and meta-analysis. Acta Oncol 2009;48:9-17.

168. Funakoshi T, Latif A, Galsky MD. Risk of hypertension in cancer patients treated with sorafenib: an updated systematic review and meta-analysis. J Hum Hypertens 2013;27:601-611.

169. Qi WX, He AN, Shen Z, Yao Y. Incidence and risk of hypertension with a novel multi-targeted kinase inhibitor axitinib in cancer patients: a systematic review and meta-analysis. Br J Clin Pharmacol 2013;76:348-357.
170. Qi WX, Shen Z, Lin F, Sun YJ, Min DL, Tang LN, He AN, Yao Y. Incidence and risk of hypertension with vandetanib in cancer patients: a systematic review and meta-analysis of clinical trials. Br 」 Clin Pharmacol 2013;75:919-930.

171. Wang Z, Xu J, Nie W, Huang G, Tang J, Guan X. Risk of hypertension with regorafenib in cancer patients: a systematic review and meta-analysis. Eur J Clin Pharmacol 2014;70:225-231.

172. Maitland ML, Bakris GL, Black HR, Chen HX, Durand JB, Elliott WJ, Ivy SP, Leier CV, Lindenfeld J, Liu G, Remick SC, Steingart R, Tang WH, Cardiovascular Toxicities Panel, Convened by the Angiogenesis Task Force of the National Cancer Institute Investigational Drug Steering Committee. Initial assessment, surveillance, and management of blood pressure in patients receiving vascular endothelial growth factor signaling pathway inhibitors. J Natl Cancer Inst 2010; 102:596-604.

173. McMurray JJ, Adamopoulos S, Anker SD, Auricchio A, Bohm M, Dickstein K, Falk V, Filippatos G, Fonseca C, Gomez-Sanchez MA, Jaarsma T, Kober L, Lip GY, Maggioni AP, Parkhomenko A, Pieske BM, Popescu BA, Ronnevik PK, Rutten FH, Schwitter J, Seferovic P, Stepinska J, Trindade PT, Voors AA, Zannad F, Zeiher A, ESC Committee for Practice Guidelines. ESC Guidelines for the diagnosis and treatment of acute and chronic heart failure 2012: the Task Force for the Diagnosis and Treatment of Acute and Chronic Heart Failure 2012 of the European Society of Cardiology. Developed in collaboration with the Heart Failure Association (HFA) of the ESC. Eur Heart J 2012;33:1787-1847.

174. Oliver IJ, Melville VP, Webb DJ. Effect of regular phosphodiesterase type 5 inhibition in hypertension. Hypertension 2006;48:622-627.

175. Ewer MS, Ewer SM. Cardiotoxicity of anticancer treatments: what the cardiologist needs to know. Nat Rev Cardiol 2010; 7:564-575.

176. Facemire CS, Nixon AB, Griffiths R, Hurwitz H, Coffman TM. Vascular endothelial growth factor receptor 2 controls blood pressure by regulating nitric oxide synthase expression. Hypertension 2009;54:652-658.

177. Rickles FR. Mechanisms of cancer-induced thrombosis in cancer. Pathophysiol Haemost Thromb 2006;35:103-110.

178. Di Nisio M, Ferrante N, Feragalli B, De Tursi M, lacobelli S, Cuccurullo F, Porreca E. Arterial thrombosis in ambulatory cancer patients treated with chemotherapy. Thromb Res 2011;127:382-383.

179. Ewer MS, Gluck S. A woman's heart: the impact of adjuvant endocrine therapy on cardiovascular health. Cancer 2009:115:1813-1826.

180. Lecumberri R, Marques M, Panizo E, Alfonso A, Garcia-Mouriz A, Gil-Bazo I, Hermida J, Schulman S, Paramo JA. High incidence of venous thromboembolism despite electronic alerts for thromboprophylaxis in hospitalised cancer patients. Thromb Haemost 2013;110:184-190.

181. Khorana AA. Risk assessment and prophylaxis for VTE in cancer patients. J Natl Compr Canc Netw 2011;9:789-797.

182. Khorana AA, Connolly GC. Assessing risk of venous thromboembolism in the patient with cancer. J Clin Oncol 2009;27:4839-4847.

183. Haddad TC, Greeno EW. Chemotherapy-induced thrombosis. Thromb Res 2006; 118:555-568.

184. O'Connell CL, Liebman HA. Approach to the management of incidental venous thromboembolic events in patients with cancer. J Natl Compr Canc Netw 2014;12: 1557-1560.

185. Akl EA, Kahale L, Barba M, Neumann I, Labedi N, Terrenato I, Sperati F, Muti P, Schunemann $\mathrm{H}$. Anticoagulation for the long-term treatment of venous thromboembolism in patients with cancer. Cochrane Database Syst Rev 2014;7:CD006650.

186. Hutten BA, Prins MH, Gent M, Ginsberg J, Tijssen JG, Buller HR. Incidence of recurrent thromboembolic and bleeding complications among patients with venous thromboembolism in relation to both malignancy and achieved international normalized ratio: a retrospective analysis. J Clin Oncol 2000;18:3078-3083.

187. Konstantinides SV, Torbicki A, Agnelli G, Danchin N, Fitzmaurice D, Galie N, Gibbs JS, Huisman MV, Humbert M, Kucher N, Lang I, Lankeit M, Lekakis J, Maack C, Mayer E, Meneveau N, Perrier A, Pruszczyk P, Rasmussen LH, Schindler TH, Svitil P, Vonk Noordegraaf A, Zamorano JL, Zompatori M, Task Force for the Diagnosis and Management of Acute Pulmonary Embolism of the European Society of Cardiology (ESC). 2014 ESC guidelines on the diagnosis and management of acute pulmonary embolism. Eur Heart J 2014;35:3033-3069, 3069a-3069k.

188. Prins MH, Lensing AW, Bauersachs R, van Bellen B, Bounameaux H, Brighton TA, Cohen AT, Davidson BL, Decousus H, Raskob GE, Berkowitz SD, Wells PS, EINSTEIN Investigators. Oral rivaroxaban versus standard therapy for the treatment of symptomatic venous thromboembolism: a pooled analysis of the EINSTEIN-DVT and PE randomized studies. Thromb / 2013;11:21.

189. Schulman S, Goldhaber SZ, Kearon C, Kakkar AK, Schellong S, Eriksson H, Hantel S, Feuring M, Kreuzer J. Treatment with dabigatran or warfarin in patients with venous thromboembolism and cancer. Thromb Haemost 2015:114:150-157.

190. Gerotziafas GT, Mahe I, Elalamy I. New orally active anticoagulant agents for the prevention and treatment of venous thromboembolism in cancer patients. Ther Clin Risk Manag 2014;10:423-436. 
191. Farge D, Debourdeau P, Beckers M, Baglin C, Bauersachs RM, Brenner B Brilhante D, Falanga A, Gerotzafias GT, Haim N, Kakkar AK, Khorana AA, Lecumberri R, Mandala M, Marty M, Monreal M, Mousa SA, Noble S, Pabinger I, Prandoni P, Prins MH, Qari MH, Streiff MB, Syrigos $K$ Bounameaux $\mathrm{H}$, Buller HR. International clinical practice guidelines for the treatment and prophylaxis of venous thromboembolism in patients with cancer. J Thromb Haemost 2013:11:56-70.

192. Barginear MF, Gralla RJ, Bradley TP, Ali SS, Shapira I, Greben C, Nier-Shoulson N, Akerman M, Lesser M, Budman DR. Investigating the benefit of adding a vena cav filter to anticoagulation with fondaparinux sodium in patients with cancer and venous thromboembolism in a prospective randomized clinical trial. Support Care Cancer 2012;20:2865-2872

193. Villemur B, Payraud E, Seetha V, De Angelis MP, Magne JL, Perennou D Carpentier P, Pernod G. [Arterial bypass iterative thrombosis and cancer: three cases]. J Mal Vasc 2014;39:14-17.

194. Plummer C, Henderson RD, O'Sullivan JD, Read SJ. Ischemic stroke and transient ischemic attack after head and neck radiotherapy: a review. Stroke 2011;42 2410-2418

195. De Bruin ML, Dorresteijn LD, van't Veer MB, Krol AD, van der Pal $H$, Kappelle AC, Boogerd W, Aleman BM, van Leeuwen FE. Increased risk of stroke and transient ischemic attack in 5 -year survivors of Hodgkin lymphoma. J Nat Cancer Inst 2009;101:928-937.

196. Yuan H, Gaber MW, Boyd K, Wilson CM, Kiani MF, Merchant TE. Effects of fractionated radiation on the brain vasculature in a murine model: blood-brain barrier permeability, astrocyte proliferation, and ultrastructural changes. Int J Radiat Oncol Biol Phys 2006;66:860-866.

197. Louis EL, McLoughlin MJ, Wortzman G. Chronic damage to medium and large arteries following irradiation. J Can Assoc Radiol 1974;25:94-104.

198. Fajardo LF. The pathology of ionizing radiation as defined by morphologic patterns. Acta Oncol 2005;44:13-22.

199. Jurado JA, Bashir R, Burket MW. Radiation-induced peripheral artery disease. Catheter Cardiovasc Interv 2008;72:563-568.

200. European Stroke Organisation, Tendera M, Aboyans V, Bartelink ML, Baumgartner I, Clement D, Collet JP, Cremonesi A, De Carlo M, Erbel R, Fowkes FG, Heras M, Kownator S, Minar E, Ostergren J, Poldermans D, Riambau V, Roffi M, Rother|, Sievert H, van Sambeek M, Zeller T, ESC Committee for Practice Guidelines. ESC Guidelines on the diagnosis and treatment of peripheral artery diseases: Document covering atherosclerotic disease of extracrania carotid and vertebral, mesenteric, renal, upper and lower extremity arteries: the Task Force on the Diagnosis and Treatment of Peripheral Artery Diseases of the European Society of Cardiology (ESC). Eur Heart J 2011;32:2851-2906.

201. Fokkema M, den Hartog AG, Bots ML, van der Tweel I, Moll FL, de Borst GJ. Stenting versus surgery in patients with carotid stenosis after previous cervical radiation therapy: systematic review and meta-analysis. Stroke 2012;43:793-801.

202. Gujral DM, Shah BN, Chahal NS, Senior R, Harrington KJ, Nutting CM. Clinica features of radiation-induced carotid atherosclerosis. Clin Oncol (R Coll Radiol) 2014; 26:94-102

203. Limsuwan A, Pakakasama S, Rochanawutanon M, Hong-eng S. Pulmonary arteria hypertension after childhood cancer therapy and bone marrow transplantation. Cardiology 2006;105:188-194.

204. Farha S, Dweik R, Rahaghi F, Benza R, Hassoun P, Frantz R, Torres F, Quinn DA, Comhair $\mathrm{S}$, Erzurum $\mathrm{S}$, Asosingh K. Imatinib in pulmonary arterial hypertension: c-Kit inhibition. Pulm Circ 2014;4:452-455.

205. Hoeper MM, Barst RJ, Bourge RC, Feldman J, Frost AE, Galie N, Gomez-Sanchez MA, Grimminger F, Grunig E, Hassoun PM, Morrell NW, Peacock AJ, Satoh T, Simonneau G, Tapson VF, Torres F, Lawrence D, Quinn DA, Ghofrani HA. Imatinib mesylate as add-on therapy for pulmonary arterial hypertension: results of the randomized IMPRES study. Circulation 2013;127 $1128-1138$.

206. Montani D, Bergot E, Gunther S, Savale L, Bergeron A, Bourdin A, Bouvaist $H$ Canuet M, Pison C, Macro M, Poubeau P, Girerd B, Natali D, Guignabert C Perros F, O'Callaghan DS, Jais X, Tubert-Bitter P, Zalcman G, Sitbon O Simonneau G, Humbert M. Pulmonary arterial hypertension in patients treated by dasatinib. Circulation 2012;125:2128-2137.

207. Ranchoux B, Gunther S, Quarck R, Chaumais MC, Dorfmuller P, Antigny F, Dumas SJ, Raymond N, Lau E, Savale L, Jais X, Sitbon O, Simonneau G, Stenmark K, Cohen-Kaminsky S, Humbert M, Montani D, Perros F Chemotherapy-induced pulmonary hypertension: role of alkylating agents. Am J Pathol 2015:185:356-371.

208. Galie N, Humbert M, Vachiery JL, Gibbs S, Lang I, Torbicki A, Simonneau G, Peacock A, Vonk Noordegraaf A, Beghetti M, Ghofrani A, Gomez Sanchez MA Hansmann G, Klepetko W, Lancellotti P, Matucci M, McDonagh T, Pierard LA, Trindade PT, Zompatori M, Hoeper M, Aboyans V, Vaz Carneiro A, Achenbach S, Agewall S, Allanore Y, Asteggiano R, Paolo Badano L, Albert Barbera J, Bouvaist H, Bueno H, Byrne RA, Carerj S, Castro G, Erol C, Falk V,
Funck-Brentano C, Gorenflo M, Granton J, lung B, Kiely DG, Kirchhof P. Kjellstrom B, Landmesser U, Lekakis J, Lionis C, Lip GY, Orfanos SE, Park MH, Piepoli MF, Ponikowski P, Revel MP, Rigau D, Rosenkranz S, Voller H, Luis Zamorano J. 2015 ESC/ERS Guidelines for the diagnosis and treatment of pulmonary hypertension: the Joint Task Force for the Diagnosis and Treatment of Pulmonary Hypertension of the European Society of Cardiology (ESC) and the European Respiratory Society (ERS). Endorsed by: Association for European Paediatric and Congenital Cardiology (AEPC), International Society for Heart and Lung Transplantation (ISHLT). Eur Heart J 2016;37:67-119.

209. Stewart JR, Fajardo LF, Gillette SM, Constine LS. Radiation injury to the heart. Int Radiat Oncol Biol Phys 1995;31:1205-1211.

210. Applefeld MM, Wiernik PH. Cardiac disease after radiation therapy for Hodgkin's disease: analysis of 48 patients. Am J Cardiol 1983;51:1679-1681.

211. Gagliardi G, Constine LS, Moiseenko V, Correa C, Pierce LJ, Allen AM, Marks LB. Radiation dose-volume effects in the heart. Int / Radiat Oncol Biol Phys 2010;76: S77-85.

212. Adler Y, Charron P, Imazio M, Badano L, Baron-Esquivias G, Bogaert J, Brucato A, Gueret P, Klingel K, Lionis C, Maisch B, Mayosi B, Pavie A, Ristic AD, Sabate Tenas M, Seferovic P, Swedberg K, Tomkowski W, Achenbach S, Agewall S, Al-Attar N, Angel Ferrer J, Arad M, Asteggiano R, Bueno H, Caforio AL, Carerj S, Ceconi C, Evangelista A, Flachskampf F, Giannakoulas G, Gielen S, Habib G, Kolh P, Lambrinou E, Lancellotti P, Lazaros G, Linhart A, Meurin P, Nieman K, Piepoli MF, Price S, Roos-Hesselink J, Roubille F, Ruschitzka F, Sagrista Sauleda J, Sousa-Uva M, Uwe Voigt J, Luis Zamorano J, European Society of Cardiology. 2015 ESC Guidelines for the diagnosis and management of pericardial diseases: the Task Force for the Diagnosis and Management of Pericardial Diseases of the European Society of Cardiology (ESC). Endorsed by: the European Association for Cardio-Thoracic Surgery (EACTS). Eur Heart J 2015;36:2921-2964.

213. Chen MH, Kerkela R, Force T. Mechanisms of cardiac dysfunction associated with tyrosine kinase inhibitor cancer therapeutics. Circulation 2008:118:84-95.

214. Ness KK, Armstrong GT. Screening for cardiac autonomic dysfunction among Hodgkin lymphoma survivors treated with thoracic radiation. J Am Coll Cardio 2015;65:584-585.

215. Diller L, Chow E), Gurney JG, Hudson MM, Kadin-Lottick NS, Kawashima TI, Leisenring WM, Meacham LR, Mertens AC, Mulrooney DA, Oeffinger KC, Packer RJ, Robison LL, Sklar CA. Chronic disease in the Childhood Cancer Survivor Study cohort: a review of published findings. J Clin Oncol 2009;27: 2339-2355

216. Tukenova M, Guibout C, Oberlin O, Doyon F, Mousannif A, Haddy N, Guerin S, Pacquement H, Aouba A, Hawkins M, Winter D, Bourhis J, Lefkopoulos D, Diallo I, de Vathaire F. Role of cancer treatment in long-term overall and cardiovascular mortality after childhood cancer. I Clin Oncol 2010;28:1308-1315.

217. Gudmundsdottir T, Winther JF, de Fine Licht S, Bonnesen TG, Asdahl PH, Tryggvadottir L, Anderson H, Wesenberg F, Malila N, Hasle H, Olsen JH, ALiCCS study group. Cardiovascular disease in adult life after childhood cancer in Scandinavia: a population-based cohort study of 32,308 one-year survivors. Int J Cancer 2015;137:1176-1186

218. Aapro M, Bernard-Marty C, Brain EG, Batist G, Erdkamp F, Krzemieniecki K, Leonard R, Lluch A, Monfardini S, Ryberg M, Soubeyran P, Wedding U. Anthracycline cardiotoxicity in the elderly cancer patient: a SIOG expert position paper. Ann Oncol 2011;22:257-267.

219. Serrano C, Cortes J, De Mattos-Arruda L, Bellet M, Gomez P, Saura C, Perez Vidal M, Munoz-Couselo E, Carreras MJ, Sanchez-Olle G, Tabernero J Baselga J, Di Cosimo S. Trastuzumab-related cardiotoxicity in the elderly: a role for cardiovascular risk factors. Ann Oncol 2012;23:897-902.

220. Ewer SM. Ewer MS. Cardiotoxicity profile of trastuzumab. Drug Saf 2008:31 459-467.

221. Gziri MM, Amant F, Debieve F, Van Calsteren K, De Catte L, Mertens L. Effects of chemotherapy during pregnancy on the maternal and fetal heart. Prenat Diagn 2012;32:614-619.

222. Van Calsteren K, Heyns L, De Smet F, Van Eycken L, Gziri MM, Van Gemert W, Halaska M, Vergote I, Ottevanger N, Amant F. Cancer during pregnancy: an analysis of 215 patients emphasizing the obstetrical and the neonatal outcomes. J Clin Oncol 2010;28:683-689.

223. Gziri MM, Debieve F, de Catte L, Mertens L, Barrea C, van Calsteren K, Han SN, Heyns L, Amant F. Chemotherapy during pregnancy: effect of anthracyclines on fetal and maternal cardiac function. Acta Obstet Gynecol Scand 2012;91 $1465-1468$.

224. Van Calsteren K, Verbesselt R, Beijnen J, Devlieger R, De Catte L, Chai DC, Van Bree R, Heyns L, de Hoon J, Amant F. Transplacental transfer of anthracyclines, vinblastine, and 4-hydroxy-cyclophosphamide in a baboon model. Gynecol Oncol 2010;119:594-600.

225. Cardonick E, Dougherty R, Grana G, Gilmandyar D, Ghaffar S, Usmani A. Breast cancer during pregnancy: maternal and fetal outcomes. Cancer J 2010;16:76-82. 
226. Bosch X, Rovira M, Sitges M, Domenech A, Ortiz-Perez JT, de Caralt TM, Morales-Ruiz M, Perea RJ, Monzo M, Esteve J. Enalapril and carvedilol for preventing chemotherapy-induced left ventricular systolic dysfunction in patients with malignant hemopathies: the OVERCOME trial (preventiOn of left Ventricular dysfunction with Enalapril and caRvedilol in patients submitted to intensive ChemOtherapy for the treatment of Malignant hEmopathies). J Am Coll Cardiol 2013;61:2355-2362

227. Gulati G, Heck SL, Ree AH, Hoffmann P, Schulz-Menger J, Fagerland MW, Gravdehaug B, von Knobelsdorff-Brenkenhoff F, Bratland A, Storas TH, Hagve TA, Rosjo H, Steine K, Geisler J, Omland T. Prevention of cardiac dysfunction during adjuvant breast cancer therapy (PRADA): a $2 \times 2$ factorial, randomized, placebo-controlled, double-blind clinical trial of candesartan and metoprolol. Eur Heart J 2016;37:1671-1680.

228. Pituskin E, Haykowsky M, Mackey JR, Thompson RB, Ezekowitz J, Koshman S, Oudit G, Chow K, Pagano J], Paterson I. Rationale and design of the Multidisciplinary Approach to Novel Therapies in Cardiology Oncology Research Trial (MANTICORE 101—Breast): a randomized, placebo-controlled trial to determine if conventional heart failure pharmacotherapy can prevent trastuzumabmediated left ventricular remodeling among patients with HER2 + early breast cancer using cardiac MRI. BMC Cancer 2011;11:318.

229. Barac A, Murtagh G, Carver JR, Chen MH, Freeman AM, Herrmann J, lliescu C, Ky B, Mayer EL, Okwuosa TM, Plana JC, Ryan TD, Rzeszut AK, Douglas PS. Cardiovascular health of patients with cancer and cancer survivors: a roadmap to the next level. J Am Coll Cardiol 2015;65:2739-2746

230. Clarke E, Lenihan D. Cardio-oncology: a new discipline in medicine to lead us into truly integrative care. Future Cardiol 2015;11:359-361.

231. Okwuosa TM, Barac A. Burgeoning cardio-oncology programs: challenges and opportunities for early career cardiologists/faculty directors. I Am Coll Cardiol 2015; 66:1193-1197.

232. Albini A, Pennesi G, Donatelli F, Cammarota R, De Flora S, Noonan DM. Cardiotoxicity of anticancer drugs: the need for cardio-oncology and cardio-oncological prevention. I Natl Cancer Inst 2010;102:14-25.

233. Speyer JL, Green MD, Zeleniuch-Jacquotte A, Wernz JC, Rey M, Sanger J, Kramer E, Ferrans $\mathrm{V}$, Hochster H, Meyers M. ICRF-187 permits longer treatment with doxorubicin in women with breast cancer. J Clin Oncol 1992;10:117-127.

234. Venturini M, Michelotti A, Del Mastro L, Gallo L, Carnino F, Garrone O, Tibaldi C Molea N, Bellina RC, Pronzato P, Cyrus P, Vinke J, Testore F, Guelfi M, Lionetto R, Bruzzi P, Conte PF, Rosso R. Multicenter randomized controlled clinical trial to evaluate cardioprotection of dexrazoxane versus no cardioprotection in women receiving epirubicin chemotherapy for advanced breast cancer. J Clin Oncol 1996; 14:3112-3120.

235. Swain SM, Whaley FS, Gerber MC, Ewer MS, Bianchine JR, Gams RA. Delayed administration of dexrazoxane provides cardioprotection for patients with advanced breast cancer treated with doxorubicin-containing therapy. I Clin Oncol 1997:15:1333-1340.

236. Lipshultz SE, Rifai N, Dalton VM, Levy DE, Silverman LB, Lipsitz SR, Colan SD, Asselin BL, Barr RD, Clavell LA, Hurwitz CA, Moghrabi A, Samson Y, Schorin MA, Gelber RD, Sallan SE. The effect of dexrazoxane on myocardial injury in doxorubicin-treated children with acute lymphoblastic leukemia. N Engl J Med 2004:351:145-153

237. Marty M, Espie M, Llombart A, Monnier A, Rapoport BL, Stahalova V, Dexrazoxane Study Group. Multicenter randomized phase III study of the cardioprotective effect of dexrazoxane (Cardioxane) in advanced/metastatic breast cancer patients treated with anthracycline-based chemotherapy. Ann Oncol 2006;17:614-622.

238. Huh WW, Jaffe N, Durand JB, Munsell MF, Herzog CE. Comparison of doxorubicin cardiotoxicity in pediatric sarcoma patients when given with dexrazoxane versus as continuous infusion. Pediatr Hematol Oncol 2010;27:546-557.

239. Asselin BL, Devidas M, Chen L, Franco VI, Pullen J, Borowitz MJ, Hutchison RE, Ravindranath Y, Armenian SH, Camitta BM, Lipshultz SE. Cardioprotection and safety of dexrazoxane in patients treated for newly diagnosed T-cell acute lymphoblastic leukemia or advanced-stage lymphoblastic non-Hodgkin lymphoma: a report of the Children's Oncology Group Randomized Trial Pediatric Oncology Group 9404. J Clin Oncol 2016;34:854-862.

240. van Dalen EC, Caron HN, Dickinson HO, Kremer LC. Cardioprotective interventions for cancer patients receiving anthracyclines. Cochrane Database Syst Rev 2011;6:CD003917.

241. Tebbi CK, London WB, Friedman D, Villaluna D, De Alarcon PA, Constine LS, Mendenhall NP, Sposto R, Chauvenet A, Schwartz CL. Dexrazoxane-associated risk for acute myeloid leukemia/myelodysplastic syndrome and other secondary malignancies in pediatric Hodgkin's disease. J Clin Oncol 2007;25:493-500.

242. Barry EV, Vrooman LM, Dahlberg SE, Neuberg DS, Asselin BL, Athale UH, Clavell LA, Larsen EC, Moghrabi A, Samson Y, Schorin MA, Cohen HJ, Lipshultz SE, Sallan SE, Silverman LB. Absence of secondary malignant neoplasms in children with high-risk acute lymphoblastic leukemia treated with dexrazoxane. J Clin Oncol 2008;26:1106-1111.
243. Hensley ML, Hagerty KL, Kewalramani T, Green DM, Meropol NJ, Wasserman TH, Cohen Gl, Emami B, Gradishar WJ, Mitchell RB, Thigpen JT, Trotti A 3rd, von Hoff D, Schuchter LM. American Society of Clinical Oncology 2008 clinical practice guideline update: use of chemotherapy and radiation therapy protectants. J Clin Oncol 2009;27:127-145.

244. European Medicines Agency. Questions and answers on the review of dexrazoxane-containing medicines, powder for solution for infusion, $500 \mathrm{mg}$. Outcome of a procedure under Article 31 of Directive 2001/83/EC as amended. http://www.ema.europa.eu/docs/en_GB/document_libraryl Referrals_document/Dexrazoxane_31/WC500108011.pdf. Date last accessed 12 April 2016.

245. Kalay N, Basar E, Ozdogru I, Er O, Cetinkaya Y, Dogan A, Inanc T, Oguzhan A, Eryol NK, Topsakal R, Ergin A. Protective effects of carvedilol against anthracycline-induced cardiomyopathy. J Am Coll Cardiol 2006;48:2258-2262.

246. Kaya MG, Ozkan M, Gunebakmaz O, Akkaya H, Kaya EG, Akpek M, Kalay N, Dikilitas M, Yarlioglues M, Karaca H, Berk V, Ardic I, Ergin A, Lam YY. Protective effects of nebivolol against anthracycline-induced cardiomyopathy: a randomized control study. Int J Cardiol 2013;167:2306-2310.

247. Akpek M, Ozdogru I, Sahin O, Inanc M, Dogan A, Yazici C, Berk V, Karaca H, Kalay N, Oguzhan A, Ergin A. Protective effects of spironolactone against anthracycline-induced cardiomyopathy. Eur J Heart Fail 2015;17:81-89.

248. Nakamae H, Tsumura K, Terada Y, Nakane T, Nakamae M, Ohta K, Yamane T, Hino M. Notable effects of angiotensin II receptor blocker, valsartan, on acute cardiotoxic changes after standard chemotherapy with cyclophosphamide, doxorubicin, vincristine, and prednisolone. Cancer 2005;104:2492-2498.

249. Yancy CW, Jessup M, Bozkurt B, Butler J, Casey DE Jr, Drazner MH, Fonarow GC, Geraci SA, Horwich T, Januzzi JL, Johnson MR, Kasper EK, Levy WC, Masoudi FA, McBride PE, McMurray لl, Mitchell JE, Peterson PN, Riegel B, Sam F, Stevenson LW, Tang WH, Tsai EJ, Wilkoff BL, American College of Cardiology Foundation, American Heart Association Task Force on Practice Guidelines. 2013 ACCF/ AHA guideline for the management of heart failure: a report of the American College of Cardiology Foundation/American Heart Association Task Force on Practice Guidelines. J Am Coll Cardiol 2013;62:e147-e239.

250. Negishi K, Negishi T, Haluska BA, Hare JL, Plana JC, Marwick TH. Use of speckle strain to assess left ventricular responses to cardiotoxic chemotherapy and cardioprotection. Eur Heart / Cardiovasc Imaging 2014;15:324-331.

251. Harris L, Batist G, Belt R, Rovira D, Navari R, Azarnia N, Welles L, Winer E, TLC D-99 Study Group. Liposome-encapsulated doxorubicin compared with conventional doxorubicin in a randomized multicenter trial as first-line therapy of metastatic breast carcinoma. Cancer 2002;94:25-36.

252. van Dalen EC, Michiels EM, Caron HN, Kremer LC. Different anthracycline derivates for reducing cardiotoxicity in cancer patients. Cochrane Database Syst Rev 2010;5:CD005006.

253. O'Brien ME, Wigler N, Inbar M, Rosso R, Grischke E, Santoro A, Catane R, Kieback DG, Tomczak P, Ackland SP, Orlandi F, Mellars L, Alland L, Tendler C, CAELYX Breast Cancer Study Group. Reduced cardiotoxicity and comparable efficacy in a phase III trial of pegylated liposomal doxorubicin HCl (CAELYX/Doxil) versus conventional doxorubicin for first-line treatment of metastatic breast cancer. Ann Oncol 2004;15:440-449.

254. Swain SM, Whaley FS, Gerber MC, Weisberg S, York M, Spicer D, Jones SE, Wadler S, Desai A, Vogel C, Speyer J, Mittelman A, Reddy S, Pendergrass K, Velez-Garcia E, Ewer MS, Bianchine JR, Gams RA. Cardioprotection with dexrazoxane for doxorubicin-containing therapy in advanced breast cancer.J Clin Oncol 1997; 15:1318-1332

255. Hayes SC, Spence RR, Galvao DA, Newton RU. Australian Association for Exercise and Sport Science position stand: optimising cancer outcomes through exercise. J Sci Med Sport 2009;12:428-434.

256. Jones LW, Liu Q, Armstrong GT, Ness KK, Yasui Y, Devine K, Tonorezos E, Soares-Miranda L, Sklar CA, Douglas PS, Robison LL, Oeffinger KC. Exercise and risk of major cardiovascular events in adult survivors of childhood Hodgkin lymphoma: a report from the Childhood Cancer Survivor Study. J Clin Oncol 2014:32:3643-3650.

257. Low CA, Beckjord E, Bovbjerg DH, Dew MA, Posluszny DM, Schmidt JE, Lowery AE, Nutt SA, Arvey SR, Rechis R. Correlates of positive health behaviors in cancer survivors: results from the 2010 LIVESTRONG survey. Psychosoc Oncol 2014;32:678-695.

258. Mishra SI, Scherer RW, Snyder C, Geigle PM, Berlanstein DR, Topaloglu O. Exercise interventions on health-related quality of life for people with cancer during active treatment. Cochrane Database Syst Rev 2012;8:CD008465.

259. Lyman GH, Bohlke K, Khorana AA, Kuderer NM, Lee AY, Arcelus Jl, Balaban EP, Clarke JM, Flowers CR, Francis CW, Gates LE, Kakkar AK, Key NS, Levine MN, Liebman HA, Tempero MA, Wong SL, Somerfield MR, Falanga A, American Society of Clinical Oncology. Venous thromboembolism prophylaxis and treatment in patients with cancer: American Society of Clinical Oncology clinical practice guideline update 2014. J Clin Oncol 2015;33:654-656. 
260. Agnelli G, Gussoni G, Bianchini C, Verso M, Mandala M, Cavanna L, Barni S Labianca R, Buzzi F, Scambia G, Passalacqua R, Ricci S, Gasparini G, Lorusso V, Bonizzoni E, Tonato M, PROTECHT Investigators. Nadroparin for the prevention of thromboembolic events in ambulatory patients with metastatic or locally advanced solid cancer receiving chemotherapy: a randomised, placebo-controlled, double-blind study. Lancet Oncol 2009;10:943-949.

261. Frere C, Debourdeau P, Hij A, Cajinger F, Nonan MN, Panicot-Dubois L Dubois C, Farge D. Therapy for cancer-related thromboembolism. Semin Oncol 2014;41:319-338.

262. Carrier M, Khorana AA, Moretto P, Le Gal G, Karp R, Zwicker Jl. Lack of evidence to support thromboprophylaxis in hospitalized medical patients with cancer. Am J Med 2014;127:82-86 e81.

263. Akl EA, Ramly EP, Kahale LA, Yosuico VE, Barba M, Sperati F, Cook D, Schunemann H. Anticoagulation for people with cancer and central venous catheters. Cochrane Database Syst Rev 2014:10:CD006468.

264. Legha SS, Benjamin RS, Mackay B, Ewer M, Wallace S, Valdivieso M, Rasmussen SL, Blumenschein GR, Freireich EJ. Reduction of doxorubicin cardiotoxicity by prolonged continuous intravenous infusion. Ann Intern Med 1982;96:133-139.

265. Torti FM, Bristow MR, Howes AE, Aston D, Stockdale FE, Carter SK, Kohler M, Brown BW Jr., Billingham ME. Reduced cardiotoxicity of doxorubicin delivered on a weekly schedule. Assessment by endomyocardial biopsy. Ann Intern Med 1983;99: 745-749.

266. Gianni L, Munzone E, Capri G, Fulfaro F, Tarenzi E, Villani F, Spreafico C, Laffranchi A, Caraceni A, Martini C. Paclitaxel by 3-hour infusion in combination with bolus doxorubicin in women with untreated metastatic breast cancer: high antitumor efficacy and cardiac effects in a dose-finding and sequence-finding study. I Clin Oncol 1995;13:2688-2699.

267. Boyle EM, Morschhauser F. Pixantrone: a novel anthracycline-like drug for the treatment of non-Hodgkin lymphoma. Expert Opin Drug Saf 2015;14:601-607.

268. Safra T, Muggia F, Jeffers S, Tsao-Wei DD, Groshen S, Lyass O, Henderson R, Berry G, Gabizon A. Pegylated liposomal doxorubicin (Doxil): reduced clinical cardiotoxicity in patients reaching or exceeding cumulative doses of $500 \mathrm{mg} / \mathrm{m}^{2}$. Ann Oncol 2000;11:1029-1033.

269. Lotrionte M, Palazzoni G, Natali R, Comerci G, Abbate A, Di Persio S, Biondi-Zoccai GG. Appraising cardiotoxicity associated with liposomal doxorubicin by means of tissue Doppler echocardiography end-points: rationale and design of the LITE (Liposomal doxorubicin-Investigational chemotherapy-Tissue Doppler imaging Evaluation) randomized pilot study. Int J Cardiol 2009;135 72-77.

270. Sparano JA, Makhson AN, Semiglazov VF, Tjulandin SA, Balashova OI, Bondarenko IN, Bogdanova NV, Manikhas GM, Oliynychenko GP, Chatikhine VA, Zhuang SH, Xiu L, Yuan Z, Rackoff WR. Pegylated liposomal doxorubicin plus docetaxel significantly improves time to progression without additive cardiotoxicity compared with docetaxel monotherapy in patients with advanced breast cancer previously treated with neoadjuvant-adjuvant anthracycline therapy: results from a randomized phase III study. J Clin Oncol 2009;27 4522-4529.

271. Rafiyath SM, Rasul M, Lee B, Wei G, Lamba G, Liu D. Comparison of safety and toxicity of liposomal doxorubicin vs. conventional anthracyclines: a meta-analysis. Exp Hematol Oncol 2012;1:10.

272. Lotrionte M, Palazzoni G, Abbate A, De Marco E, Mezzaroma E, Di Persio S, Frati G, Loperfido F, Biondi-Zoccai G. Cardiotoxicity of a non-pegylated liposomal doxorubicin-based regimen versus an epirubicin-based regimen for breas cancer: the LITE (Liposomal doxorubicin-Investigational chemotherapy-Tissue Doppler imaging Evaluation) randomized pilot study. Int J Cardiol 2013;167 1055-1057.

273. Jones SE, Savin MA, Holmes FA, O'Shaughnessy JA, Blum JL, Vukelja S, McIntyre KJ Pippen JE, Bordelon JH, Kirby R, Sandbach J, Hyman WJ, Khandelwal P. Negron AG, Richards DA, Anthony SP, Mennel RG, Boehm KA, Meyer WG, Asmar L. Phase III trial comparing doxorubicin plus cyclophosphamide with docetaxel plus cyclophosphamide as adjuvant therapy for operable breast cancer. J Clin Oncol 2006;24:5381-5387.

274. Holmes FA, Rowinsky EK. Pharmacokinetic profiles of doxorubicin in combination with taxanes. Semin Oncol 2001:28:8-14.

275. Salvatorelli E, Menna P, Cascegna S, Liberi G, Calafiore AM, Gianni L, Minotti G. Paclitaxel and docetaxel stimulation of doxorubicinol formation in the human heart: implications for cardiotoxicity of doxorubicin-taxane chemotherapies. J Pharmacol Exp Ther 2006;318:424-433.

276. Floyd JD, Nguyen DT, Lobins RL, Bashir Q, Doll DC, Perry MC. Cardiotoxicity of cancer therapy. J Clin Oncol 2005;23:7685-7696.

277. Tan-Chiu E, Yothers G, Romond E, Geyer CE Jr, Ewer M, Keefe D, Shannon RP, Swain SM, Brown A, Fehrenbacher L, Vogel VG, Seay TE, Rastogi P, Mamounas EP, Wolmark N, Bryant J. Assessment of cardiac dysfunction in a randomized tria comparing doxorubicin and cyclophosphamide followed by paclitaxel, with or without trastuzumab as adjuvant therapy in node-positive, human epidermal growth factor receptor 2-overexpressing breast cancer: NSABP B-31. J Clin Oncol 2005;23:7811-7819.

278. Slamon D, Eiermann W, Robert N, Pienkowski T, Martin M, Press M, Mackey J Glaspy J, Chan A, Pawlicki M, Pinter T, Valero V, Liu MC, Sauter G, von Minckwitz G, Visco F, Bee V, Buyse M, Bendahmane B, Tabah-Fisch I, Lindsay MA, Riva A, Crown J, Breast Cancer International Research Group. Adjuvant trastuzumab in HER2-positive breast cancer. N Engl / Med 2011;365: 1273-1283.

279. Smith I, Procter M, Gelber RD, Guillaume S, Feyereislova A, Dowsett M, Goldhirsch A, Untch M, Mariani G, Baselga J. Kaufmann M, Cameron D, Bell R, Bergh I, Coleman R, Wardley A, Harbeck N, Lopez RI, Mallmann P, Gelmon K, Wilcken N, Wist E, Sanchez Rovira P, Piccart-Gebhart MJ, HERA study team. 2-year follow-up of trastuzumab after adjuvant chemotherapy in HER2-positive breast cancer: a randomised controlled trial. Lancet 2007;369:29-36

280. Piccart-Gebhart MJ, Procter M, Leyland-Jones B, Goldhirsch A, Untch M, Smith I, Gianni L, Baselga J, Bell R, Jackisch C, Cameron D, Dowsett M, Barrios CH, Steger G, Huang CS, Andersson M, Inbar M, Lichinitser M, Lang I, Nitz U, Iwata H, Thomssen C, Lohrisch C, Suter TM, Ruschoff J, Suto T, Greatorex V, Ward C, Straehle C, McFadden E, Dolci MS, Gelber RD, Herceptin Adjuvant Tria Study Team. Trastuzumab after adjuvant chemotherapy in HER2-positive breast cancer. N Engl J Med 2005;353:1659-1672.

281. Romond EH, Perez EA, Bryant J, Suman VJ, Geyer CE Jr, Davidson NE, Tan-Chiu E, Martino S, Paik S, Kaufman PA, Swain SM, Pisansky TM, Fehrenbacher L, Kutteh LA, Vogel VG, Visscher DW, Yothers G, Jenkins RB, Brown AM, Dakhil SR, Mamounas EP, Lingle WL, Klein PM, Ingle JN, Wolmark N. Trastuzumab plus adjuvant chemotherapy for operable HER2-positive breast cancer. $N$ Engl J Med 2005;353:1673-1684

282. Seicean S, Seicean A, Alan N, Plana JC, Budd GT, Marwick TH. Cardioprotective effect of beta-adrenoceptor blockade in patients with breast cancer undergoing chemotherapy: follow-up study of heart failure. Circ Heart Fail 2013;6:420-426.

283. Jones AL, Barlow M, Barrett-Lee PJ, Canney PA, Gilmour IM, Robb SD Plummer CJ, Wardley AM, Verrill MW. Management of cardiac health in trastuzumab-treated patients with breast cancer: updated United Kingdom National Cancer Research Institute recommendations for monitoring. Br I Cancer 2009;100:684-692

284. Scott JM, Khakoo A, Mackey JR, Haykowsky MJ, Douglas PS, Jones LW. Modulation of anthracycline-induced cardiotoxicity by aerobic exercise in breast cancer current evidence and underlying mechanisms. Circulation 2011;124:642-650.

285. Haykowsky MJ, Mackey JR, Thompson RB, Jones LW, Paterson DI. Adjuvant trastuzumab induces ventricular remodeling despite aerobic exercise training. Clin Cancer Res 2009;15:4963-4967.

286. Task Force Members, Montalescot G, Sechtem U, Achenbach S, Andreotti F, Arden C, Budaj A, Bugiardini R, Crea F, Cuisset T, Di Mario C, Ferreira JR, Gersh BJ, Gitt AK, Hulot JS, Marx N, Opie LH, Pfisterer M, Prescott E, Ruschitzka F, Sabate M, Senior R, Taggart DP, van der Wall EE, Vrints C], ESC Committee for Practice Guidelines, Zamorano JL, Achenbach S, Baumgartner H, Bax JJ, Bueno H, Dean V, Deaton C, Erol C, Fagard R, Ferrari R, Hasdai D, Hoes AW, Kirchhof P, Knuuti J, Kolh P, Lancellotti P, Linhart A, Nihoyannopoulos P. Piepoli MF, Ponikowski P. Sirnes PA, Tamargo JL, Tendera M, Torbicki A, Wijns W, Windecker S, Document R, Knuuti J, Valgimigli M, Bueno H, Claeys MJ, Donner-Banzhoff N, Erol C. Frank H, Funck-Brentano C, Gaemperli O, Gonzalez-Juanatey JR, Hamilos M, Hasdai D, Husted S, James SK, Kervinen K, Kolh P, Kristensen SD, Lancellotti P, Maggioni AP, Piepoli MF, Pries AR, Romeo F, Ryden L, Simoons ML, Sirnes PA Steg PG, Timmis A, Wijns W, Windecker S, Yildirir A, Zamorano JL. 2013 ESC guidelines on the management of stable coronary artery disease: the Task Force on the management of stable coronary artery disease of the European Society of Cardiology. Eur Heart J 2013;34:2949-3003.

287. Saif MW, Shah MM, Shah AR. Fluoropyrimidine-associated cardiotoxicity: revisited. Expert Opin Drug Saf 2009;8:191-202.

288. Oleksowicz L, Bruckner HW. Prophylaxis of 5-fluorouracil-induced coronary vasospasm with calcium channel blockers. Am J Med 1988;85:750-751.

289. Eskilsson J, Albertsson M. Failure of preventing 5-fluorouracil cardiotoxicity by prophylactic treatment with verapamil. Acta Oncol 1990:29:1001-1003.

290. Polk A, Vaage-Nilsen M, Vistisen K, Nielsen DL. Cardiotoxicity in cancer patients treated with 5-fluorouracil or capecitabine: a systematic review of incidence, manifestations and predisposing factors. Cancer Treat Rev 2013;39:974-984.

291. Hancock SL, Tucker MA, Hoppe RT. Factors affecting late mortality from heart disease after treatment of Hodgkin's disease. JAMA 1993;270:1949-1955.

292. Prosnitz RG, Chen YH, Marks LB. Cardiac toxicity following thoracic radiation. Semin Oncol 2005;32(2 Suppl 3):S71-S80.

293. Louwe RJ, Wendling M, van Herk MB, Mijnheer B. Three-dimensional heart dose reconstruction to estimate normal tissue complication probability after breast irradiation using portal dosimetry. Med Phys 2007;34:1354-1363. 
294. Bruzzaniti V, Abate A, Pinnaro P, D’Andrea M, Infusino E, Landoni V, Soriani A, Giordano C, Ferraro A, Strigari L. Dosimetric and clinical advantages of deep inspiration breath-hold (DIBH) during radiotherapy of breast cancer. J Exp Clin Cancer Res 2013;32:88.

295. Xu Q, Chen Y, Grimm J, Fan J, An L, Xue J, Pahlajani N, Lacouture T. Dosimetric investigation of accelerated partial breast irradiation (APBI) using CyberKnife. Med Phys 2012;39:6621-6628.

296. Bartlett FR, Colgan RM, Donovan EM, McNair HA, Carr K, Evans PM, Griffin C, Locke I, Haviland JS, Yarnold JR, Kirby AM. The UK HeartSpare Study (Stage IB): randomised comparison of a voluntary breath-hold technique and prone radiotherapy after breast conserving surgery. Radiother Oncol 2015;114:66-72.

297. McCabe MS, Bhatia S, Oeffinger KC, Reaman GH, Tyne C, Wollins DS, Hudson MM. American Society of Clinical Oncology statement: achieving highquality cancer survivorship care. / Clin Oncol 2013;31:631-640.

298. Lenihan DJ, Oliva S, Chow EJ, Cardinale D. Cardiac toxicity in cancer survivors. Cancer 2013;119(Suppl 11):2131-2142.

299. Hequet O, Le QH, Moullet I, Pauli E, Salles G, Espinouse D, Dumontet C, Thieblemont C, Arnaud P, Antal D, Bouafia F, Coiffier B. Subclinical late cardiomyopathy after doxorubicin therapy for lymphoma in adults. J Clin Oncol 2004;22: 1864-1871.

300. de Azambuja E, Ameye L, Diaz M, Vandenbossche S, Aftimos P, Bejarano Hernandez S, Shih-Li C, Delhaye F, Focan C, Cornez N, Vindevoghel A, Beauduin M, Lemort M, Paesmans M, Suter T, Piccart-Gebhart M. Cardiac assessment of early breast cancer patients 18 years after treatment with cyclophosphamide-, methotrexate-, fluorouracil- or epirubicin-based chemotherapy. Eur J Cancer 2015;51:2517-2524.

301. Mitani I, Jain D, Joska TM, Burtness B, Zaret BL. Doxorubicin cardiotoxicity: prevention of congestive heart failure with serial cardiac function monitoring with equilibrium radionuclide angiocardiography in the current era. J Nucl Cardiol 2003:10:132-139.

302. Ewer MS, Lenihan DJ. Left ventricular ejection fraction and cardiotoxicity: is our ear really to the ground? J Clin Oncol 2008;26:1201-1203.

303. Lenihan DJ, Cardinale DM. Late cardiac effects of cancer treatment. J Clin Oncol 2012;30:3657-3664.

304. Heidenreich PA, Hancock SL, Lee BK, Mariscal CS, Schnittger I. Asymptomatic cardiac disease following mediastinal irradiation. J Am Coll Cardiol 2003;42: $743-749$.

305. Koppelmans V, Vernooij MW, Boogerd W, Seynaeve C, Ikram MA, Breteler MM, Schagen SB. Prevalence of cerebral small-vessel disease in long-term breast cancer survivors exposed to both adjuvant radiotherapy and chemotherapy. J Clin Oncol 2015;33:588-593.
306. Glanzmann C, Huguenin P, Lutolf UM, Maire R, Jenni R, Gumppenberg V. Cardiac lesions after mediastinal irradiation for Hodgkin's disease. Radiother Oncol 1994; 30:43-54.

307. Armstrong GT, Joshi VM, Zhu L, Srivastava D, Zhang N, Ness KK, Stokes DC, Krasin MT, Fowler JA, Robison LL, Hudson MM, Green DM. Increased tricuspid regurgitant jet velocity by Doppler echocardiography in adult survivors of childhood cancer: a report from the St Jude Lifetime Cohort Study. J Clin Oncol 2013; 31:774-781.

308. Copeland KA, Hosmane VR, Jurkovitz C, Kolm P, Bowen J, DiSabatino A, Banbury MK, Strasser JF, Weintraub WS, Doorey AJ. Frequency of severe valvular disease caused by mediastinal radiation among patients undergoing valve surgery in a community-based, regional academic medical center. Clin Cardiol 2013;36: 217-221.

309. Machann W, Beer M, Breunig M, Stork S, Angermann C, Seufert I, Schwab F, Kolbl O, Flentje M, Vordermark D. Cardiac magnetic resonance imaging findings in 20-year survivors of mediastinal radiotherapy for Hodgkin's disease. Int J Radiat Oncol Biol Phys 2011;79:1117-1123.

310. Lenihan DJ, Cardinale D, Cipolla CM. The compelling need for a cardiology and oncology partnership and the birth of the International CardiOncology Society. Prog Cardiovasc Dis 2010;53:88-93.

311. Moslehi J, Cheng S. Cardio-oncology: it takes two to translate. Sci Transl Med 2013; 5:187fs120.

312. Martin M, Esteva FJ, Alba E, Khandheria B, Perez-Isla L, Garcia-Saenz JA, Marquez A, Sengupta P, Zamorano J. Minimizing cardiotoxicity while optimizing treatment efficacy with trastuzumab: review and expert recommendations. Oncologist 2009;14:1-11.

313. Lu CY, Srasuebkul P, Drew AK, Chen K, Ward RL, Pearson SA. Trastuzumab therapy in Australia: which patients with HER2 + metastatic breast cancer are assessed for cardiac function? Breast 2013;22:482-487.

314. Seicean S, Seicean A, Plana JC, Budd GT, Marwick TH. Effect of statin therapy on the risk for incident heart failure in patients with breast cancer receiving anthracycline chemotherapy: an observational clinical cohort study. J Am Coll Cardiol 2012; 60:2384-2390.

315. Yoon G], Telli ML, Kao DP, Matsuda KY, Carlson RW, Witteles RM. Left ventricular dysfunction in patients receiving cardiotoxic cancer therapies are clinicians responding optimally? J Am Coll Cardiol 2010;56:1644-1650.

316. Lancellotti P, Anker SD, Donal E, Edvardsen T, Popescu BA, Farmakis D, Filippatos G, Habib G, Maggioni AP, Jerusalem G, Galderisi M. EACVI/HFA Cardiac Oncology Toxicity Registry in breast cancer patients: rationale, study design, and methodology (EACVI/HFA COT Registry)—EURObservational Research Program of the European Society of Cardiology. Eur Heart J Cardiovasc Imaging 2015; 16:466-470. 